\title{
SARS-COV2 VARIANTS AND VACCINES MRNA SPIKES FIBONACCI NUMERICAL UA/CG METASTRUCTURES
}

\author{
Jean-Claude Perez ${ }^{1 * 凶}$
}

${ }^{* 1}$ PhD Maths § Computer Science Bordeaux University, RETIRED Interdisciplinary Researcher (IBM Emeritus, IBM European Research Center on Artificial Intelligence Montpellier), Bordeaux metropole, France, ADDENDUM by Luc Montagnier, Fondation Luc Montagnier Quai Gustave-Ador 621207 Geneva, Switzerland.

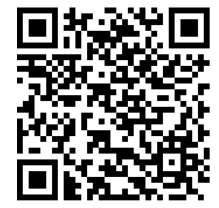

DOI: https://doi.org/10.29121/granthaalayah.v9.i6.2021.4040

Article Type: Research Article

Article Citation: Jean-Claude Perez. (2021). SARS-COV2 VARIANTS AND VACCINES MRNA SPIKES FIBONACCI NUMERICAL UA/CG METASTRUCTURES. International Journal of Research -

GRANTHAALAYAH, 9(6), 349-396. https://doi.org/10.29121/granthaa layah.v9.i6.2021.4040

Received Date: 15 June 2021

Accepted Date: 30 June 2021

Keywords:

Vaccines

Spikes

Fibonacci

Numerical

\section{ABSTRACT}

In this paper, we suggest a biomathematical numerical method for analysing mRNA nucleotides sequences based on UA/CG Fibonacci numbers proportions.

This method is used to evaluate then compare the spike genes related to the main SARS-CoV2 VARIANTS currently circulating within the world population.

The 10 main results proposed to be reproduced by peers are:

1) SARS-CoV2 genome and spike evolution in one year 2020-2021.

2) SARS-CoV2 Origins.

3) Comparing 11 reference variants spikes.

4) Analysing 32 CAL.20C California variant patients' spikes.

5) Toward a meta mRNA Fibonacci gene end message code.

6) Analysing S501 UK, S484 South Africa and « 2 mutations » INDIA variants.

7) Suggesting a possible variants spike mRNA palindrome symmetry metastructure improving mRNA stability then infectiousness.

8) Analysing Fibonacci Metastructures in the mRNA coding for the vaccines PFIZER and MODERNA.

9) Does the CG-rich modification of the synonymous codons of the spikes of the 2 mRNA vaccines affect the expression and quantity of SARS-CoV2 antibodies?

10) The exceptional case of the Brazilian variant P.1.

Particularly, we suggest the following conjecture at mRNA folding level:

CONJECTURE of SARS-CoV2 VARIANTS:

The growth of long Fibonacci structures in the shape of "podiums" for almost all of the variants studied (UK, California, South Africa, India, etc.) suggests the probable folding of the Spike mRNA in the form of a "hairpin", which can strengthen the cohesion and the lifespan of this mRNA.

Finally, we show that these kinds of Fibonacci matastructures disapear TOTALLY by analysing the published mRNA sequences of PFIZER and MODERNA vaccines. One fact is certain, the two mRNAs of the Moderna and Pfizer vaccines will result in a low functionality of the spike vaccine. This is because their designers by seeking greater stability, have doped to build CG rich sequences which, as soon as they are inserted into the human host, will, paradoxically, seek to mutate, like SARS-CoV2 variants, towards $\mathrm{CG}==>\mathrm{UA}$ forms in order to improve their STABILITY and LIFETIME. We conclude using new biomathematics theoretical methods (Master code and numerical standing waves), and comparing the Spikes of the two vaccines Moderna and Pfizer, that there will be very probable differences in stability and shelf life of the two respective mRNAs vaccines. However, "State of the Art" analyzes will disclose that their two protein sequences are strictly identical. By modified their synonymous codons using different strategies, no one can guarantee that the quantity of antibodies generated will be identical in the two cases.

We wish to draw attention to the great ADAPTATION power - at the global scale of their genomes - of the most infectious VARIANTS, such as the BRAZIL 20J / 501Y.V3 variant (P.1). This is very worrying for the VACCINES <==> VARIANTS run: We demonstrate how the Brazilian variant P.1 which becomes uncontrollable in Brazil in April 2021 has a level of organization of long metastructures of 17,711 bases covering the genome which is 3.6 more important than that of the 2 reference genomes SARS-CoV2

and worldwide D614G. We suggest that this high level of overall structure of this variant contributes to the stability of this genome and, might explain its greater contagiousness.

To complete this article, an ADDENDUM by Nobelprizewinner Luc Montagnier vas added at the end of this paper. 


\section{INTRODUCTION}

Thirty years ago, after pioneering in A.I (Perez, 1988, 1991), we published in a paper entitled "chaos, DNA, and neuro computers: the golden link" (Perez, 1991), presenting a numerical method to analyse DNA sequences based on Fibonacci numbers. In 2017 (Perez, 1997, 2017, 2019), we revisited this method to démonstrate application of this method in mtDNA mutations involved on Human cancers.

Fiftyeight years ago, (Montagnier L. § Kingsley Sanders F., 1963) Luc Montagnier described the isolation of an infectious double helix RNA in cells infected with a picornavirus. It is perhaps likely that there is an analogous form in the coronavirus, specifically on VARIANTS mRNA spikes. This structure is very stable, resistant to RNase, and can therefore retain the genetic information of the virus for a long time. The palindromic structures detected here could constitute a "hairpin" double stranded RNA form.

\section{METHODS AND DATA SOURCES}

\subsection{COMPUTING FIBONACCI METASTRUCTURES}

Consider the sequence of Fibonacci numbers

0112358132134558914423337761098715972584418167651094617711 28657463687502512139319641831781151422983204013462692178309 $35245785702887 \ldots$

Example of the SPIKE from Wuhan reference genome, this mRNA SPIKE is 3822 bases UCAG in length. Recall Wuhan reference https://www.ncbi.nlm.nih.gov/nuccore/NC 045512

Severe acute respiratory syndrome coronavirus 2 isolate Wuhan-Hu-1, complete genome NCBI Reference Sequence: NC_045512.2

the longest Fibonacci structures would therefore measure 2584 bases. When looking for such structures, the first one found is in 1200 location: therefore, the bases located between 1201 and $3784(1200+2584)$ :

These 2584 bases are broken down respectively into:

1597 bases UA

et 987 bases CG

Here are the first 20 basics that the reader can easily check:

SPIKREF [1200+1/420]
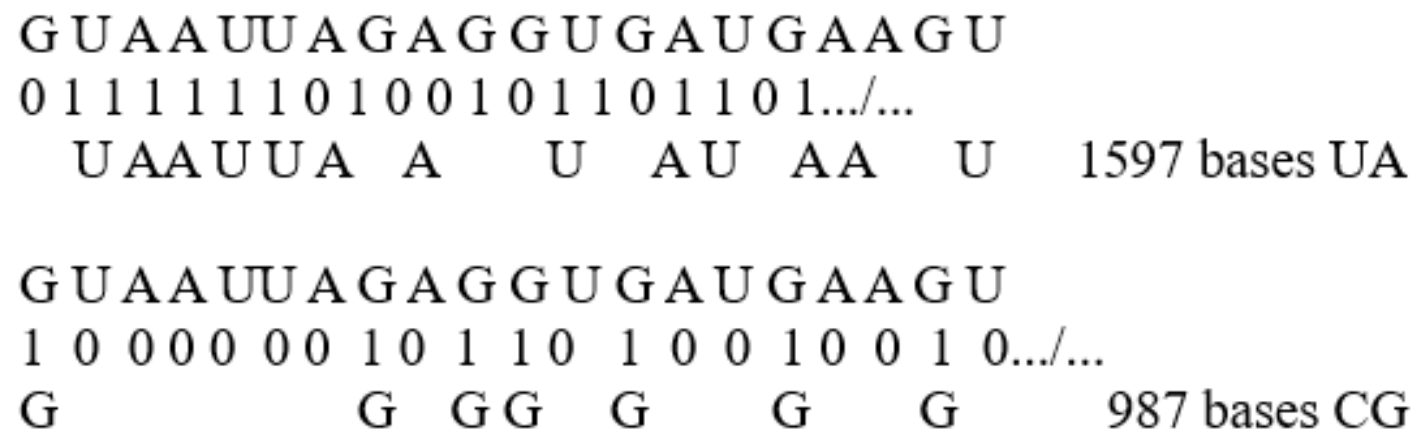

The SPIKE analyzes of this Wuhan-Hu-1 reference genome reports 63 metastructures of this type if we close the sequence on itself (as in mtDNA or bacteria) and 7 metastructures and if we consider the mRNA sequence in its linear form, as will be the case throughout this study. 


\subsection{ANALYZES OF REFERENCE VARIANTS}

We analysed 5 tracks of variants:

UK variant $\mathrm{N} 501 \mathrm{Y}$

South Africa variant E484K

Brazil variant N501Y + E484K

California variant $\mathrm{L} 452 \mathrm{R}$

India variant $\mathrm{E} 484 \mathrm{Q}+\mathrm{L} 452 \mathrm{R}$

Main data source: https://covariants.org/

- VARIANT South Africa MUTATIONS:
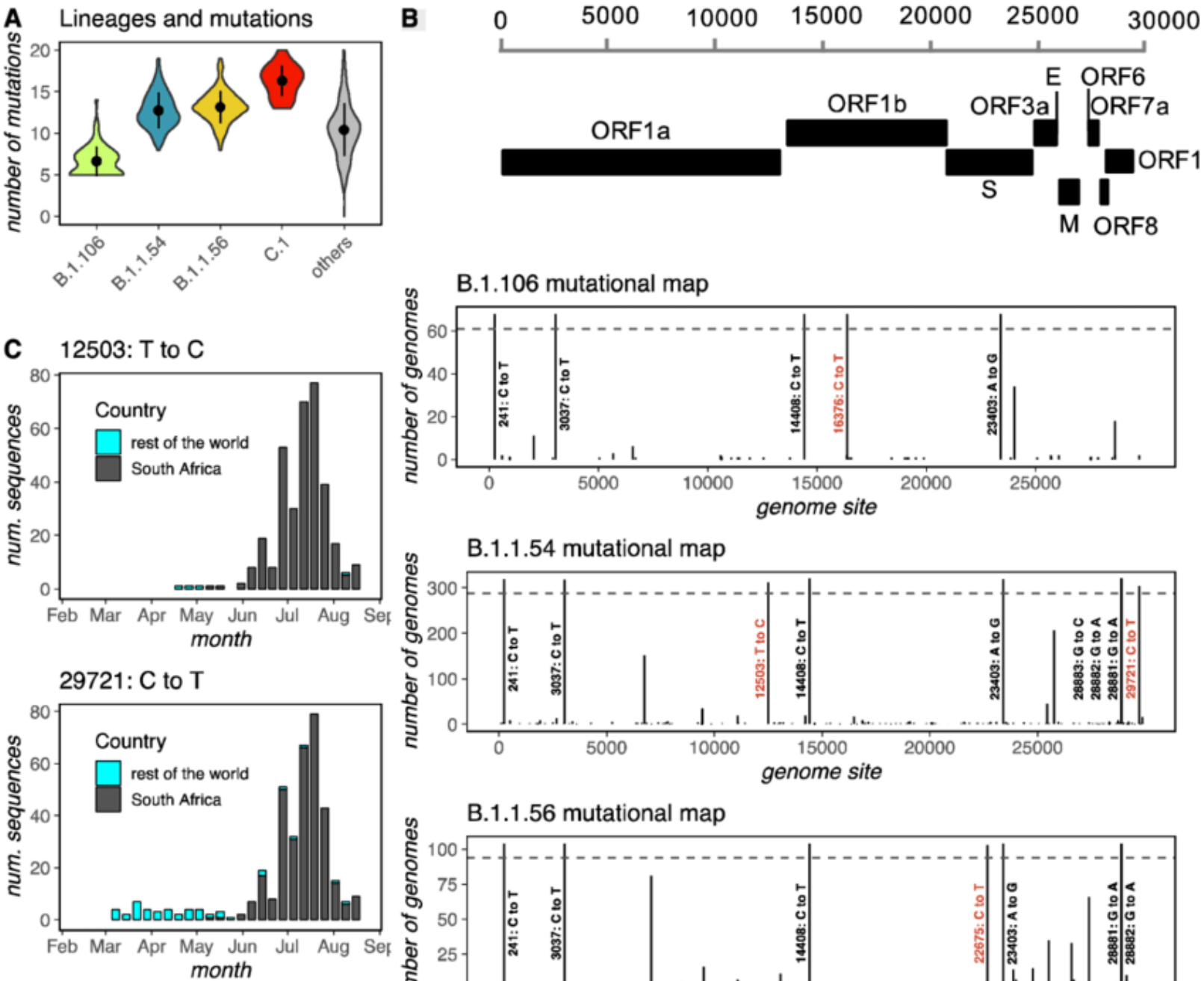

B.1.1.56 mutational map
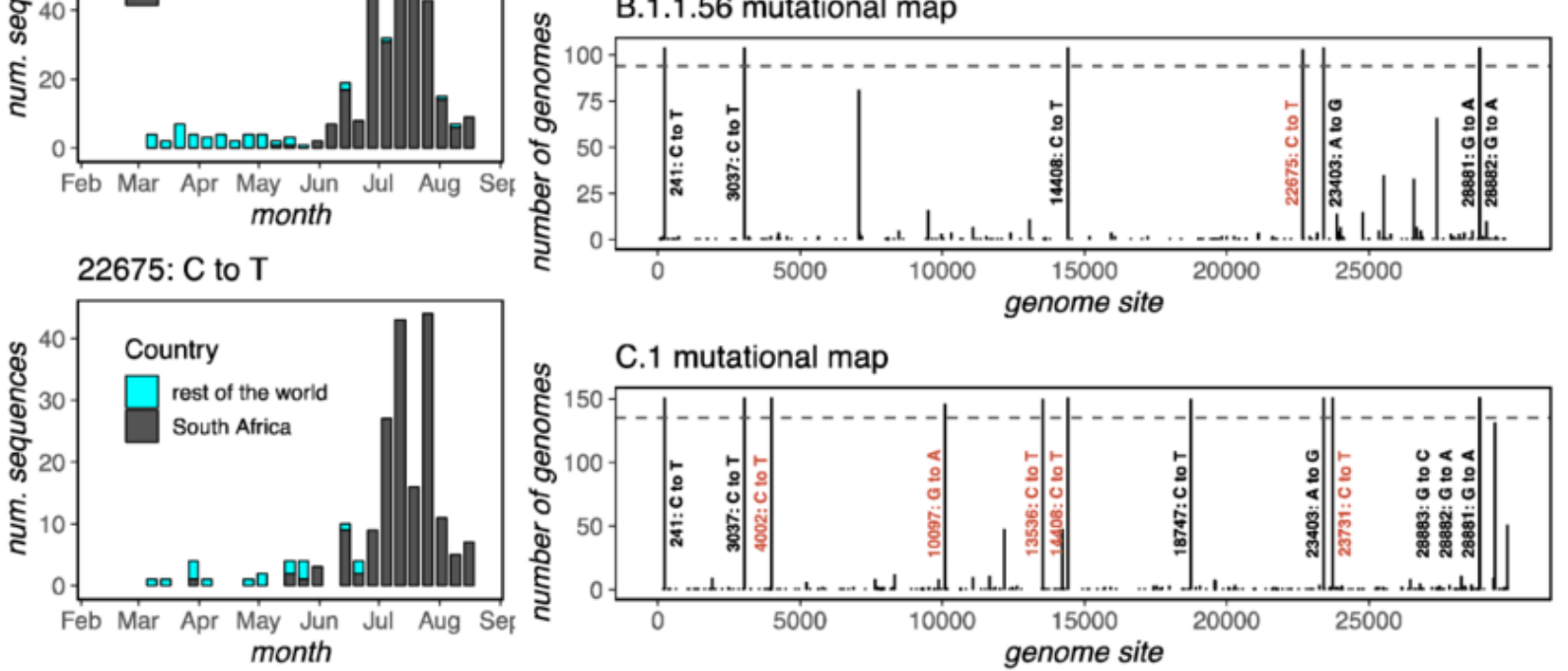

Figure 1: Mutations of the four reference variants from South Africa. 
- VARIANT U.K. MUTATIONS:

Source (Da Silva Filipe et al, 2020), https://www.nature.com/articles/s41564-020-00838-z

Table 1: Mutations in U.K. variant

\begin{tabular}{|c|c|c|}
\hline Gene & Nucleotide & Amino Acid \\
\hline ORF1ab & C3267T & T1001I \\
\hline & C5388A & A1708D \\
\hline & T6954C & I2230T \\
\hline Spike & 211788-11296 deletion & SGF 3675-3677 deletion \\
\hline & 21991-21993 deletion & Y144 deletion \\
\hline & A23063T & N501Y \\
\hline & C23271A & A570D \\
\hline & C23604A & P681H \\
\hline & C23709T & T716I \\
\hline & T24506G & S982A \\
\hline & G24914C & D1118H \\
\hline Orf8 & C27972T & Q27stop \\
\hline & G28048T & R52I \\
\hline & A28111G & Y73C \\
\hline N & 28280 GAT->CTA & D3L \\
\hline & C28977T & S235F \\
\hline
\end{tabular}

- VARIANT BRAZIL MUTATIONS:

\section{Sources}

First reference:

VARIANTS BRAZIL JAPAN (Naveca F et al, 2021)

https://virological.org/t/phylogenetic-relationship-of-sars-cov-2-sequences-from-amazonas-with-emergingbrazilian-variants-harboring-mutations-e484k-and-n501y-in-the-spike-protein/585

Phylogenetic relationship of SARS-CoV-2 sequences from Amazonas with emerging Brazilian variants harboring mutations E484K and N501Y in the Spike protein

second reference: (Gröhs Ferrareze P. A., et al, 2021),

E484K as an innovative phylogenetic event for viral evolution: Genomic analyzes of the E484K spike mutation in SARS-CoV-2 lineages from Brazil. https://www.biorxiv.org/content/10.1101/2021.01.27.426895v1 
Jean-Claude Perez

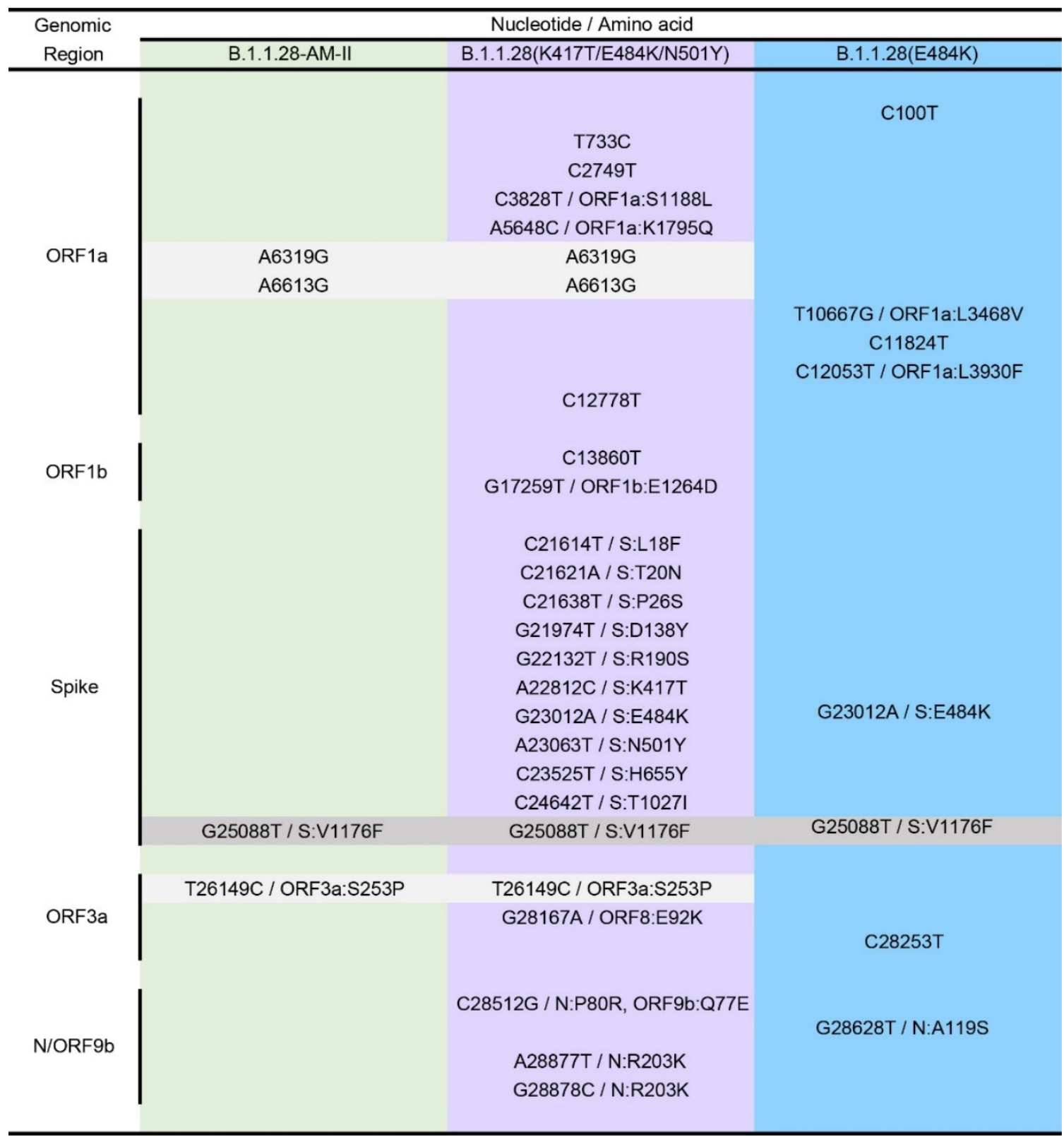

Figure 2: Mutations of 3 Brazil variants

\section{- VARIANT CAL.20C from California Mutations (L452):}

It is possible that S13I increases the efficiency of cleavage on the 12 amino-peptide terminals, which may increase the volume of S-protein on the host cell.

CAL.20C has three unique amino acid substitutions in its spike protein. The spike protein is the part of the virus that interacts and locks into proteins from the human host cell, essentially the key to open the host to the virus. Among these are S13I and W152C in the N-terminal domain, and L452R in the receptor-binding domain.

Reference (Wenjuan Zhang et al, 2021)

https://www.medrxiv.org/content/10.1101/2021.01.18.21249786v1.full.pdf+html

\section{- ANALYZING W152C Mutation:}

Among these are S13I and W152C in the N-terminal domain, and L452R in the receptor-binding domain. Other general source: 


\section{california-covid-19-variant/}

32 California patients' genomes from GenBank:

CA1ID: MW433772.1 California 5 January

CA3ID: MW433769.1 California 5 January 2021

CA5ID: MW433764.1 California 5 January 2021

CA6ID: MW433763.1 California 5 January 2021

CA8ID: MW433758.1 California 5 January 2021

CA10ID: MW433752.1 California 5 January 2021

CA11ID: MW505197.1 California 2 February 2021

CA17ID: MW505189.1 California 22 January 2021

CA19ID: MW505187.1 California 2February 2021

CA20ID: MW505186.1 California 2February 2021

CA25ID: MW505149.1 California 22 January 2021

CA27ID: MW505147.1 California 22 January 2021

CA51ID: LR883179.1 netherland 25 January 2021

CA52ID: MW525111.1 California 26 January 2021

CA53ID: MW525040.1 USA MO 26 January 2021

CA54ID: MW525020.1 USA FL 26 January 2021

CA55ID: MW524999.1 USA NY 26 January 2021

CA56ID: MW524976.1 USA CA 26 January 2021

CA57ID: MW524942.1 USA CA 26 January 2021

CA58ID: MW523875.1 USA CA 26 January 2021

CA59ID: MW523873.1 USA CA 26 January 2021

CA60ID: MW523867.1 USA TX 26 January 2021

CA61ID: MW523795.1 USA CA 26 January 2021

CA62ID: MW523792.1 USA CA 26 January 2021 
CA63ID: MW519791.1 USA NV 25 January 2021

CA64ID: MW519755.1 USA AZ 25 January 2021

CA65ID: MW519751.1 USA AZ 25 January 2021

CA66ID: MW519739.1 USA CA 25 January 2021

CA67ID: MW519738.1 USA CA 25 January 2021

CA68ID: MW519725.1 USA CA 25 January 2021

CA69ID: MW519715.1 USA CA 25 January 2021

CA70ID: MW519708.1 USA CA 25 January 2021

- Indian « two mutations » variant:

Samples with the E484Q and L452R, soient South Africa + California variants

Sources:

https://www.bbc.com/news/world-asia-india-56507988

and

https://pib.gov.in/PressReleaselframePage.aspx?PRID=1707177

We must note that variant is E484K while Indian variant is $\mathrm{E} 484 \mathrm{Q}$.

\begin{tabular}{|c|c|c|c|c|c|}
\hline & U & C & A & $\mathbf{G}$ & \\
\hline \multirow{4}{*}{ G } & \multirow{4}{*}{$\begin{array}{l}\text { Valine } \\
\text { Val-y }\end{array}$} & \multirow{4}{*}{$\begin{array}{c}\text { Alanine } \\
\text { Ala - A }\end{array}$} & Aspartic acid & \multirow{4}{*}{$\begin{array}{c}\text { slyine } \\
\text { sly-6 }\end{array}$} & $\bar{U}$ \\
\hline & & & $A s p-0$ & & $\mathrm{C}$ \\
\hline & & & Clubmis atid & & A \\
\hline & & & Gli - E & & $G$ \\
\hline \multirow{3}{*}{ C } & \multirow{3}{*}{$\begin{array}{c}\text { Leucine } \\
\text { Lei-I }\end{array}$} & \multirow{3}{*}{$\begin{array}{l}\text { Proline } \\
\text { Po - p }\end{array}$} & Histidine & \multirow{3}{*}{$\begin{array}{c}\text { Areinine } \\
\text { Ars - i }\end{array}$} & $\mathrm{U}$ \\
\hline & & & His - H & & C \\
\hline & & & $\begin{array}{c}\text { slutamine } \\
\text { Gln-9 }\end{array}$ & & $\begin{array}{l}\text { A } \\
G\end{array}$ \\
\hline \multirow{4}{*}{ A } & & \multirow{4}{*}{$\begin{array}{c}\text { Threonine } \\
\text { Thr = T }\end{array}$} & Asparagine & Serine & U \\
\hline & lobleutine & & Ast - H & Ser-5 & C \\
\hline & $\|\bar{e}-\|$ & & yine & Arginine & A \\
\hline & Mathine Bet - is & & Lys $=\mathbb{X}$ & $\mathbf{A r}=\mathbb{R}$ & 6 \\
\hline \multirow{4}{*}{$\mathrm{U}$} & Phemplalanine & \multirow{4}{*}{$\begin{array}{l}\text { Serine } \\
\text { ser-5 }\end{array}$} & Tyrosine & Cysteine & U \\
\hline & Phe = $F$ & & $\mathrm{Tr}=\mathrm{Y}$ & $\mathrm{Cr}=\mathrm{C}$ & $\mathrm{C}$ \\
\hline & Leucine & & \multirow{2}{*}{ STOP codon } & 510 codon & A \\
\hline & LEL - L & & & Trypioghan Trp - S & G \\
\hline
\end{tabular}

Figure 3: Recall Universal Genetic Code Table. 


\section{RESULTS and DISCUSSION}

\subsection{SARS-COV2 GENOME AND SPIKE EVOLUTION IN ONE YEAR 2020-2021.}

Whole Wuhan reference SARS-CoV2 genome

FIBONACCImRNA Metastructures 17711 UACG $==>10946$ UA ==> 6765 CG

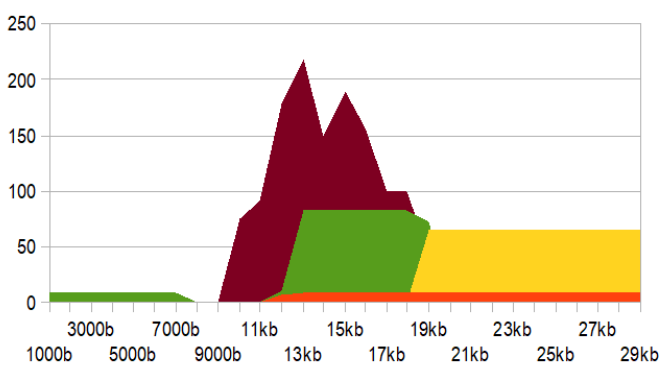

SARS-CoV2 Wuhan Reference Spike UAVGFibonacci Metastructures

2584UACG ==> 1597 UA and 987 CG only between base 1000 and the Spike End
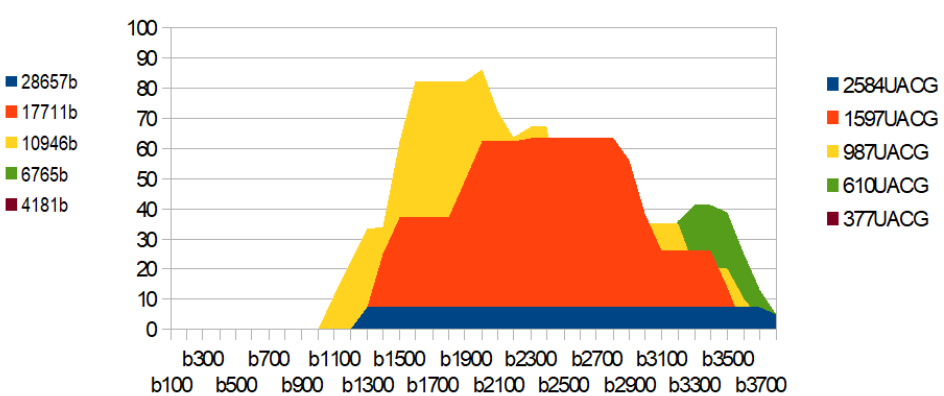

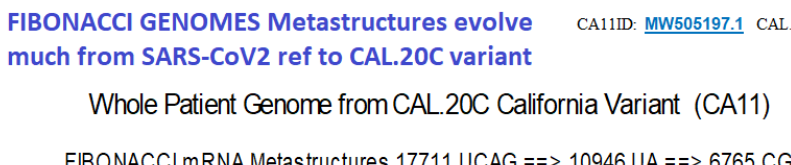

FIBONACCI mRNA Metastructures 17711 UCAG ==> 10946 UA ==> 6765 CG

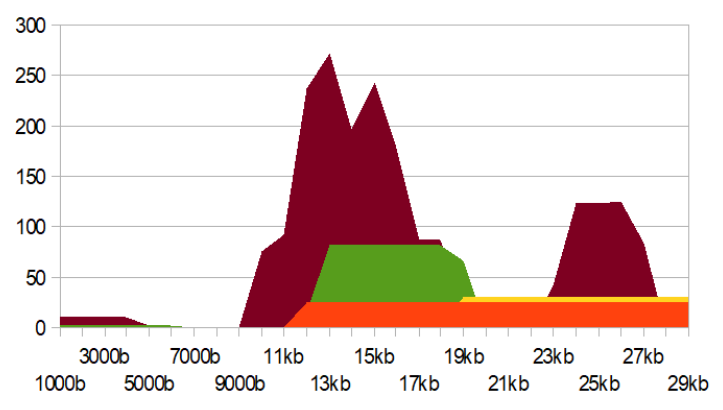

FIBONACCI SPIKES Metastructures evolve much from SARS-CoV2 ref to CAL.20C variant

SPIKE from patient CAL.20 California variant (ref CA11)

FIBONACCI mRNA Metastructures 2584 UACG $==>1597$ UA ==> 987 CG

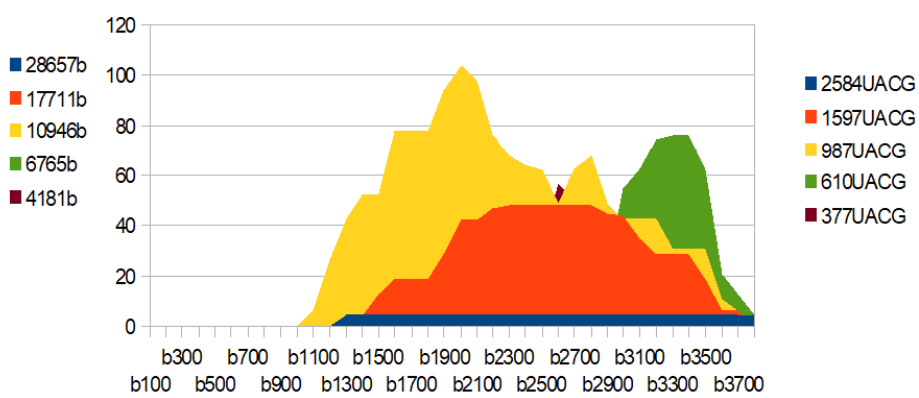

1/ Left top: Wuhan SARS-Cov2 reference GENOME - 2/ Left bottom: single patient GENOME CAL.20C VARIANT

3/ Right top: SARS-CoV2 ref SPIKE

- 4/ Right bottom: CALIFORNIA VARIANT CAL.20C SPIKE

\section{Comparing FIBONACCI mRNA Metastructures GENOMES§SPIKES between 2020 SARS-CoV2 ref. and 2021 California patient VARIANT}

Figure 4: comparing SARS-CoV2 genome and spike evolution between Wuhan strain (january 2020) and CAL.20C variant (january 2021).

At the level of the genomes, the very long Fibonacci metastructures (17711nt) increase considerably, which means a reinforcement of the overall mRNA structure of the genome.

On the contrary, the overall metastructure of the spike seems to be reduced, although this variant has evolved at the level of amino acid mutations (mutations in CAL.20C california

L452R, S13I, W152C).

\subsection{SARS-COV2 ORIGINS}

Fibonacci metastructures "shed a radically new light on" the relationships already recognized or suspected "between the four Sars-CoV2 Wuhan (1/2020), SARS-covZC45 (2017), SARS-covZXC21 (2015) and bat RATG13 genomes (2013) revealing evidence of manipulation of CODONS synonymous with Spike of one or the other between SARS-CoV2 and beats RATG13, giving rise to the question "which of the two was manipulated?" (Perez, 2020), 
(Perez§Montagnier, 2020), (Castro-Chavez, 2020). We can assert that it is the SARS-Cov2 spike that has been manipulated to modify synonymous CODONS while retaining the functionality of the same amino acids. We believe that this manipulation will most certainly have attenuated the virulence and pathogenicity of SARS-CoV2 opposite bat RATG13* (blue regions of the 2 images of their Spikes).

Moreover, if at the level of the four respective genomes, the strong neighborhoods between SARS-CoV2 and bat RATG13 on one hand, and ZC45 and ZXC21 on the other, are confirmed by these Fibonacci metastructures (vertical analogies in the image). A less expected bi-duality is highlighted at the level of their four respective spikes: on one hand, this obvious neighborhood between ZXC21 and bat RATG13, and, on the other, although less obvious, this other neighbour

$==>$ ZXc21

https://www.google.com/url?sa=t\&source=web\&rct=j\&url=https://www.ncbi.nlm.nih.gov/nuccore/MG7729 34\&ved=2ahUKEwi63MmXkIfvAhVPrxoKHc7rBkAQFjAAegQIBBAD\&usg=AOvVaw2DaPGodhGxK_sv2JPdNU29

\section{Bat SARS-like coronavirus isolate bat-SL-CoVZXC21, complete genome}

GenBank: MG772934.1

/collection_date="Jul-2015"

21483..25220

$$
\text { /note="S" }
$$

/codon_start=1

/product="spike

\section{$==>$ Bat Ratg13}

https://www.google.com/url?sa=t\&source=web\&rct=j\&url=https://www.ncbi.nlm.nih.gov/nuccore/MN9965 32\&ved=2ahUKEwjO1KKqkIfvAhVlx4UKHYypB4oQFjABegQIARAC\&usg=AOvVaw1NImUic0dN6Ke140Hf408t

\section{Bat coronavirus RaTG13, complete genome}

GenBank: MN996532.2

Go to:

LOCUS MN996532 29855 bp RNA linear VRL 24-NOV-2020

COMMENT On Oct 13, 2020 this sequence version replaced MN996532.1.

/isolation_source="fecal swab"

/collection_date="24-Jul-2013"

/gene="S"

CDS 21560.25369

/gene="S"

\section{$==\mathbf{Z C 4 5}$}

https://www.google.com/url?sa=t\&source=web\&rct=j\&url=https://www.ncbi.nlm.nih.gov/nuccore/MG7729 33\&ved=2ahUKEwig_s_0j4fvAhUPKBoKHe_oD44QFjAAegQIBBAD\&usg=AOvVaw0IPCwtlOcZJxs4SzfZhzPu

\section{Bat SARS-like coronavirus isolate bat-SL-CoVZC45, complete genome}

GenBank: MG772933.1

/collection_date="Feb-2017"

$$
\begin{array}{cc}
\text { SPIKE } & \\
\text { CDS } & 21549.25289 \\
& / \text { note="S" } \\
& \text { /codon_start=1 }
\end{array}
$$

The following SARS-CoV2 "quadrille", bat RATG13, ZC45 and ZXC21 is remarkable for its enigmatic nature over the actual origins of SARS-CoV2. Indeed, when the first two are supposed to be of natural origin, we have the certainty and the evidence that the last two were read to the point - and published - by military laboratories.

Fibonacci analyzes of these four genomes and their Spike genes will reveal links, subfamilies and correlations two to two between these four key genomes in the history and genesis of the COVID-19 pandemic. 


\section{Genome's scale analyzes:}
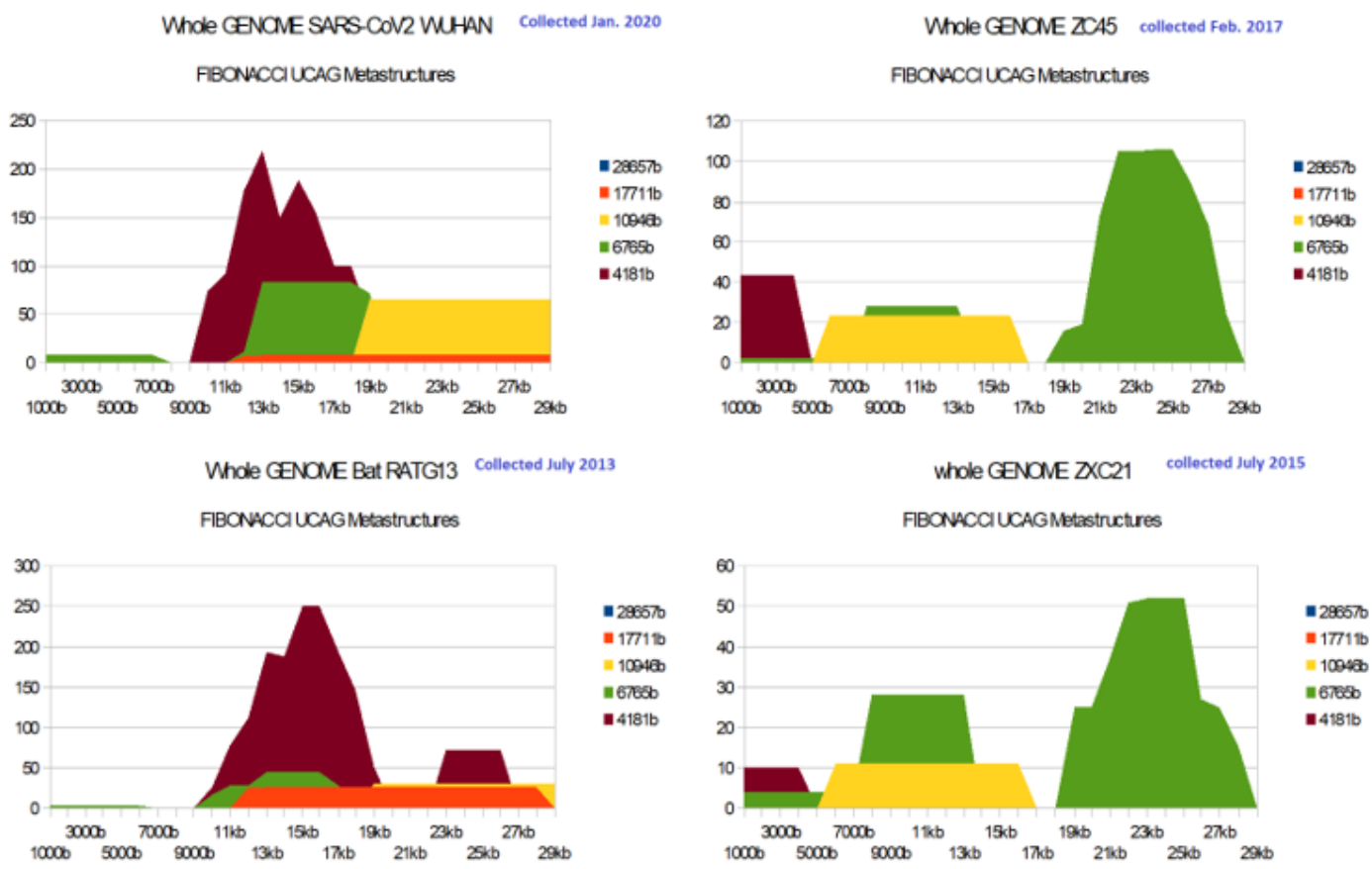

Figure 5: remarkable vertical analogies (SARS-CoV2 vs bat RaTG13). Spike's scale analyzes:

SARS-CoV2 Wuhan Reference Spike UACG Fibonacci Metastructures collected Jan. 2020

SPIKE COVZC45 collected Feb.2017

2584 UACG $=>1597$ UA and 987 CG only between base 1000 and the Spike End
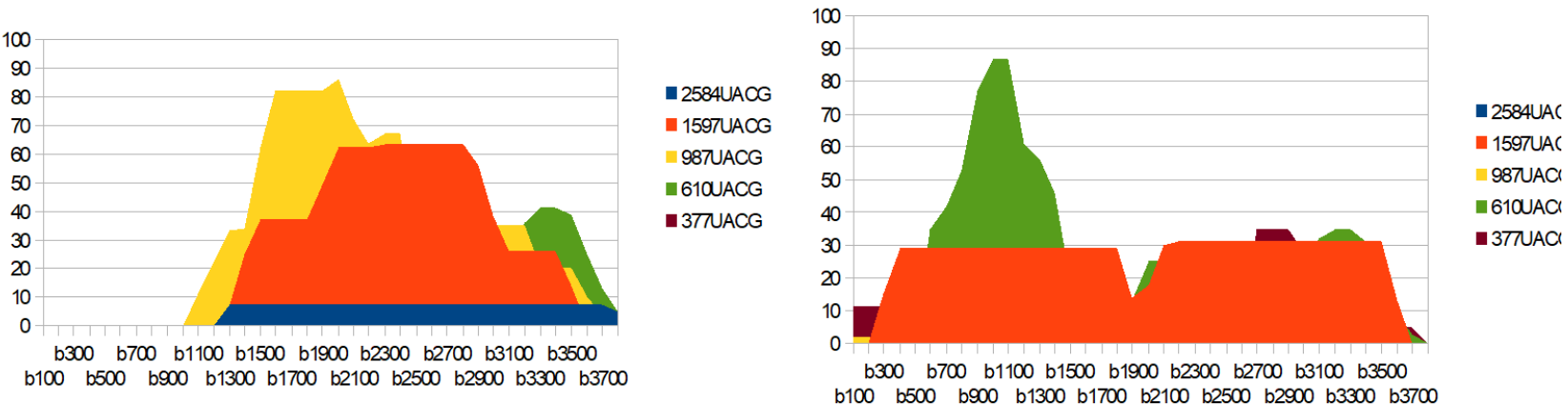

BatRATG13 SPIKE Fibonacci UACGMetastructures collected July 2013

2584 UACG/ 1597 UA/ 987 CG
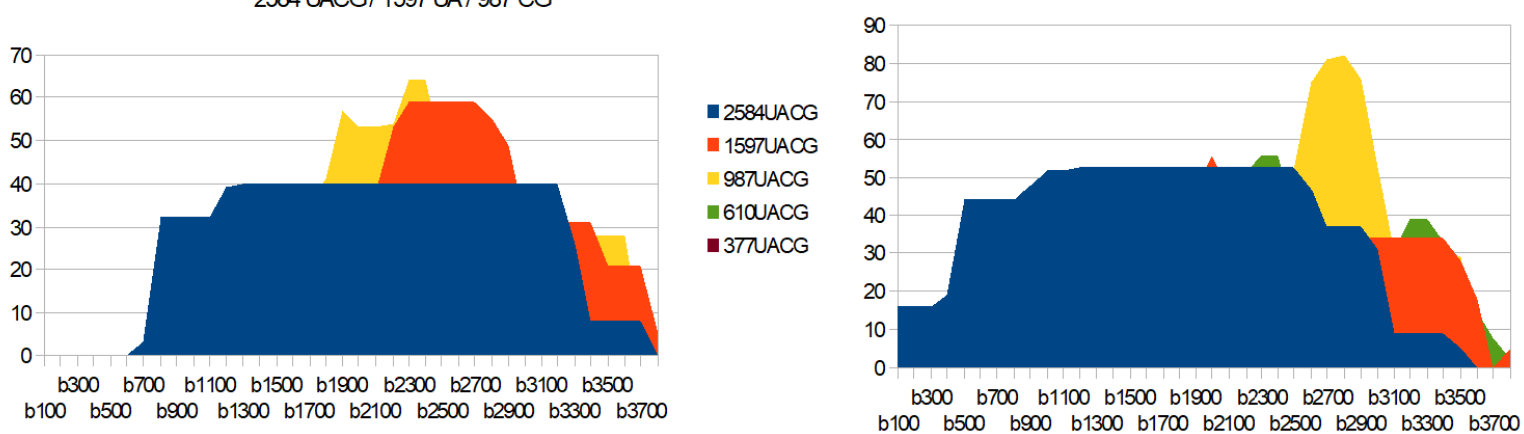

2584UA

1597UA

987UAC

$\square 610 \mathrm{AC}$

- 3 TINAC

Wuhan ref SARS-COV2 and bat RATG13, sharing 96\% nucleotiedes

Homology? No! This comparative chart demonstrate a formal

PROOF that both SPIKES mRNA sequences are radically differents at

FIBONACCI UA/CG Metastructures level...

Figure 6: remarkable horizontal analogies (Bat RATG13 vs ZXC21). 
A

ZC45 vs. ZXC21

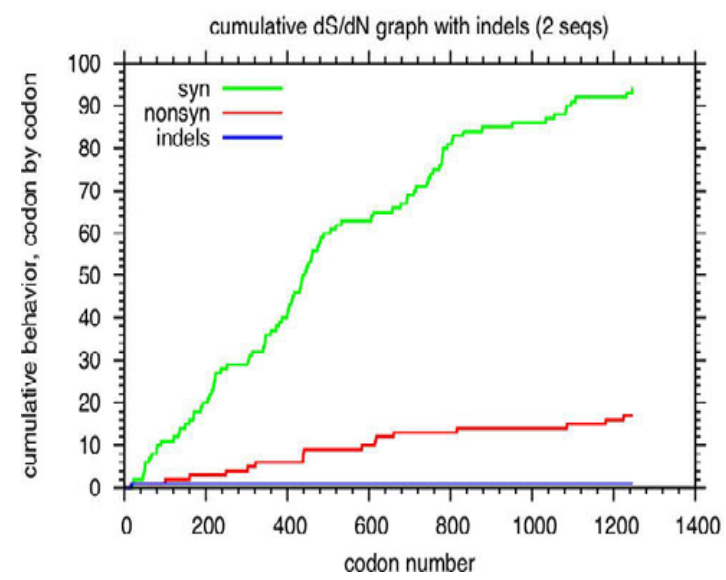

B SARS-CoV-2 vs. RaTG13

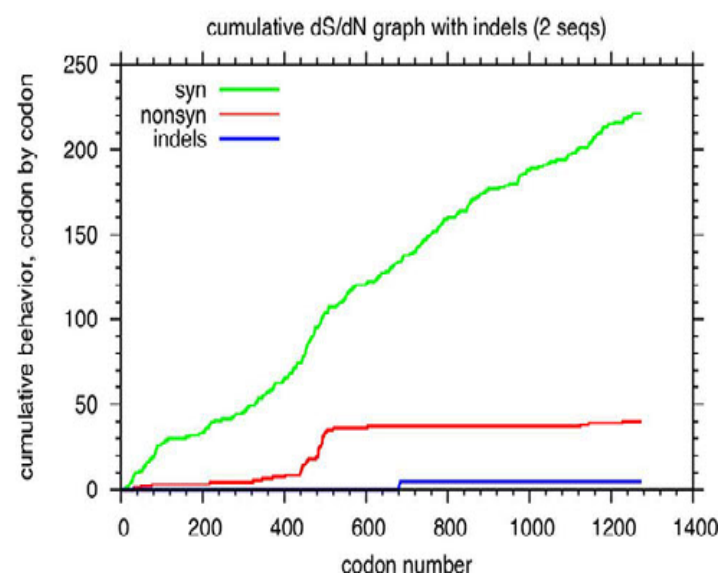

Figure 7: Evidence of patterns analogies at Synonimes/non synonimes codons.

FIGURE. 7 concerning the abnormal number of synonymous codons between SARS-CoV2 and bat RATG13 on the one hand and ZXC21 and ZC45 on the other hand confirms and reinforces the dichotomy which has just been revealed here by the Fibonacci analyzes.

Particularly, both bat RATG13 and ZXC21 Spikes provide a high level of Fibonacci long range UA/CG resonances (blue coloured in Fig7). For us, that is the proof of natural evolutionary contraints contrarly the 2 remaining spikes SARS-CoV2 and ZC45.

Let us summarize the respective results of figures 5, 6 and 7: figure 5 (genomes) confirms the above dichotomy natural versus laboratory. indeed, a double vertical analogy clearly classifies these four genomes into two + two by the clear graphic correlation of their Fibonacci images.

On the contrary (figure 6 spikes), the comparative analyzes of the four spikes clearly shows a horizontal dichotomy between SARS-CoV2 and ZC45 on the one hand and bat RATG13 and ZCX21 on the other hand. Does this mean that ZC45 would have served as a "model" for SARS-CoV2 while ZXC21 would have "inspired" bat RATG13, or perhaps the reverse if we take into account the respective dates: bat RATG13 (2013/2020) ZXC21 (2015) ZC45 (2017) SARS-CoV2 (2019/2020).

SARS-Cov2 is directly linked to RaTG13 as ZC45 is linked to ZXC21 and the reduction or even disappearance of the 2584 UACG metastructures in SARS-Cov2 and ZC45 shows that practically ZC45 is "made from" ZXC21 like SARSCov2 from RaTG13.

\subsection{COMPARING 11 REFERENCE VARIANTS SPIKES}

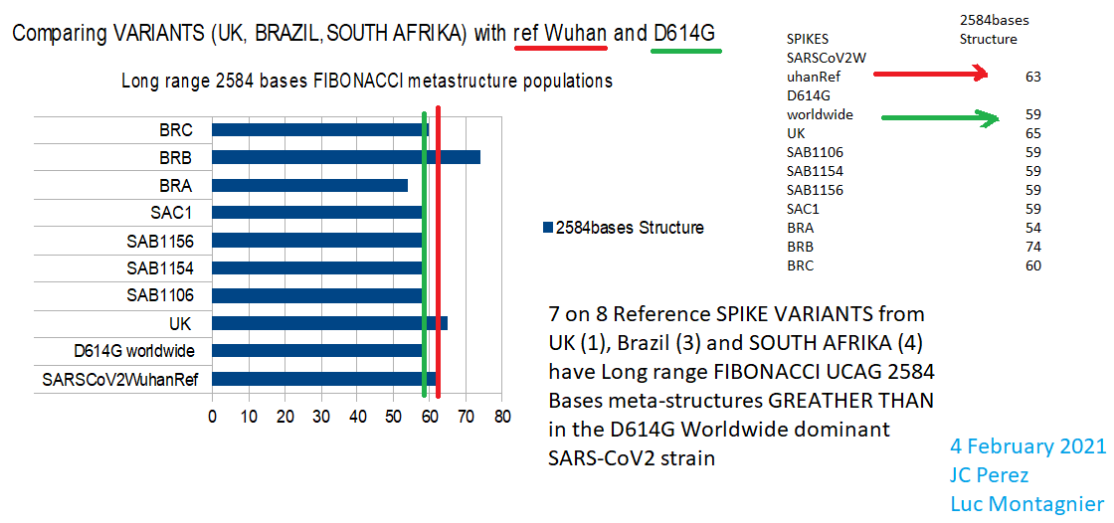

Figure 8: Comparing CIRCULAR Fibonacci metastructures between reference variants and Wuhan and D614G worldwide spikes. 


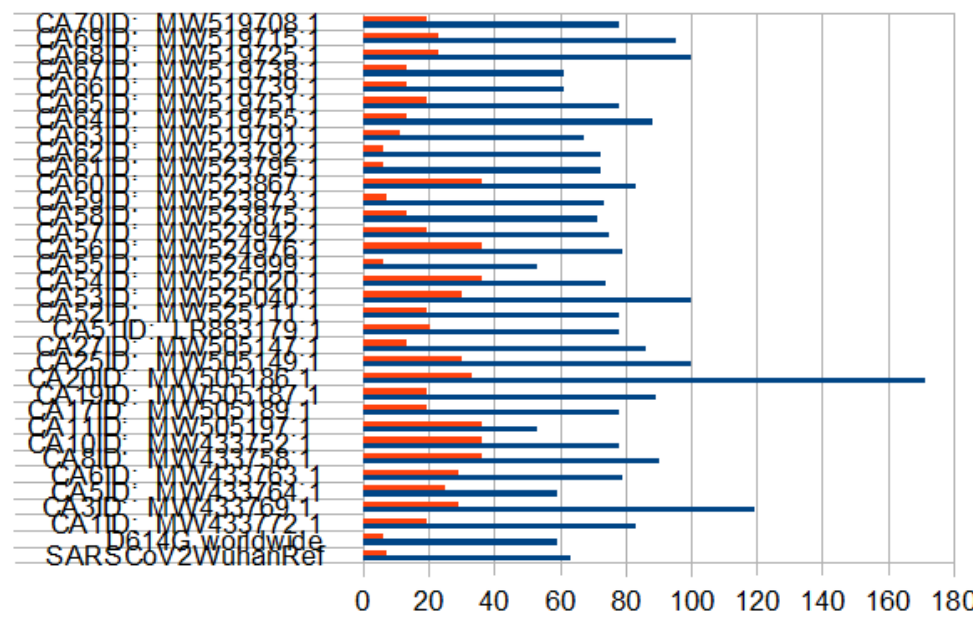

- Circular 2584b

- Linear 2584b

Figure 9: Comparing CIRCULAR and LINEAR Fibonacci metastructures between 32 CAL.20C Sample patients spikes variants and Wuhan and D614G worldwide spikes.

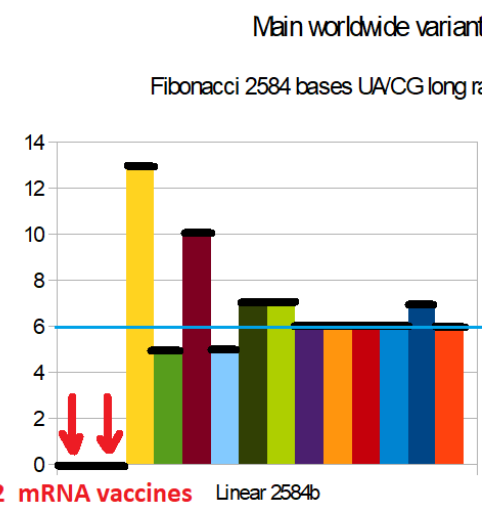

2 mRNA vaccines Linear 2584b

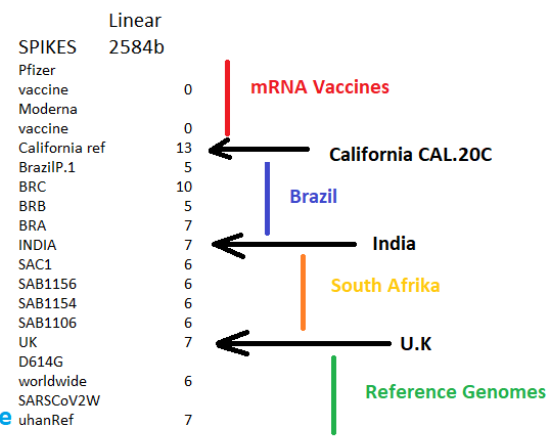

D614G worldwide reference uhanRef

Comparing Fibonacci 2084 bases metastructures for all variants SPIKE worldwide including the 2 mRNA vaccines and reference SARS-CoV2

Figure 10: Comparing LINEAR Fibonacci metastructures between reference variants and Wuhan and D614G worldwide spikes, note: The cases of mRNA vaccines are discussed in $\S 8$ and 9.

Table 2: Comparing LINEAR Fibonacci metastructures between reference variants and Wuhan and D614G worldwide spikes.

\begin{tabular}{|c|c|}
\hline SPIKES variants or vaccines & Linear 2584 bases \\
\hline Pfizer vaccine & 0 \\
\hline Moderna vaccine & 0 \\
\hline California CAL20C reference & 13 \\
\hline Brazil P1 & 5 \\
\hline Brazil C & 10 \\
\hline Brazil B & 5 \\
\hline Brazil A & 7 \\
\hline INDIA & 7 \\
\hline South Afrika SAC1 & 6 \\
\hline South Afrika SAB1156 & 6 \\
\hline
\end{tabular}


Jean-Claude Perez

\begin{tabular}{|c|c|}
\hline South Afrika SAB1154 & 6 \\
\hline South Afrika SAB1106 & 6 \\
\hline UK & 7 \\
\hline D614G worldwide & 6 \\
\hline SARS-CoV2 Wuhan & 7 \\
\hline
\end{tabular}

In this paragraph 3, we attempt to answer the question: "Do the variants strengthen or reduce the level of Fibonacci metastructures of the Spikes vis-à-vis the original Wuhan and worldwide D614G strains?".

We carry out two types of additional analyzes: on the one hand by considering the mRNA spike looped back on itself (ring like: figures 8 and 9), which is inaccurate here but nevertheless provides information which makes sense, and corresponds to the actual situation (figure 10 and table 2).

Globally, it appears that there is a significant increase in Fibonacci structures for the variants, but these variants are only theoretical sequences; we will see in the following that the increase in metastructure of the variant spikes is much more pronounced in the case of patients (see study of CAL.20C variant patients).

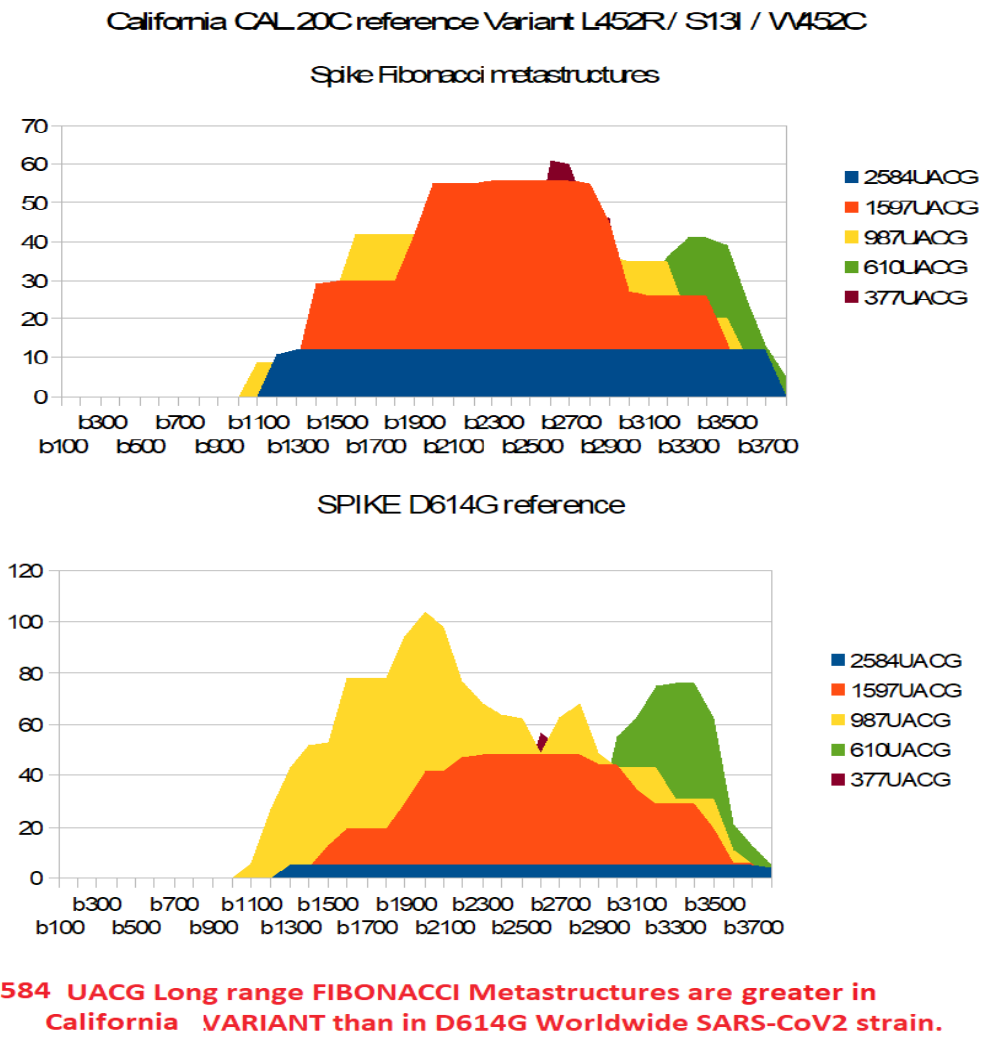

Figure 11: Comparing reference variant CAL.20C Fibonacci metastructures with worldwide spike D614G.

\subsection{ANALYSING 32 CAL.20C CALIFORNIA VARIANT PATIENTS' SPIKES}

This section analyzes the genomes and spikes of thirtytwo patients with the California variant CAL.20C. Figure 11 and tables 4 to 6 summarize two major results:

- the very great diversity of the results.

- the very clear trend of an increase in the number of Fibonacci structures compared to the reference genome D614G.

But the newest and most remarkable is the one which will be the subject of the next $\& 5 \ldots$

Data sources: GenBank.

International Journal of Research -GRANTHAALAYAH 
Table 3: Variant California CAL.20C: 32 individual patients spikes

\begin{tabular}{|c|c|c|c|c|c|c|c|c|c|c|}
\hline \multirow{2}{*}{$\begin{array}{c}32 \\
\text { L452R } \\
\text { varian } \\
\text { ts }\end{array}$} & \multicolumn{3}{|c|}{$\begin{array}{c}\text { S13I California variant } \\
\text { mutation }\end{array}$} & \multicolumn{3}{|c|}{$\begin{array}{l}\text { W152C California } \\
\text { variant mutation }\end{array}$} & \multirow{2}{*}{$\begin{array}{c}2584 \text { UCAG } \\
\text { FIBONACCI } \\
\text { circular } \\
\text { matastructu } \\
\text { res } \\
\text { population } \\
\text { D614G spik } \\
\text { e: } 59\end{array}$} & \multirow{2}{*}{$\begin{array}{l}2584 \text { UCAG } \\
\text { FIBONACCI } \\
\text { linear } \\
\text { matastructu } \\
\text { res } \\
\text { population } \\
\text { D614G spik } \\
\text { e: } \\
5\end{array}$} & \multirow{2}{*}{$\begin{array}{c}\text { "mRNA } \\
\text { checksu } \\
m \\
\text { natural } \\
\text { law" } \\
\text { SPIKE }\end{array}$} & \multirow{2}{*}{$\begin{array}{l}17711 \text { UCAG } \\
\text { FIBONACCI } \\
\text { linear } \\
\text { matastructu } \\
\text { res } \\
\text { population } \\
\text { D614G } \\
\text { genome: } \\
8 \\
\end{array}$} \\
\hline & $\begin{array}{l}\text { AGU } \\
\text { regul } \\
\text { ar } \\
(S 13)\end{array}$ & $\begin{array}{c}\text { AUU } \\
\text { varia } \\
\text { nt } \\
\text { (I13I) }\end{array}$ & $\begin{array}{c}\text { Other } \\
\text { (deletio } \\
\text { ns) }\end{array}$ & $\begin{array}{c}\text { UGG } \\
\text { regul } \\
\text { ar } \\
\text { (W15 } \\
2)\end{array}$ & $\begin{array}{c}\text { UGU } \\
\text { varia } \\
\text { nt } \\
(152 \\
\text { C) }\end{array}$ & $\begin{array}{c}\text { Other } \\
\text { (deletio } \\
\text { ns) }\end{array}$ & & & & \\
\hline CA1 & & AUU & & & UGU & & 83 & 19 & $\begin{array}{l}1597 \\
1597\end{array}$ & 5 \\
\hline CA3 & & AUU & & & & GCA & 119 & 29 & $\begin{array}{l}1597 \\
1595\end{array}$ & 21 \\
\hline CA5 & & & UAA & & & UGA & 59 & 25 & $\begin{array}{l}1597 \\
1598\end{array}$ & 11 \\
\hline CA6 & & & UAC & & & ACU & 79 & 29 & $\begin{array}{l}1597 \\
1595\end{array}$ & 31 \\
\hline CA8 & & AUU & & & & AUG & 90 & 36 & $\begin{array}{l}1597 \\
1596 \\
\end{array}$ & 8 \\
\hline CA10 & & & UAC & & & ACA & 78 & 36 & $\begin{array}{l}1597 \\
1594 \\
\end{array}$ & 9 \\
\hline CA11 & & AUU & & & & GGU & $53<==$ & 36 & $\begin{array}{l}1597 \\
1594 \\
\end{array}$ & 25 \\
\hline CA17 & & AUU & & & UGU & & 78 & 19 & $\begin{array}{l}1597 \\
1597 \\
\end{array}$ & 9 \\
\hline CA19 & & AUU & & & UGU & & 89 & 19 & $\begin{array}{l}1597 \\
1597 \\
\end{array}$ & 39 \\
\hline CA20 & & & UAG & & & CUU & 171 & 33 & $\begin{array}{l}1597 \\
1597\end{array}$ & 39 \\
\hline CA25 & & AUU & & & UGU & & 100 & 30 & $\begin{array}{l}1597 \\
1596 \\
\end{array}$ & 28 \\
\hline CA27 & & AUU & & & UGU & & 86 & 27 & $\begin{array}{l}1597 \\
1598 \\
\end{array}$ & 28 \\
\hline CA51 & & & UCA & & & UAU & 78 & 20 & $\begin{array}{l}1597 \\
1598 \\
\end{array}$ & 47 \\
\hline CA52 & & AUU & & & UGU & & 78 & 19 & $\begin{array}{l}1597 \\
1597 \\
\end{array}$ & 8 \\
\hline CA53 & & AUU & & & UGU & & 100 & 30 & $\begin{array}{l}1597 \\
1596\end{array}$ & 29 \\
\hline
\end{tabular}


Jean-Claude Perez

\begin{tabular}{|c|c|c|c|c|c|c|c|c|c|c|}
\hline CA54 & & AUU & & & & AUU & 74 & 36 & $\begin{array}{l}1597 \\
1592\end{array}$ & 9 \\
\hline CA55 & AGU & & & UGG & & & $53<==$ & 6 & $\begin{array}{l}1597 \\
1599\end{array}$ & 12 \\
\hline CA56 & & & CUA & & & ACC & 79 & 36 & $\begin{array}{l}1597 \\
1595\end{array}$ & 35 \\
\hline CA57 & & AUU & & & UGU & & 75 & 19 & $\begin{array}{l}1597 \\
1597\end{array}$ & 33 \\
\hline CA58 & AGU & & & UGG & & & 71 & 13 & $\begin{array}{l}1597 \\
1598\end{array}$ & 43 \\
\hline CA59 & & & UCA & & & GAU & 73 & 7 & $\begin{array}{l}1597 \\
1601\end{array}$ & 43 \\
\hline CA60 & & & GCA & & & GAA & 83 & 36 & $\begin{array}{l}1597 \\
1589\end{array}$ & 39 \\
\hline CA61 & & AUU & & & UGU & & 72 & 6 & $\begin{array}{l}1597 \\
1599\end{array}$ & 39 \\
\hline CA62 & & AUU & & & UGU & & 72 & 6 & $\begin{array}{l}1597 \\
1599\end{array}$ & 13 \\
\hline CA63 & & AUU & & & UGU & & 67 & 11 & $\begin{array}{l}1597 \\
1597\end{array}$ & 33 \\
\hline CA64 & & AUU & & & UGU & & 88 & 12 & $\begin{array}{l}1597 \\
1598\end{array}$ & 26 \\
\hline CA65 & & AUU & & & UGU & & 78 & 19 & $\begin{array}{l}1597 \\
1597\end{array}$ & 28 \\
\hline CA66 & & AUU & & & UGU & & 61 & 12 & $\begin{array}{l}1597 \\
1598\end{array}$ & 33 \\
\hline CA67 & & AUU & & & UGU & & 61 & 12 & $\begin{array}{l}1597 \\
1598\end{array}$ & 40 \\
\hline CA68 & & AUU & & & & GAA & 100 & 22 & $\begin{array}{l}1597 \\
1597\end{array}$ & 12 \\
\hline CA69 & & AUU & & & & GAA & 95 & 22 & $\begin{array}{l}1597 \\
1597\end{array}$ & 33 \\
\hline CA70 & & AUU & & & UGU & & 78 & 19 & $\begin{array}{l}1597 \\
1597\end{array}$ & 3 \\
\hline
\end{tabular}

Table 4: VARIANT L452R and variability S13I California CAL.20C vs HIV/SIV « EIE » (July 2020: Perez, J. C., \& Montagnier, L. (2020). COVID-19, SARS AND BATS CORONAVIRUSES GENOMES PECULIAR HOMOLOGOUS RNA SEQUENCES. International Journal of Research -GRANTHAALAYAH, 8(7), 217-263.

https://zenodo.org/record/3975589).

\begin{tabular}{|c|c|c|c|c|}
\hline $\begin{array}{c}\text { California } \\
\text { VARIANT } \\
\text { S13I }\end{array}$ & $\begin{array}{c}\text { AGU regular } \\
\text { (S13) }\end{array}$ & AUU variant(I13I) & Other (deletions) & $\begin{array}{c}\text { Total } \\
\text { (L452R) }\end{array}$ \\
\hline
\end{tabular}


Sars-Cov2 Variants and Vaccines mRNA Spikes Fibonacci Numerical UA/Cg Metastructures

\begin{tabular}{|c|c|c|c|c|}
$\begin{array}{c}\text { Number of } \\
\text { strains }\end{array}$ & 2 & 22 & 8 & 32 \\
\hline$\%$ of strains & $6,00 \%$ & $69,00 \%$ & $25,00 \%$ & $100,00 \%$ \\
\hline Nota & & $\begin{array}{r}94 \% \text { mutations or deletions where HIV/SIV « EIE » } \\
\text { Perez§Montagnier article are involved }\end{array}$ & \\
\hline
\end{tabular}

Note: for information, a first mutation is located in the HIV zone (S13I). 3 bases after Kenya (1 in chart) and 8 bases before the second HIV (2 in chart). See Perez§Montagnier 2020.

We analyzed (table 3) the genomes and spikes of thirtytwo patients with the California variant CAL.20C. The result is very interesting:

For the circular structures analyzes of the spike, thirty out of thirtytwo cases increase the metastructures 2584 AU / CG vis-à-vis the reference D614G (column 8).

For the linear structures analyzes of the spike (column 9), the integrity of the thirtytwo cases increases these same metastructures 2584 AU / CG.

At the level of whole genomes, the $17711 \mathrm{UA} / \mathrm{CG}$ metastructures (column 11) increase in thirty out of thirtytwo cases with respect to the reference genome D614G.

We can only conclude that the reference variants are only textbook cases, much less rich in synonymous mutations than the genomes of real patients. We conclude that a large number of synonymous mutations specific to each patient reinforce the overall structure of genomes and spikes, it suffices to observe the diversity of the results for each of the thirtytwo patients.

Another remark, if all thirtytwo patient cases have the L452R, for the two remaining mutations characterizing CAL.20C, there is a large diversity of individual cases for mutations S13I and W152C: someone has one or other or none between these mutations. There are also cases with deletions overlaping these S13I or W152C crucial mutations. Finally, we must conclude that the key of variants evolution and pathogenicity knowledge provides more from individual patients sequences full analyzes than that from theoretical reference variants description.

Table 5: VARIANT L452R and variability W152C California CAL.20C vs HIV/SIV « EIE » (July 2020: Perez, J. C., \& Montagnier, L. (2020). COVID-19, SARS AND BATS CORONAVIRUSES GENOMES PECULIAR HOMOLOGOUS RNA SEQUENCES. International Journal of Research -GRANTHAALAYAH, 8(7), 217-263. https://zenodo.org/record/3975589).

\begin{tabular}{|c|c|c|c|c|}
\hline $\begin{array}{l}\text { W152C California } \\
\text { variant mutation }\end{array}$ & $\begin{array}{c}\text { UGG } \\
\text { regular } \\
\text { (W152) }\end{array}$ & $\begin{array}{c}\text { UGU } \\
\text { variant } \\
(152 C)\end{array}$ & $\begin{array}{c}\text { Other } \\
\text { (deletions) }\end{array}$ & $\begin{array}{c}\text { Total } \\
\text { (L452R) }\end{array}$ \\
\hline Number of strains & 2 & 16 & 14 & 32 \\
\hline$\%$ of strains & $6,00 \%$ & $50,00 \%$ & $44,00 \%$ & $100,00 \%$ \\
\hline Nota & & \multicolumn{2}{|c|}{$\begin{array}{l}\text { 94\% mutations or deletions just after where HIV/SIV «EIE » } \\
\text { Perez§Montagnier article are involved }\end{array}$} & \\
\hline
\end{tabular}


Jean-Claude Perez
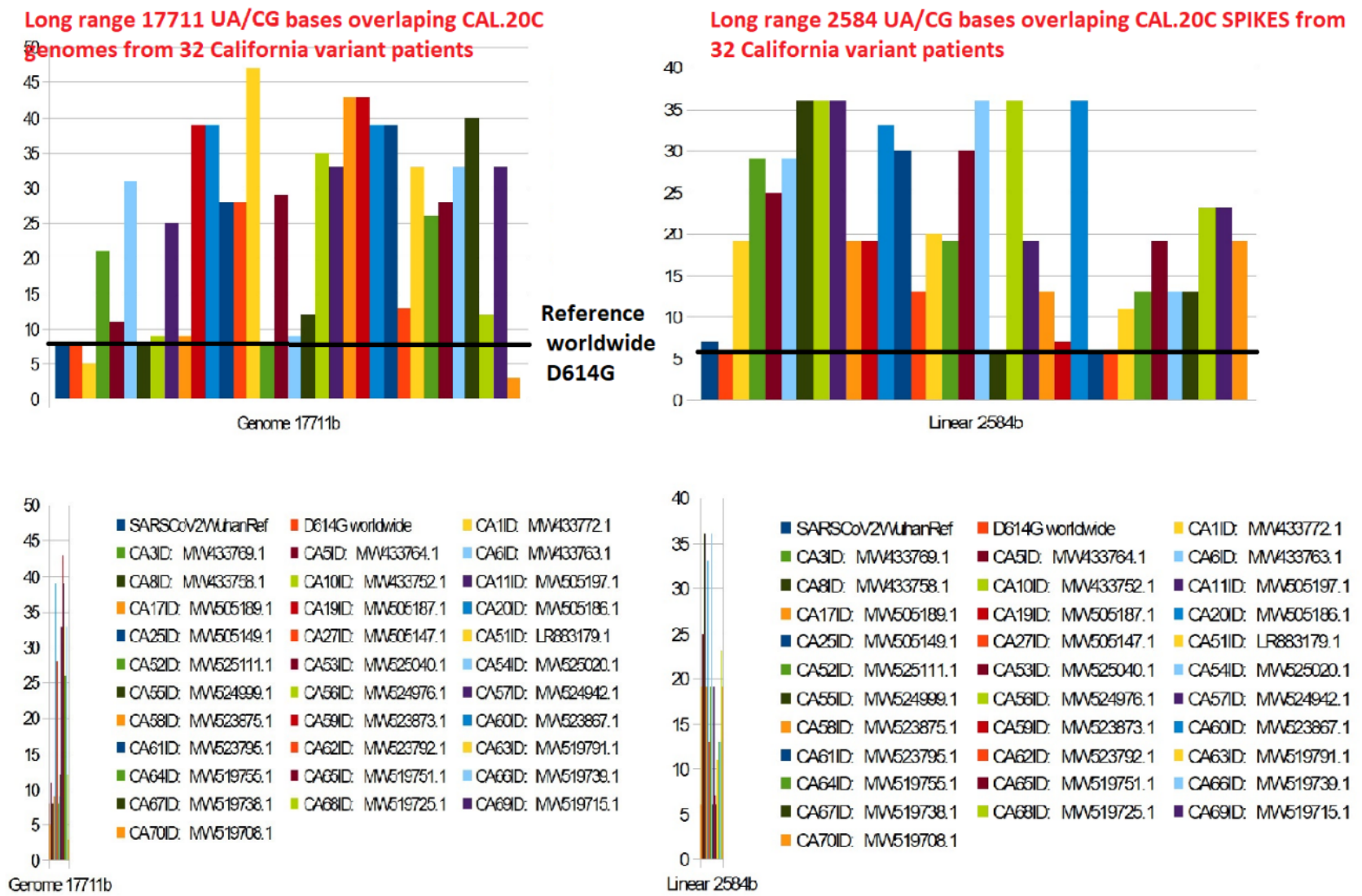

28 patients on 32 have a GENOME overlaping 17711 UA/CG metasructures greater than D614G worldwide SARS-Cov2 genome 29 patients on 32 have a SPIKE overlaping 2584 UA/CG metastructures greater than D614G worldwide SARS-CoV2 SPIKE

Figure 12: Comparing genome and spike between 32 CAL.20C patients and ref Wuhan and D614G worldwide reference.

Table 6: Comparing genome and spike between 32 CAL.20C patients and ref Wuhan and D614G worldwide reference.

\begin{tabular}{|c|c|c|}
\hline SPIKES references, Genbank link and dates & $\begin{array}{l}\text { Linear GENOME Fibonacci UA/CG } \\
17711 \text { bases }\end{array}$ & $\begin{array}{c}\text { Linear SPIKE } \\
\begin{array}{c}\text { Fibonacci UA/CG } 2584 \\
\text { bases }\end{array}\end{array}$ \\
\hline SARS-CoV2 Wuhan reference & 8 & 7 \\
\hline D614G worldwide & 8 & 6 \\
\hline CA1ID: MW433772.1 California 5 January 2021 & 5 & 19 \\
\hline CA3ID: MW433769.1 California 5 January 2021 & 21 & 29 \\
\hline CA5ID: MW433764.1 California 5 January 2021 & 11 & 25 \\
\hline CA6ID: MW433763.1 California 5 January 2021 & 31 & 29 \\
\hline CA8ID: MW433758.1 California 5 January 2021 & 8 & 36 \\
\hline
\end{tabular}




\begin{tabular}{|c|c|c|}
\hline CA10ID: MW433752.1 California 5 January 2021 & 9 & 36 \\
\hline CA11ID: MW505197.1 California 2 February 2021 & 25 & 36 \\
\hline CA17ID: MW505189.1 California 22 January 2021 & 9 & 19 \\
\hline CA19ID: MW505187.1 California 2February 2021 & 39 & 19 \\
\hline CA20ID: MW505186.1 California 2February 2021 & 39 & 33 \\
\hline CA25ID: MW505149.1 California 22 January 2021 & 28 & 30 \\
\hline CA27ID: MW505147.1 California 22 January 2021 & 28 & 13 \\
\hline CA51ID: LR883179.1 netherland 25 January 2021 & 47 & 20 \\
\hline CA52ID: MW525111.1 California 26 January 2021 & 8 & 19 \\
\hline CA53ID: MW525040.1 USA MO 26 January 2021 & 29 & 30 \\
\hline CA54ID: MW525020.1 USA FL 26 January 2021 & 9 & 36 \\
\hline CA55ID: MW524999.1 USA NY 26 January 2021 & 12 & 6 \\
\hline CA56ID: MW524976.1 USA CA 26 January 2021 & 35 & 36 \\
\hline CA57ID: MW524942.1 USA CA 26 January 2021 & 33 & 19 \\
\hline CA58ID: MW523875.1 USA CA 26 January 2021 & 43 & 13 \\
\hline CA59ID: MW523873.1 USA CA 26 January 2021 & 43 & 7 \\
\hline CA60ID: MW523867.1 USA TX 26 January 2021 & 39 & 36 \\
\hline CA61ID: MW523795.1 USA CA 26 January 2021 & 39 & 6 \\
\hline CA62ID: MW523792.1 USA CA 26 January 2021 & 13 & 6 \\
\hline CA63ID: MW519791.1 USA NV 25 January 2021 & 33 & 11 \\
\hline CA64ID: MW519755.1 USA AZ 25 January 2021 & 26 & 13 \\
\hline CA65ID: MW519751.1 USA AZ 25 January 2021 & 28 & 19 \\
\hline CA66ID: MW519739.1 USA CA 25 January 2021 & 33 & 13 \\
\hline CA67ID: MW519738.1 USA CA 25 January 2021 & 40 & 13 \\
\hline
\end{tabular}


Jean-Claude Perez

\begin{tabular}{|l|c|c|}
\hline & & 12 \\
\hline CA68ID: MW519725.1 USA CA 25 January 2021 & 33 & 23 \\
\hline CA69ID: MW519715.1 USA CA 25 January 2021 & 3 & 19 \\
\hline CA70ID: MW519708.1 USA CA 25 January 2021 & 33 \\
\hline
\end{tabular}

\subsection{TOWARD A META MRNA FIBONACCI GENE END MESSAGE CODE}

This point is at a level of fundamental research of mechanisms unknown to biology. Indeed, we demonstrate how, beyond and above the STOP codon which commands the protein manufacturing machinery to end the process, there would exist a sort of "end of gene message", which would be addressed, on the scale of messenger RNA, to this "code" and would be digital in nature, carried by the ultimate UA / CG metastructure of Fibonacci. We observe that this message would be of Nature GIGOGNE, constituted like the Russian dolls of a nesting of proportions all ending on one of the three bases of the STOP codon. This discovery is validated in this article on fortythree Spikes from UK, South Africa, BRAZIL and California variants. Of these Spikes, thirtytwo were from real patients.

In each box of the penultimate column of table 3, there are two very close numbers: the first number 1597 is the optimal number of UA bases with a final resonance of 2584 UACG which would end in the immediate vicinity of the codon stop UAA of the Spike. The second number (ie. 1598) is the real number of UA bases contained among these last 2584 bases of the spike. Remember that 2584 bases cover $2 / 3$ of the spike which has about 3800 bases. It is therefore a strong meta-structure which would control the relative proportions of nucleotides in the spike.

Table 7: Distribution of cases around the three bases of the UAA stop codon of the spike.

\begin{tabular}{|c|c|c|}
\hline 1597 Fibonacci UA bases & Base number & Number cases \\
\hline & 1594 & 2 \\
\hline & 1595 & 3 \\
\hline 1597 A (stop codon) & 1596 & 3 \\
\hline $1598 \quad$ A (stop codon) & 1597 & 11 \\
\hline $1599 \quad$ U (stop codon) & 1599 & 8 \\
\hline & 1600 & 8 \\
\hline & 1601 & 2 \\
\hline & 1602 & 1 \\
\hline & & 2 \\
\hline
\end{tabular}


Analysing mRNA CHECKSUM from 42 SARS-CoV2 SPIKES

TAA Stop codon signal revealed by 1597 to 1599 UA in 2584 last FIBONACCI

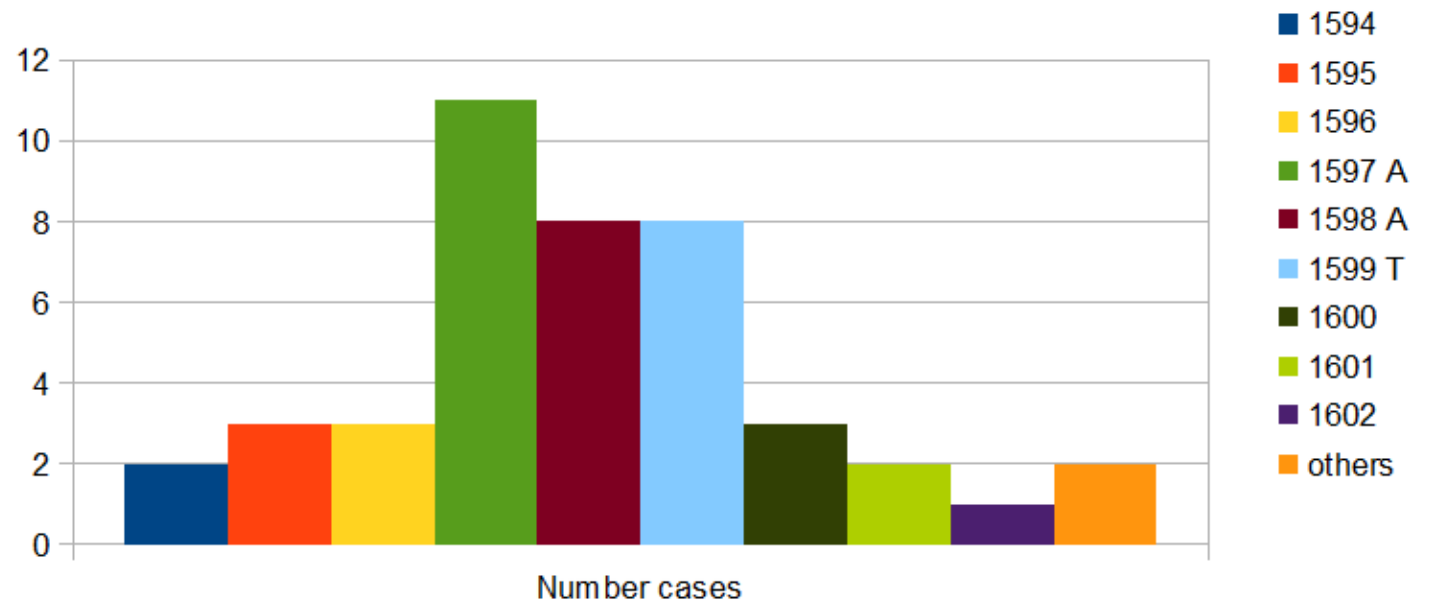

Figure 13: histogram perfectly illustrating the "bell" concentration of cases around the 3 bases of the UAA stop codon of the spike.

Table 7 and the histogram of FIG. 13 illustrate this remarkable phenomenon of "end-of-gene meta-structure" generalized to the thirty two spike strains of CAL.20C patients plus eleven spikes of reference variants, for a total of forty three cases. The histogram perfectly illustrates the "bell" concentration of cases around the three bases of the UAA stop codon of the spike.

\subsection{ANALYSING S501 UK, S484 SOUTH AFRICA, AND LAST "TWO MUTATIONS" INDIAN VARIANTS}

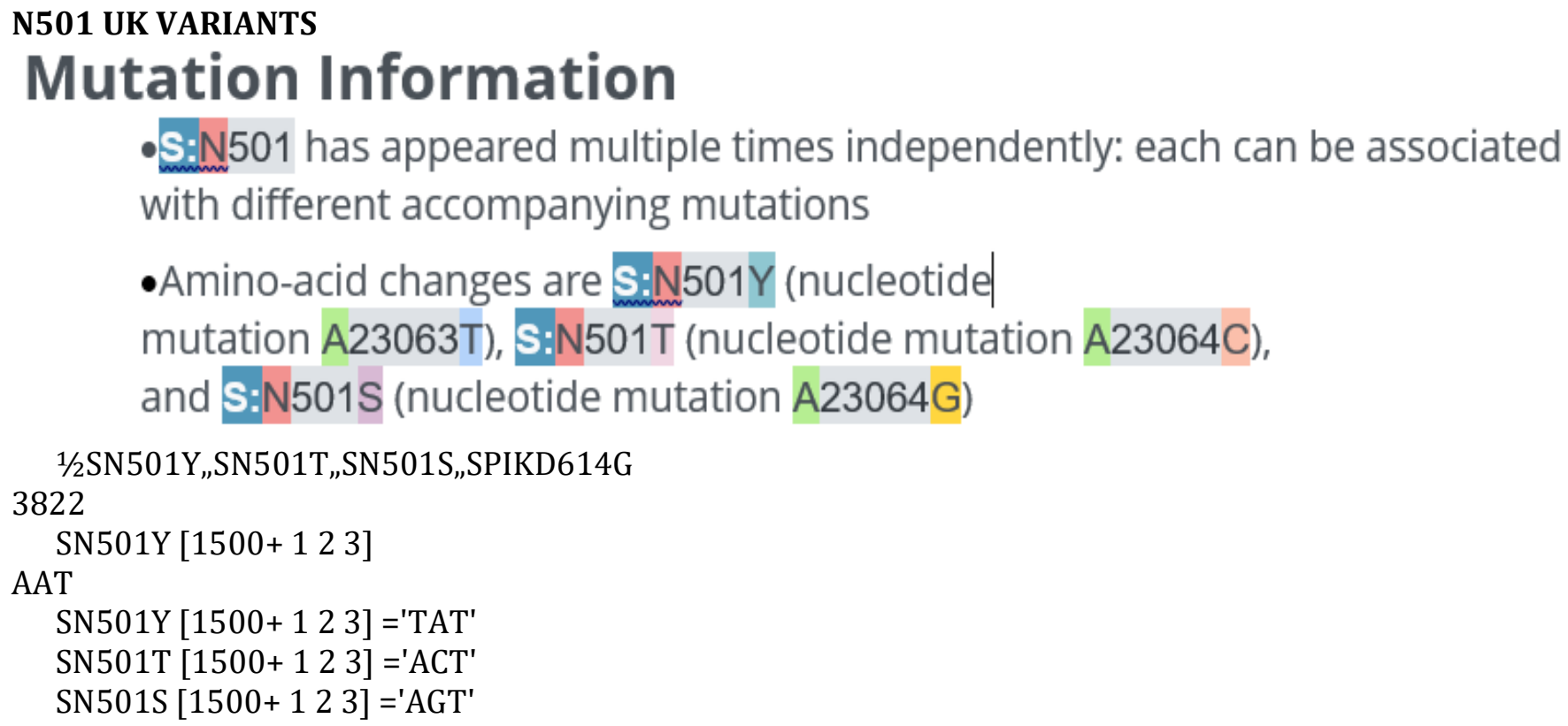


SPIKE D614Greference

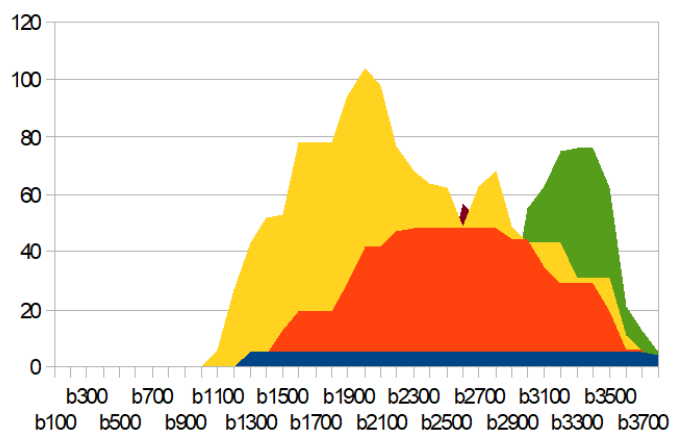

SPIKE N501Y UK variant

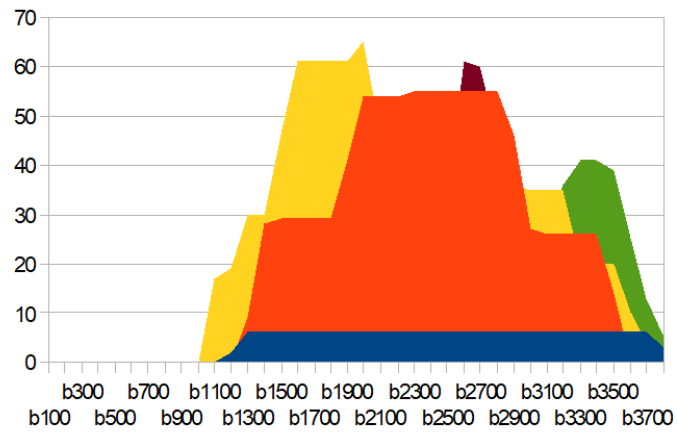

SPIKE SNE01T UK Variant
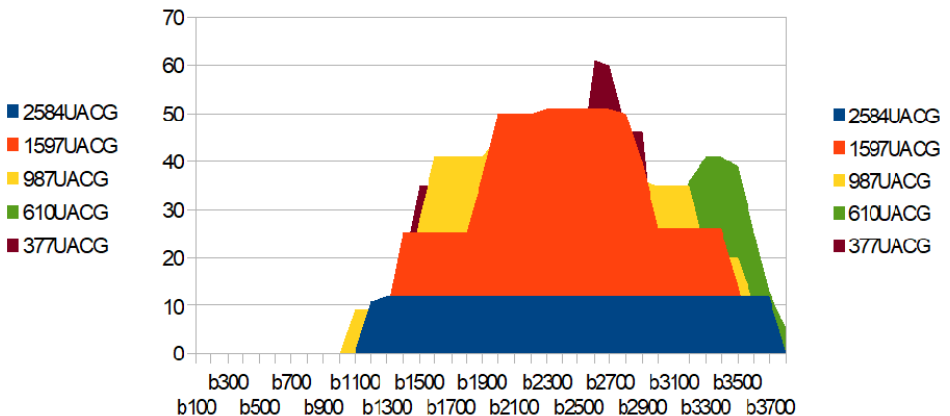

SPIKE SN501S UK Variant

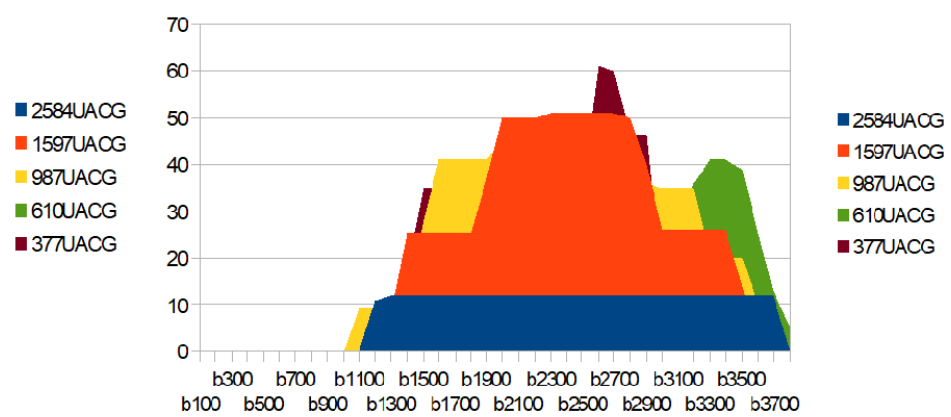

Comparing FIBONACCI mRNA SPIKES Metastructures between D614G worlwide ref. and the three U.K VARIANTS SN501Y, SN501T and SN501S: we note increasing 2584 UACG § 1597 UACG Metastructures. Suggesting they could be linked with mRNA SPIKE STABILITY § LIFE-TIME then INFECTUOSITY.

24 February 2021 J.C Perez Luc Montagnier

Figure 14: Comparing 3 UK variants Spike codon 501 mutations with reference D614G spike.

For the English variant (Figure 14), we see that at least two of the three mutations significantly increase the long metastructures of 2584 UACG bases (blue regions in Figure 14). This can generate better stability and life of the mRNA of the spine of these variants, and therefore correspond to the increase in infectivity and pathogenicity observed in patients who are victims of this English variant.

\section{South Africa VARIANT}

\section{H/501Y.V2}

Also

Announced in December 2020, 501Y.V2 originated and/or initially expanded in South Africa (Tegally et al., medRxiv ).

501YV2 is associated including: S: N501Y (see

Additionally,

there

with multiple mutations N501 page), S:E484K, S:K417N, in Spike, There is also a mutation in Nucleocapsid: $\mathbf{N}:$ T205l and a deletion in ORF1a(Nsp6) at positions 3675-3677 (also seen in 501Y.V1 and 501Y.V3). $\mathrm{GAA}==>\mathrm{AAA} \quad \mathrm{E} 484 \mathrm{~K}$

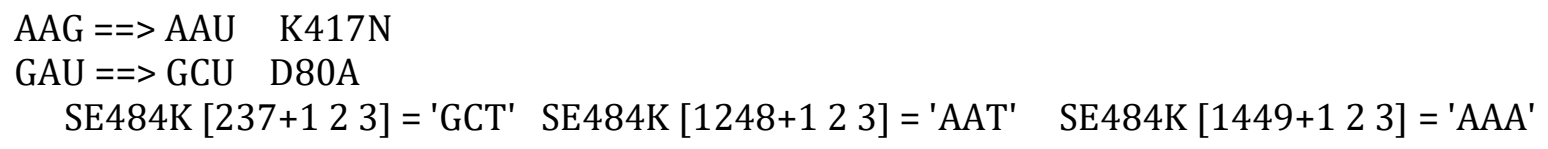




\section{SOUTH AFRIKA VARIANT 20H/501Y.V2 \\ E484K / N501Y / K417N / D80A \\ FBONACCI long range SPIKE Metastuctures UACG}

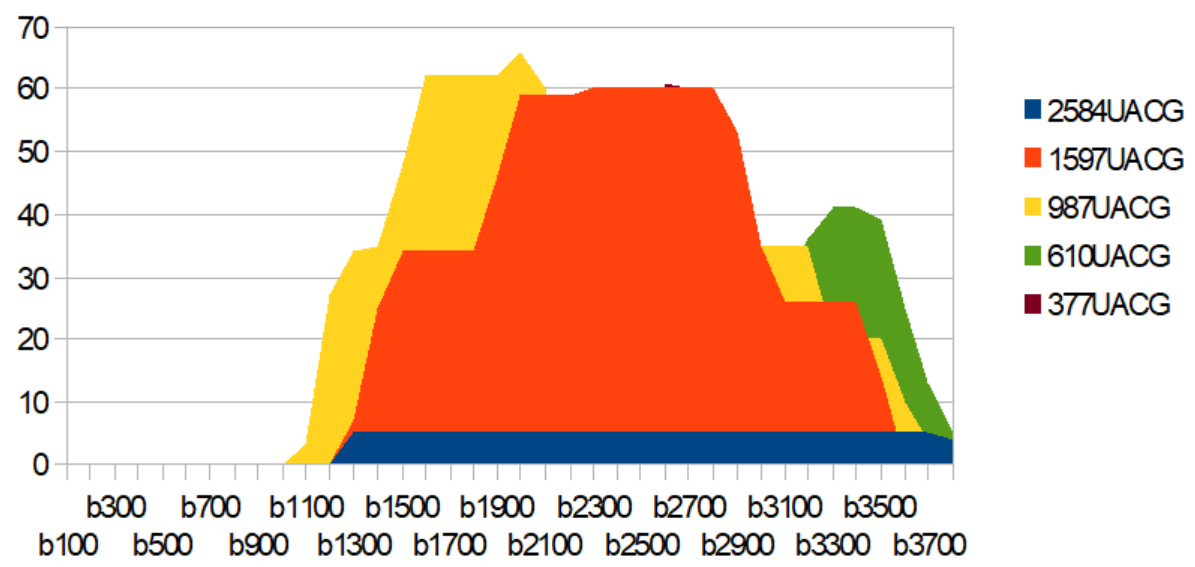

\section{SPIKE D614G reference}

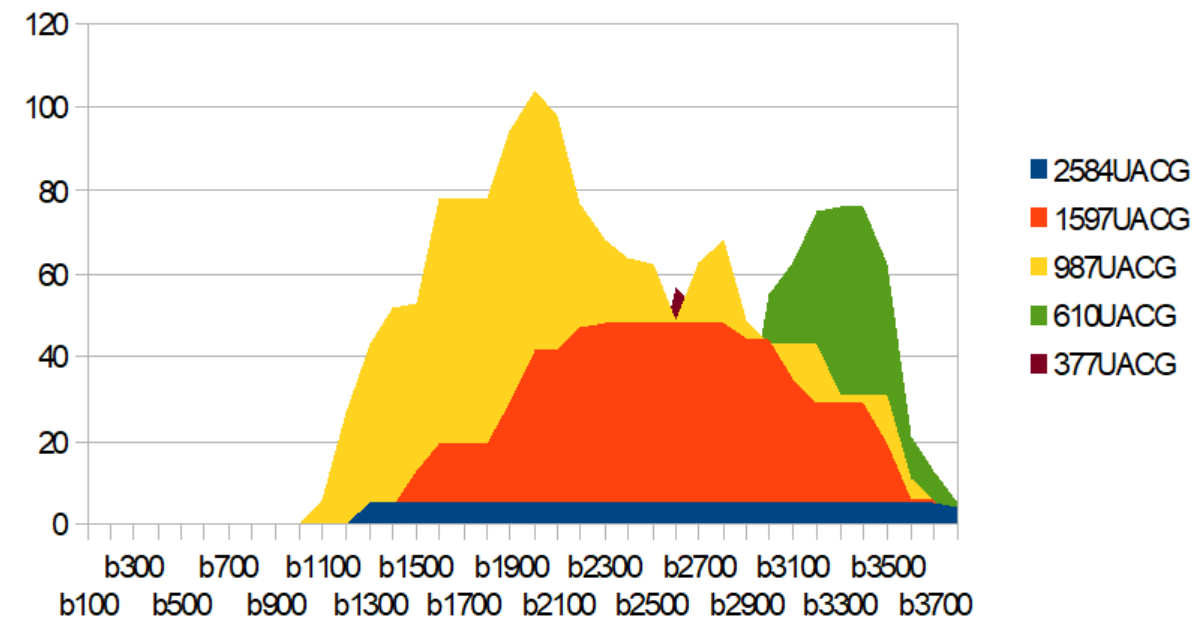

1597 UACG Long range FIBONACCI Metastructures are greather in SOUTH AFRIKA VARIANT than in D614G Worldwide SARS-CoV2 strain.

Figure 15: Comparing South Africa variant spike with reference D614G spike.

For this South African variant (figure 15), we see above all a strong increase in metastructures 1597 UACG (orange in figure 15).

On the other hand, the "podium" shape, already observed for the English variant, becomes very clear here. This enigmatic form will be the subject of the next and last paragraph \& 7 ...

\section{Indian « two mutations » variant:}

We analyse here two cases:

Basic variant

Full variant

See also (Govinarajan, 2020a) and (Govinarajan, 2020b).

In BASIC VARIANT, we modify spike D614G only with these two mutations: E484Q and L452R.

International Journal of Research -GRANTHAALAYAH 
In FULL VARIANT, we manage the fusion between South Africa variant, California variant and the small change vs. South Africa variant doing E484Q.

SINDIABASIC

INDIAN"2 mutations" Variant Spike Fibonacci Mbtastructures

E484Qand L452R, then FUSIONof south afika + califoria variats

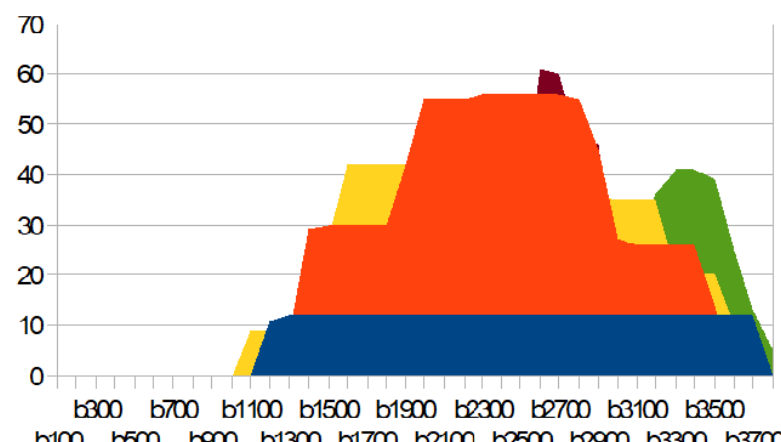

-2584UAOG

- 1597 ACG

987 AOG

-610ACG

-3TRAOG

SPIKE D614G reference

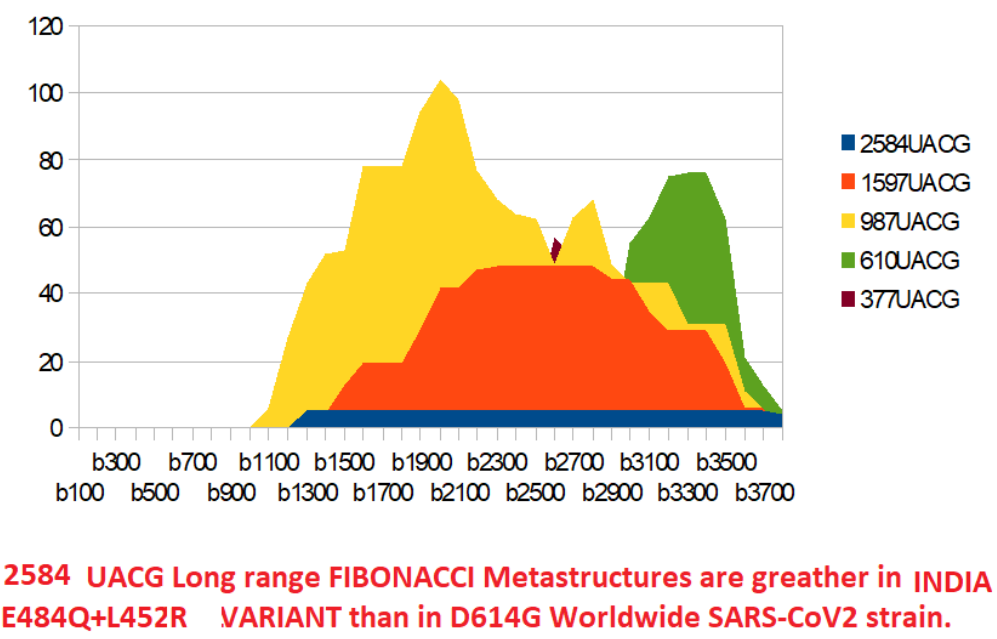

Figure 16: Analysing INDIAN variant Basic (only with 2 mutations E484Q and L452R

SINDIAFULL:

We run following process:

SINDIAFULL $=$ SPIKD614G

Dim SE484K 3822 bases

Dim S614CALREF 3822 bases

Locations of differences in nucleotides between SINDIAFULL and S614CALREF:

384561355

Values of mutations to do in SINDIAFULL:

TTG

SINDIAFULL [38 456 1355] = 'TTG'

Locations of differences in nucleotides between SE484K South Africa and S614CALREF:

239125114501501

Values of mutations to do in SINDIAFULL:

CTAT

SINDIAFULL [2391251 1450 1501] = 'CTAT' 
Manage difference E484K to E484Q:

SINDIAFULL [1355] = 'G'

Control:

cumulate SINDIAFULL different SPIKD614G

7

cumulate SINDIAFULL different INDIABASIC

6

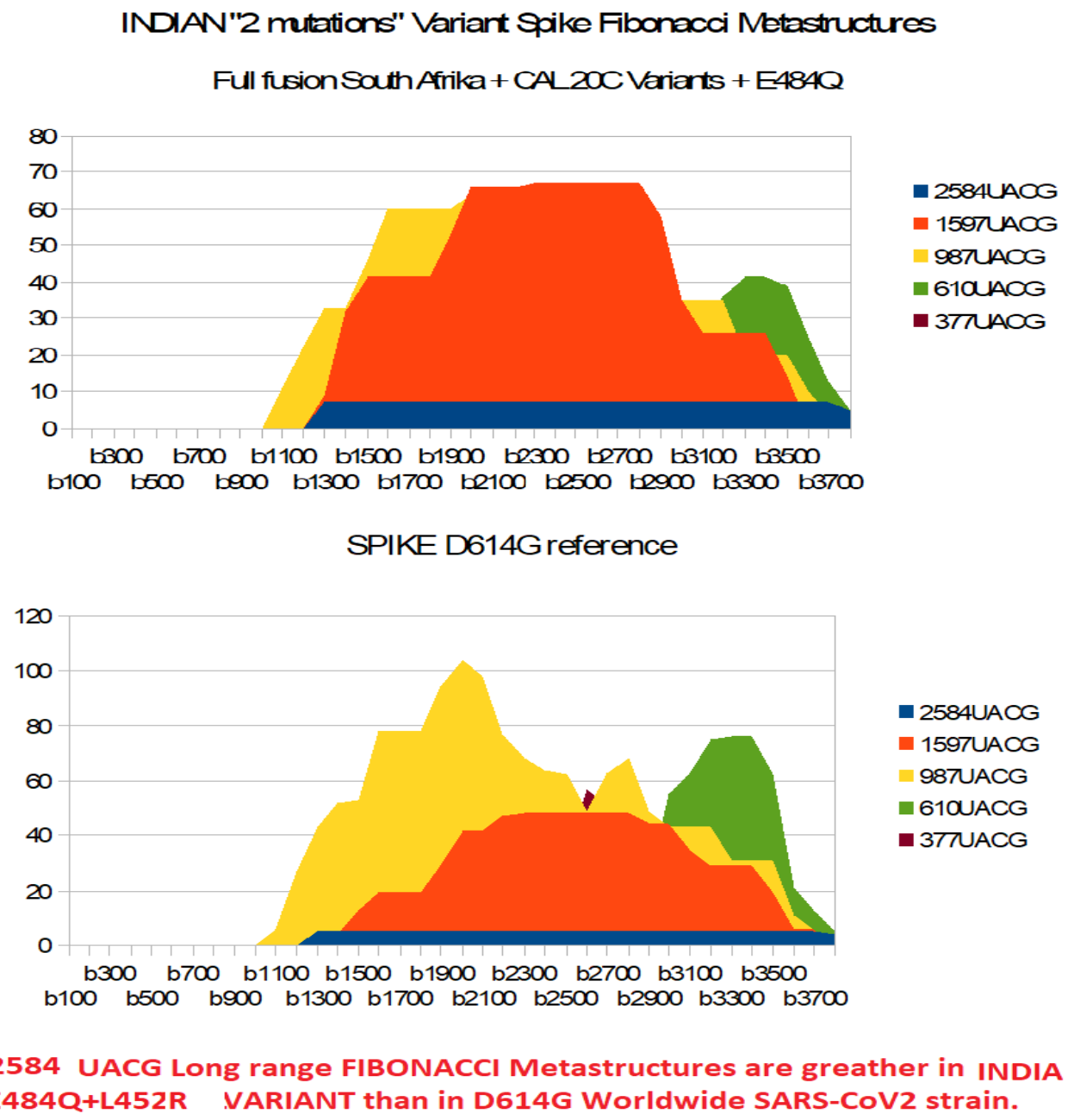

Figure 17: Analysing INDIAN variant Full (fusion CAL.20C and South Africa + difference with South Africa E484Q) Samples with the E484Q and L452R, then South Africa + California variants https://www.bbc.com/news/world-asia-india-56507988

https://pib.gov.in/PressReleaselframePage.aspx?PRID=1707177

\subsection{SUGGESTING A POSSIBLE VARIANTS SPIKE MRNA PALINDROME SYMMETRY METASTRUCTURE IMPROVING MRNA STABILITY THEN INFECTIOUSNESS}

Here, we have gathered several pieces of evidence showing that, as they evolve, the variants would constitute and reinforce a kind of Palindrome-type symmetry based on "Russian doll" interlocking of their mRNA, which could lead to a double strand of the "hairpin" type, thus reinforcing the stability and the lifespan of the Spike mRNA, thus certainly the increasing contagiousness of the variant virus. 


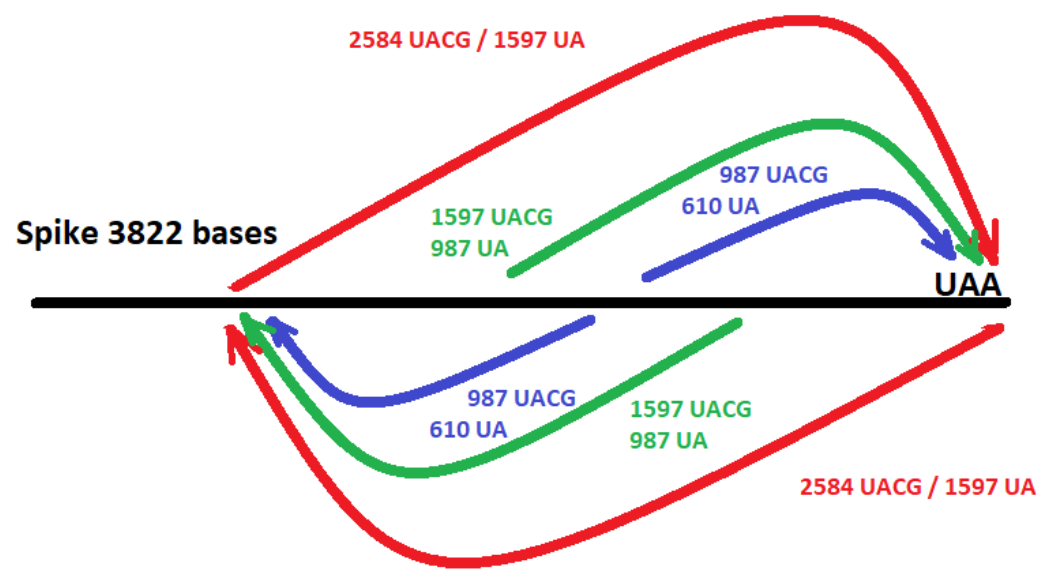

we rotate symmetrically 2584 UACG

\section{Fibonacci "GLOBAL PALINDROMES": mRNA Spike Checksum Symmetry}

Figure 18: « Fibonacci GLOBAL PALINDROMES » scenario test.

Clearly more pronounced "PODIUM-like" structures appear in these UK, South Africa, India, California (figures 14 to 17) variants than in the strain D614G Spike.

The structures in orange 1597UACG form a curious "PODIUM" ...

Is this the sign of a PALINDROME TYPE SYMMETRY BETWEEN 2 STRUCTURES

FIBONACCI 1597 UACG?

FIBONACCI PALINDROMES EFFECT?

It would seem that in these UK variants, (especially Figure 14, the 2 on the right, particularly right, bottom: Spike UK SN501S variant), a kind of

phenomenon FIBONACCI PALINDROMES (Symmetry) as presented and schematized

in handwritten graph (part in orange STRUCTURES 1597 UACG)

Addresses first and last STRUCTURES of 1597UACG:

First: $1111+1597=2708$ end of the first 1597 structure.

Last: $1973+1597=3570$ end of the last 1597 structure.

Then, we considere now area between 1973 and 2708.

The first structure: V1 = SN501S [1111 on 1597]

The last structure: V2 = SN501S [1973 on 1597]

Building the symmetrical palindrome of $\mathrm{V} 2$ : $\mathrm{V} 2$ = rotate $\mathrm{V} 2$

Now, we test « hypothetical global palindrome nature » matching on various dimensions:

Comparing matching between the 100 first bases of V1 and the 100 first bases of V2.

In fact, this is similar with comparing the 100 first bases of the first 1597 structure with the 100 last bases of the last 1507 structure...

100 bases test:

$\mathrm{V} 1[$ on 100$]=$ 'UA' ==> 66 bases

$\mathrm{V} 2[$ on 100] = 'UA' ==> 61 bases

Then, we continue:

200 bases test:

$\mathrm{V} 1[$ on 200$]=$ 'UA' ==> 129 bases

V2[on 200] = 'UA' ==> 129 bases

Then, we continue:

International Journal of Research -GRANTHAALAYAH 
300 bases test:

$\mathrm{V} 1[$ on 300] = 'UA' ==> 198 bases

$\mathrm{V} 2[$ on 300] = 'UA' ==> 192 bases

Then, we continue:

400 bases test:

$\mathrm{V} 1[$ on 400$]=$ ' $U A^{\prime}==>258$ bases

V2[on 400] = 'UA' ==> 249 bases

Then, we continue:

500 bases test:

$\mathrm{V} 1[$ on 500$]=$ ' $U A^{\prime}==>324$ bases

$\mathrm{V} 2[$ on 500$]=$ ' $U A^{\prime}==>308$ bases

Then, we continue:

.......

800 bases test:

$\mathrm{V} 1[$ on 800$]=$ ' $U A^{\prime}==>501$ bases

$\mathrm{V} 2$ [on 800] = 'UA' ==> 495 bases

Then, we continue:

1000 bases test:

$\mathrm{V} 1[$ on 1000$]=$ 'UA' ==> 613 bases

V2[on 1000] = 'UA' ==> 615 bases

Then, we continue:

1200 bases test:

$\mathrm{V} 1[$ on 1200$]=$ 'UA' ==> 743 bases

V2[on 1200] = 'UA' ==> 742 bases

Then, we continue:

.......

1400 bases test:

$\mathrm{V} 1[$ on 1400$]=$ 'UA' $==>877$ bases

$\mathrm{V} 2[$ on 1400] = 'UA' ==> 872 bases

Then, we continue:

1500 bases test:

$\mathrm{V} 1[$ on 1500] = 'UA' ==> 934 bases

V2[on 1500] = 'UA' ==> 936 bases

Then, we continue:

FULL 1597 bases test:

$\mathrm{V} 1[$ on 1597] = 'UA' ==> 987 bases

$\mathrm{V} 2$ [on 1597] = 'UA' ==> 987 bases

Then 987 UA and 610 CG

Globally, the palindrome like mRNA folding is good...

Palindrome symmetry test on the first eighty bases of the first 1597 UACG and the first eighty bases of the symmetrical of the last 1597 UACG. They are superimposed face to face like Palindrome.

It does appear $\mathrm{C}<==>\mathrm{G}$ relations on the hypothetical double strand of mRNA. 
Jean-Claude Perez

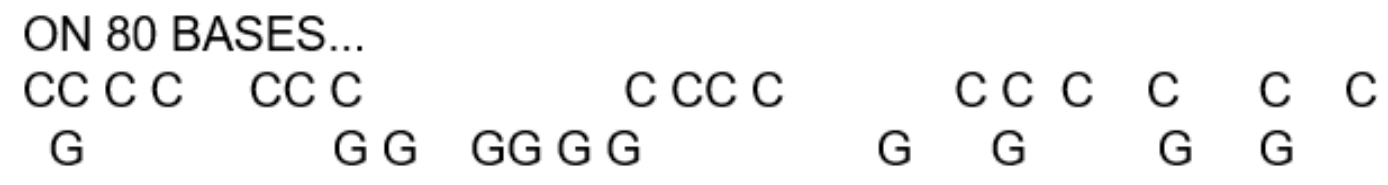

IDEM ON 100 BASES...

$\begin{array}{cccccccccc}\text { CC C C } & \text { CC C } & \text { C CC C } & & \text { C C C } & \text { C } & \text { C } & \text { C } & \text { C } & \\ \text { G } & \text { G } & \text { GG G } & G & G & G & G & G & G & G G G\end{array}$

Nota: «» is a U or A nucleotide (space).

Particularly, we suggest the following conjecture at mRNA folding level (Mengwen et al, 2006):

CONJECTURE of SARS-CoV2 VARIANTS:

The growth of long Fibonacci structures in the shape of "podiums" for almost all of the variants studied (UK, California, South Africa, India, etc.) suggests the probable folding of the Spike mRNA in the form of a "hairpin", which can strengthen the cohesion and the lifespan of this mRNA.

\subsection{ANALYSING FIBONACCI METASTRUCTURES IN THE MRNA CODING FOR THE VACCINES PFIZER AND MODERNA}

Stanford University team published and provide experimental sequence information for the RNA components of the initial Moderna (https://pubmed.ncbi.nlm.nih.gov/32756549/) and Pfizer/BioNTech (https://pubmed.ncbi.nlm.nih.gov/33301246/) COVID-19 vaccines (Dae Eun Jeong et al, 2021).

Then we analysed using the same method the hypothetic metastructure of this mRNA vaccine...

Here are the results:

Dim VACCINPFIZER $=4175$ bases.

Dim VACCINMODERNA $=4004$ bases. 
Figure 1 : Spike-encoding contig assembled from BioNTech/Pfizer BNT-162b2 vaccine. GAGAATAAACTAGTATTCTTCTGGTCCCCACAGACTCAGAGAGAACCCGCCACCATGTTCGTGTTCCTGGTGCTGCTGCCTCTGGTGT

CCA GCCAGTGTGTGAACCTGACCACCAGA_ACACAGCTGCCTCCAGCCTACACCAACAGCTTTACCAGAGGCGTGTACTACCCCGACAAGGTGTT CAGATCCAGCGTGCTGCACTCTACCCAGGACCTGTTCCTGCCTTTCTTCAGCAACGTGACCTGGTTCCACGCCATCCACGTGTCCGGCACC A.ATGGCACCAAGAGATTCGACAACCCCGTGCTGCCCTTCAACGACGGGGTGTACTTTGCCAGCACCGAGAAGTCCA.ACATCATCAGAGGCT GGATCTTCGGCACCACACTGGACAGCAAGACCCAGAGCCTGCTGATCGTGAACAACGCCACCAACGTGGTCATCAAAGTGTGCGAGTTCCA GTTCTGCAACGACCCCTTCCTGGGCGTCTACTACCACAAGAACAACAAGAGCTGGATGGAAAGCGAGTTCCGGGTGTACAGCAGCGCCAAC A.ACTGCACCTTCGAGTACGTGTCCCAGCCTTTCCTGATGGACCTGGAAGGCAAGCAGGGCAACTTCAAGAAACCTGCGCGAGTTCGTGTTTA AGAACATCGACGGCTACTTCAAGATCTACAGCAAGCACACCCCTATCAACCTCGTGCGGGATCTGCCTCAGGGCTTCTCTGCTCTGGAACC CCTGGTGGATCTGCCCATCGGCATCAACATCACCCGGTTTCAGACACTGCTGGCCCTGCACAGAAGCTACCTGACACCTGGCGATAGCAGC AGCGGATGGACAGCTGGTGCCGCCGCTTACTATGTGGGCTACCTGCAGCCTAGAACCTTCCTGCTGAAGTACAACGAGAACGGCACCATCA CCGACGCCGTGGATTGTGCTCTGGATCCTCTGAGCGAGACAAAGTGCACCCTGAAGTCCTTCACCGTGGAAAAAGGGCATCTACCAGACCAG CAACTTCCGGGTGCAGCCCACCGAATCCATCGTGCGGTTCCCCAATATCACCAATCTGTGCCCCTTCGGCGAGGTGTTCA.ATGCCACCAGA TTCGCCTCTGTGTACGCCTGGAACCGGAAGCGGATCAGCAATTGCGTGGCCGACTACTCCGTGCTGTACAACTCCGCCAGCTTCAGCACCT TCAAGTGCTACGGCGTGTCCCCTACCAAGCTGAACGACCTGTGCTTCACAAACGTGTACGCCGACAGCTTCGTGATCCGGGGAGATGAAGT GCGGCAGATTGCCCCTGGACAGACAGGCA.AGATCGCCGACTACAACTACAAGCTGCCCGACGACTTCACCGGCTGTGTGATTGCCTGGAAC AGCAACAACCTGGACTCCAAAGTCGGCGGCAACTACAATTACCTGTACCGGCTGTTCCGGAAGTCCAATCTGA_AGCCCTTCGAGCGGGACA TCTCCACCGAGATCTATCAGGCCGGCAGCACCCCTTGTAACGGCGTGGAAGGCTTCAACTGCTACTTCCCACTGCAGTCCTACGGCTTTCA GCCCACAAATGGCGTGGGCTATCAGCCCTACAGAGTGGTGGTGCTGAGCTTCGAACTGCTGCATGCCCCTGCCACAGTGTGCGGCCCTAAG A.AAAGCACCAATCTCGTGAAGAACAAATGCGTGAACTTCAACTTCAACGGCCTGACCGGCACCGGCGTGCTGACAGAGAGCAACA.AGAAGT TCCTGCCATTCCAGCAGTTTGGCCGGGATATCGCCGATACCACAGACGCCGTTAGAGATCCCCAGACACTGGAAATCCTGGACATCACCCC TTGCAGCTTCGGCGGAGTGTCTGTGATCACCCCTGGCACCAACACCAGCAATCAGGTGGCAGTGCTGTACCAGGACGTGAACTGTACCGAA GTGCCCGTGGCCATTCACGCCGATCAGCTGACACCTACATGGCGGGTGTACTCCACCGGCAGCAATGTGTTTCAGACCAGAGCCGGCTGTC TGATCGGAGCCGAGCACGTGAACAATAGCTACGAGTGCGACATCCCCATCGGCGCTGGAATCTGCGCCAGCTACCAGACACAGACAAACAG CCCTCGGAGAGCCAGAAGCGTGGCCAGCCAGAGCATCATTGCCTACACAAATGTCTCTGGGCGCCGAGAACAGCGTGGCCTACTCCAACAAC TCTATCGCTATCCCCACCAACTTCACCATCAGCGTGACCACAGAGATCCTGCCTGTGTCCATGACCAAGACCAGCGTGGACTGCACCATGT ACATCTGCGGCGATTCCACCGAGTGCTCCAACCTGCTGCTGCAGTACGGCAGCTTCTGCACCCAGCTGAATAGAGCCCTGACAGGGATCGC CGTGGAACAGGACA.AGAACACCCA.AGAGGTGTTCGCCCAAGTGAAGCAGATCTACAAAGACCCCTCCTATCAAGGACTTCGGCGGCTTCAAT TTCAGCCAGATTCTGCCCGATCCTAGCAAGCCCAGCAAGCGGAGCTTCATCGAGGACCTGCTGTTCAACAAAGTGACACTGGCCGACGCCG GCTTCATCAAGCAGTATGGCGATTGTCTGGGCGACATTGCCGCCAGGGATCTGATTTGCGCCCAGAAGTTTAACGGACTGACAGTGCTGCC TCCTCTGCTGACCGATGAGATGATCGCCCAGTACACATCTGCCCTGCTGGCCGGCACAATCACAAGCGGCTGGACATTTGGAGCAGGCGCC GCTCTGCAGATCCCCTTTGCTATGCAGATGGCCTACCGGTTCAACGGCATCGGAGTGACCCAGAATGTGCTGTACGAGAACCAGAAGCTGA TCGCCAACCAGTTCAACAGCGCCATCGGCAAGATCCAGGACAGCCTGAGCAGCACAGCAAACGCCCTGGGAAAGCTGCAGGACGTGGTCAA CCAGAATGCCCAGGCACTGAACACCCTGGTCAAGCAGCTGTCCTCCAACTTCGGCGCCATCAGCTCTGTGCTGAACGATATCCTGAGCAGA CTGGACCCTCCTGAGGCCGAGGTGCAGATCGACAGACTGATCACAGGCAGACTGCAGAGCCTCCAGACATACGTGACCCAGCAGCTGATCA GAGCCGCCGAGATTAGAGCCTCTGCCAATCTGGCCGCCACCAAGATGTCTGAGTGTGTGCTGGGCCAGAGCAAGAGAGTGGACTTTTGCGG CAAGGGCTACCACCTGATGAGCTTCCCTCAGTCTGCCCCTCACGGCGTGGTGTTTCTGCACGTGACATATGTGCCCGCTCA.AGAGAAGAAT TTCACCACCGCTCCAGCCATCTGCCACGACGGCAAAGCCCACTTTCCTAGAGAAGGCGTGTTCGTGTCCAACGGCACCCATTGGTTCGTGA CACAGCGGAACTTCTACGAGCCCCAGATCATCACCACCGACAACACCTTCGTGTCTGGCAACTGCGACGTCGTGATCGGCATTGTGAACAA TACCGTGTACGACCCTCTGCAGCCCGAGCTGGACAGCTTCAAAAGAGGAACTGGACAAGTACTTTAAGAACCACACAAGCCCCGACGTGGAC CTGGGCGATATCAGCGGAATCAATGCCAGCGTCGTGAACATCCAGAAAGAGATCGACCGGCTGAACGAGGTGGCCAAAGAATCTGAACGAGA GCCTGATCGACCTGCAAGAACTGGGGAAGTACGAGCAGTACATCAAGTGGCCCTGGTACATCTGGCTGGGCTTTATCGCCGGACTGATTGC CATCGTGATGGTCACAATCATGCTGTGTTGCATGACCAGCTGCTGTAGCTGCCTGAAGGGCTGTTGTAGCTGTGGCAGCTGCTGCAAGTTC

GACGAGGACGATTCTGAGCCCGTGCTGAAGGGCGTGAAACTGCACTACACATGATGACTCGAGCTGGTACTGCATGCACGCA.ATGCTAGCT GCCCCTTTCCCGTCCTGGGTACCCCGAGTCTCCCCCGACCTCGGGTCCCAGGTATGCTCCCACCTCCACCTGCCCCACTCACCACCTCTGC TAGTTCCAGACACCTCCCAAGCACGCAGCAATGCAGCTCAAAAACGCTTAGCCTAGCCACACCCCCACGGGAAACAGCAGTGATTAACCTTT AGCAATAAACGAAAGTTTAACTAAGCTATACTAACCCCAGGGTTGGTCA.ATTTCGTGCCAGCCACACCCTGGAGCTAGCA

Cyan : Putative 5' UTR Green : Start Codon Yellow : Signal Peptide Orange : Spike encoding region Red : Stop codon(s) Purple : 3' UTR Blue : Start of polyA region (incomplete)

Figure 19: Spike-encoding contig assembled from BioNTech/Pfizer BNT-162b2 vaccine. 
Jean-Claude Perez

Figure 2 : Spike-encoding contig asgembled from Moderna mRNA-1273 vaccine.

GGGAAATA.AGAGAGAAAAGAAGAGTAAGAAGAAATATAAGACCCCGGCGCCGCCACCATGTTCGTGTTCCTGGTGCTGCTGCCCCTGG

TGAGCAGCCAGTGCGTGAACCTGACCACCCGGACCCAGCTGCCACCAGCCTACACCAACAGCTTCACCCGGGGCGTCTACTACCCCGACAAGG T GTTCCGGAGCAGCGTCCTGCACAGCACCCAGGACCTGTTCCTGCCCTTCTTCAGCAACGTGACCTGGTTCCACGCCATCCACGTGAGCGGC ACCAACGGCACCAAGCGGTTCGACAACCCCGTGCTGCCCTTCAACGACGGCGTGTACTTCGCCAGCACCGAGAAGAGCAACATCATCCGGG GCTGGATCTTCGGCACCACCCTGGACAGCAAGACCCAGAGCCTGCTGATCGTGAATAACGCCACCAACGTGGTGATCAAGGTGTGCGAGTT CCAGTTCTGCAACGACCCCTTCCTGGGCGTGTACTACCACAAGAACAACAAGAGCTGGATGGAGAGCGAGTTCCGGGTGTACAGCAGCGCC A.ACAACTGCACCTTCGAGTACGTGAGCCAGCCCTTCCTGATGGACCTGGAGGGCAAGCAGGGCAACTTCAAGAACCTGCGGGAGTTCGTGT TCAAGAACATCGACGGCTACTTCAAGATCTACAGCAAGCACACCCCAATCAACCTGGTGCGGGATCTGCCCCAGGGCTTCTCAGCCCTGGA GCCCCTGGTGGACCTGCCCATCGGCATCAACATCACCCGGTTCCAGACCCTGCTGGCCCTGCACCGGAGCTACCTGACCCCAGGCGACAGC AGCAGCGGGTGGACAGCAGGCGCGGCTGCTTACTACGTGGGCTACCTGCAGCCCCGGACCTTCCTGCTGAAGTACA.ACGAGAACGGCACCA TCACCGACGCCGTGGACTGCGCCCTGGACCCTCTGAGCGAGACCAAGTGCACCCTGAAGAGCTTCACCGTGGAGAAGGGCATCTACCAGAC CAGCAACTTCCGGGTGCAGCCCACCGAGAGCATCGTGCGGTTCCCCAACATCACCAACCTGTGCCCCTTCGGCGAGGTGTTCAACGCCACC CGGTTCGCCAGCGTGTACGCCTGGAACCGGAAGCGGATCAGCAACTGCGTGGCCGACTACAGCGTGCTGTACAACAGCGCCAGCTTCAGCA CCTTCAAGTGCTACGGCGTGAGCCCCACCAAGCTGAACGACCTGTGCTTCACCAACGTGTACGCCGACAGCTTCGTGATCCGTGGCGACGA GGTGCGGCAGATCGCACCCGGCCAGACAGGCAAGATCGCCGACTACAACTACAAGCTGCCCGACGACTTCACCGGCTGCGTGATCGCCTGG A.ACAGCA.ACA.ACCTCGACAGCAAGGTGGGCGGCAACTACAACTACCTGTACCGGCTGTTCCGGAAGAGCAACCTGAAGCCCTTCGAGCGGG ACATCAGCACCGAGATCTACCAAGCCGGCTCCACCCCTTGCAACGGCGTGGAGGGCTTCAACTGCTACTTCCCTCTGCAGAGCTACGGCTT CCAGCCCACCAACGGCGTGGGCTACCAGCCCTACCGGGTGGTGGTGCTGAGCTTCGAGCTGCTGCACGCCCCAGCCACCGTGTGTGGCCCC A.AGAAGAGCACCAACCTGGTGAAGAACAAGTGCGTGAACTTCAACTTCAACGGCCTTACCGGCACCGGCGTGCTGACCGAGAGCAACAAGA AATTCCTGCCCTTTCAGCAGTTCGGCCGGGACATCGCCGACACCACCGACGCTGTGCGGGATCCCCAGACCCTGGAGATCCTGGACATCAC CCCTTGCAGCTTCGGCGGCGTGAGCGTGATCACCCCAGGCACCAACACCAGCAACCAGGTGGCCGTGCTGTACCAGGACGTGAACTGCACC GAGGTGCCCGTGGCCATCCACGCCGACCAGCTGACACCCACCTGGCGGGTCTACAGCACCGGCAGCAACGTGTTCCAGACCCGGGCCGGTT GCCTGATCGGCGCCGAGCACGTGAACAACAGCTACGAGTGCGACATCCCCATCGGCGCCGGCATCTGTGCCAGCTACCAGACCCAGACCAA TTCACCCCGGAGGGCAAGGAGCGTGGCCAGCCAGAGCATCATCGCCTACACCATGAGCCTGGGCGCCGAGAACAGCGTGGCCTACAGCAAC AACAGCATCGCCATCCCCACCAACTTCACCATCAGCGTGACCACCGAGATTCTGCCCGTGAGCATGACCAAGACCAGCGTGGACTGCACCA TGTACATCTGCGGCGACAGCACCGAGTGCAGCAACCTGCTGCTGCAGTACGGCAGCTTCTGCACCCAGCTGAACCGGGCCCTGACCGGCAT CGCCGTGGAGCAGGACAAGAACACCCAGGAGGTGTTCGCCCAGGTGAAGCAGATCTACAAGACCCCTCCCATCAAGGACTTCGGCGGCTTC AACTTCAGCCAGATCCTGCCCGACCCCAGCAAGCCCAGCAAGCGGAGCTTCATCGAGGACCTGCTGTTCAACAAGGTGACCCTAGCCGACG CCGGCTTCATCAAGCAGTACGGCGACTGCCTCGGCGACATAGCCGCCCGGGACCTGATCTGCGCCCAGAAGTTCAACGGCCTGACCGTGCT GCCTCCCCTGCTGACCGACGAGATGATCGCCCAGTACACCAGCGCCCTGTTAGCCGGAACCATCACCAGCGGCTGGACTTTCGGCGCTGGA GCCGCTCTGCAGATCCCCTTCGCCATGCAGATGGCCTACCGGTTCAACGGCATCGGCGTGACCCAGAACGTGCTGTACGAGAACCAGAAGC TGATCGCCAACCAGTTCAACAGCGCCATCGGCAAGATCCAGGACAGCCTGAGCAGCACCGCTAGCGCCCTGGGCAAGCTGCAGGACGTGGT GAACCAGAACGCCCAGGCCCTGAACACCCTGGTGAAGCAGCTGAGCAGCAACTTCGGCGCCATCAGCAGCGTGCTGAACGACATCCTGAGC CGGCTGGACCCTCCCGAGGCCGAGGTGCAGATCGACCGGCTGATCACTGGCCGGCTGCAGAGCCTGCAGACCTACGTGACCCAGCAGCTGA TCCGGGCCGCCGAGATTCGGGCCAGCGCCAACCTGGCCGCCACCAAGATGAGCGAGTGCGTGCTGGGCCAGAGCAAGCGGGTGGACTTCTG CGGCAAGGGCTACCACCTGATGAGCTTTCCCCAGAGCGCACCCCACGGAGTGGTGTTCCTGCACGTGACCTACGTGCCCGCCCAGGAGAAG AACTTCACCACCGCCCCAGCCATCTGCCACGACGGCAAGGCCCACTTTCCCCGGGAGGGCGTGTTCGTGAGCAACGGCACCCACTGGTTCG TGACCCAGCGGAACTTCTACGAGCCCCAGATCATCACCACCGACAACACCTTCGTGAGCGGCAACTGCGACGTGGTGATCGGCATCGTGAA CAACACCGTGTACGATCCCCTGCAGCCCGAGCTGGACAGCTTCA.AGGAGGAGCTGGACAAGTACTTCAAGAATCACACCAGCCCCGACGTG GACCTGGGCGACATCAGCGGCATCAACGCCAGCGTGGTGAACATCCAGAAGGAGATCGATCGGCTGAACGAGGTGGCCAAGAACCTGAACG AGAGCCTGATCGACCTGCAGGAGCTGGGCAAGTACGAGCAGTACATCAAGTGGCCCTGGTACATCTGGCTGGGCTTCATCGCCGGCCTGAT CGCCATCGTGATGGTGACCATCATGCTGTGCTGCATGACCAGCTGCTGCAGCTGCCTGAAGGGCTGTTGCAGCTGCGGCAGCTGCTGCAAG TTCGACGAGGACGACAGCGAGCCCGTGCTGAAGGGCGTGAAGCTGCACTACACCTGATAATAGGCTGGAGCCTCGGTGGCCTAGCTTCTTG CCCCTTGGGCCTCCCCCCAGCCCCTCCTCCCCTTCCTGCACCCGTACCCCCGTGGTCTTTGAATAAAGTCTGAGTGGGCGGCAAAAAAAAAA

Cyan : Putative 5' UTR Green : Start Codon Yellow : Signal Peptide Orange : Spike encoding region Red : Stop codon(s) Purple : 3' UTR Blue : Start of polyA region (incomplete)

Figure 20: Spike-encoding contig assembled from Moderna mRNA-1273 vaccine.

It is interesting to note that the starting region of the Spike was modified in both vaccines. We show $\mathrm{i}$ (Perez§Montagnier 2020) that this crucial region contains « EIE » HIV like inserts, particularly HIV1 Kenya.

Recall the 100 first bases of SARS-CoV2 Spike:

ATGTTTGTTTTTCTTGTTTTATTGCCACTAGTCTCTAGTCAGTGTGTTAATCTTACAACCAGAACTCAATTACCCCCTG CATACACTAATTCTTTCACAC

It is interesting comparing this region with the same areas in both vaccines (bold).

What should we conclude about this total absence of Fibonacci metastructures in the mRNAs of these 2 vaccines?

This implies that, although functional, these mRNAs will have a short lifespan and their overall physical structure will be very weak. These mRNAs will be able to split rather quickly into separate fragments which will risk combining with other mRNAs present in their environment.

International Journal of Research -GRANTHAALAYAH 


\section{Fibonacci metastructures in full vector PFIZER vaccine \\ Pfizer BNT-162b2 vaccine \\ ZERO ("O") metastructures}

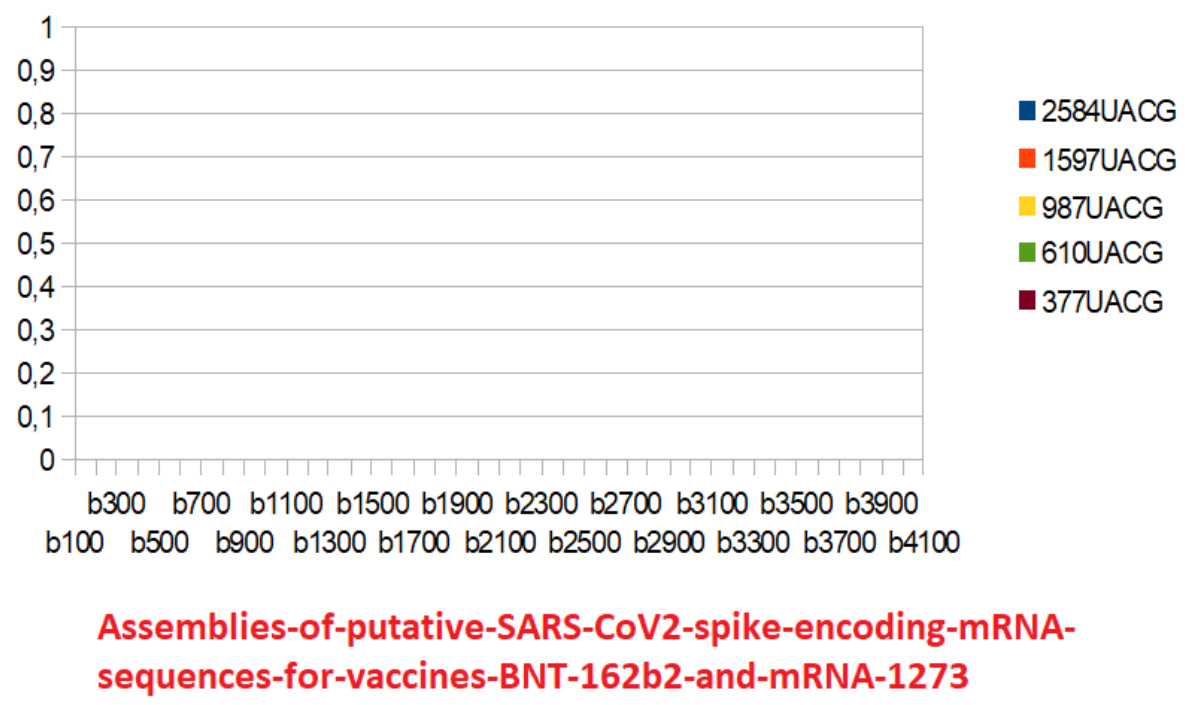

Figure 21: Flat response for Fibonacci Metastructures from BioNTech/Pfizer BNT-162b2 vaccine.

Fibonacci metastructures in full vector Moderna vaccine Moderna mRNA-1273 vaccine ZERO ("O") metastructures

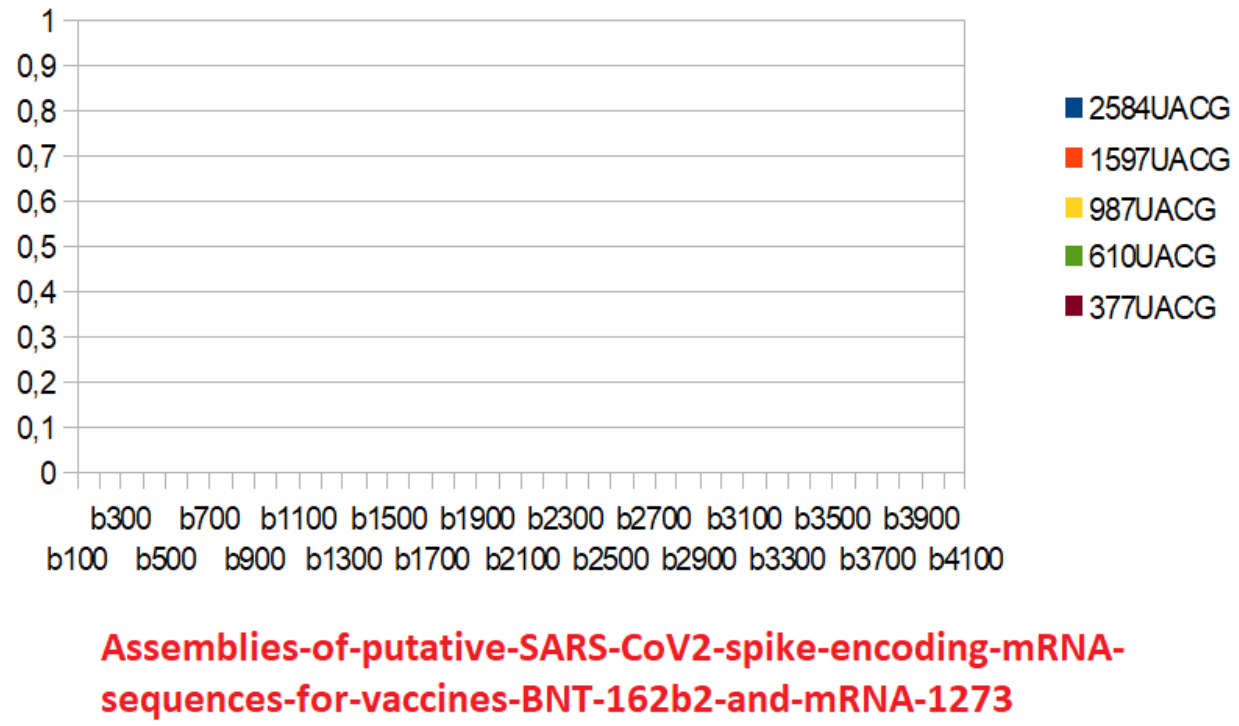

Figure 22: Flat response for Fibonacci Metastructures from Moderna mRNA-1273 vaccine.

We will now explain the technological reasons which, in the design of these two vaccines, led to such differences between the Fibonacci structures of real SARS-CoV2, their variants and these two mRNA vaccines. 
A necessary but not sufficient condition for the possible emergence of Fibonacci UA / CG metastructures is that the ratio between the total number of UA and CG bases of the analyzed sequence is> 1 and, ideally, close to the optimum Phi $=1.618$, the "Golden ratio".

Let us calculate these ratios for certain SARS-CoV2 genomes and spikes various variants, then for the two mRNAs of the Moderna and Pfizer vaccines.

Table 8 below demonstrates how the entire genomes as well as the spikes and the different variants all have an $\mathrm{AU} / \mathrm{CG}$ ratio very close to 1.618 . The maximum error is less than $4 \%$. On the contrary, the two of the Pfizer and Moderna mRNA vaccines have radically INVERTED ratios such as CG> UA.

Table 8: Comparing various UA/CG ratios from 20 SARS-CoV2, variants, and mRNA vaccines.

\begin{tabular}{|c|c|c|}
\hline MRNA sequence & Ratio UA/CG & Error 1.618 - ratio UA/CG \\
\hline \multicolumn{3}{|l|}{ Whole Genomes } \\
\hline SARS-CoV2 ref & 1.633465434 & -0.01543144473 \\
\hline SARSCOV2 D614G & 1.633233533 & -0.01519954393 \\
\hline Bat RATG13 & 1.629006692 & -0.0109727035 \\
\hline CoVZC45 & 1.570467483 & 0.04756650582 \\
\hline CoVZXC21 & 1.575760201 & 0.04227378801 \\
\hline VCA19 (patient California variant ref Table4) & 1.633710647 & -0.01567665833 \\
\hline \multicolumn{3}{|c|}{ Spikes } \\
\hline Spike SARS-CoV2 ref & 1.680224404 & -0.06219041493 \\
\hline D614G & 1.678346181 & -0.0603121918 \\
\hline Bat RaTG13 & 1.661774983 & -0.04374099353 \\
\hline CoVZC45 & 1.600834492 & 0.01719949665 \\
\hline CoVZXC21 & 1.627988748 & -0.009954759242 \\
\hline SCA19 (patient California variant ref Table4) & 1.682105263 & -0.06407127416 \\
\hline Variant UK SN501Y & 1.678346181 & -0.0603121918 \\
\hline Variant UK SN501T & 1.676470588 & -0.05843659924 \\
\hline Variant UK SN501S & 1.676470588 & -0.05843659924 \\
\hline Variant South Africa SE484K & 1.680224404 & -0.06219041493 \\
\hline Variant INDIABASIC (ref §3.6) & 1.676470588 & -0.05843659924 \\
\hline Variant INDIAFULL (ref §3.6) & 1.682105263 & -0.06407127416 \\
\hline \multicolumn{3}{|l|}{ mRNA vaccines } \\
\hline Pfizer & 0.7593763169 & 0.8586576721 \\
\hline Moderna & 0.6132151491 & 1.00481884 \\
\hline
\end{tabular}

Faced with such a distortion between the real and "humanized" SARS-CoV2 strains and its variants on the one hand, and the mRNAs of the two vaccines on the other hand, we will now try to answer two essential questions:

1) Is there a mutation "strategy" governing the adaptation of the virus and its variants to its host? This strategy, if it exists, will ALSO constitute a strong mutation constraint for the two mRNAs of the Moderna and Pfizer vaccines? Table 10 below will answer this key question. 
2) For what technological reasons did the designers of the two mRNA vaccines decide to "dope" the sequences constituting their vaccines in CG bases?

Does this predominance of AU / CG ratios located around Phi $=1.618$ extend to other SARS-CoV2 genes?

In Table 9, we demonstrate this generalization. Only two sequences, very short, have a UA / CG ratio $<1$. We find that the entire genome, the large ORF1ab gene, the spike gene, as well as the average of all genes closely obey this law. The average cumulative error over all genes is .03. (1.85\%)

Particularly, the gene ORF1ab17 with a ratio $<1$ is a very short quasi palindrome mRNA sequence:

Coronavirus frameshifting stimulation element stem-loop 1"

Semi palindrome

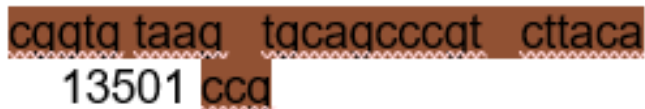

The second region with $\mathrm{UA} / \mathrm{CG}<1$

The second region with UA/CG $<1$

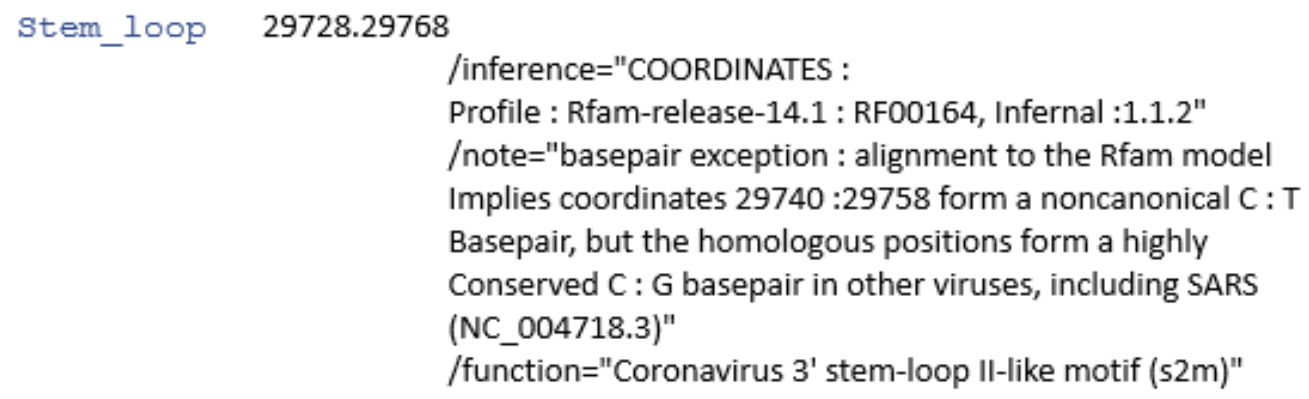

\section{VSARSCOV2REF [29727+1/4 (29768-29727)]}

\section{TTCACCGAGGCCACGCGGAGTACGATCGAGTGTACAGTGAA}

This sequence is also very short.

Recall SARS-CoV2 Wuhan references

https://www.ncbi.nlm.nih.gov/nuccore/NC_045512

Table 9: Computing UA/CG ratio for all SARS-CoV2 Wuhan reference genes.

\begin{tabular}{|c|c|c|}
\hline MRNA sequence & Ratio UA/CG & Error 1.618 - ratio UA/CG \\
\hline Whole Genomes & 1.633465434 & $\mathbf{- 0 . 0 1 5 4 3 1 4 4 4 7 3}$ \\
\hline SARS-CoV2 ref & 1.245762712 & $\mathbf{0 . 3 7 2 2 7 1 2 7 7 1}$ \\
\hline Genes & 1.669927264 & $\mathbf{- 0 . 0 5 1 8 9 3 2 7 4 6 1}$ \\
\hline 5 UTR & 1.061068702 & $\mathbf{0 . 5 5 6 9 6 5 2 8 6 7}$ \\
\hline ORF 1AB & 1.508519004 & $\mathbf{0 . 1 0 9 5 1 4 9 8 5 1}$ \\
\hline ORF1 ab1 & 1.785202864 & $\mathbf{- 0 . 1 6 7 1 6 8 8 7 5}$ \\
\hline ORF1 ab2 & 1.742230347 & $\mathbf{0 . 1 2 4 1 9 6 3 5 8 3}$ \\
\hline ORF1 ab3 & 1.742230347 & $\mathbf{0 . 1 2 4 1 9 6 3 5 8 3}$ \\
\hline ORF1 ab4 & &
\end{tabular}


Jean-Claude Perez

\begin{tabular}{|c|c|c|}
\hline ORF1 ab6 & 1.740112994 & -0.1220790054 \\
\hline ORF1 ab7 & 1.621052632 & -0.003018642579 \\
\hline ORF1 ab8 & 1.605263158 & 0.01277083111 \\
\hline ORF1 ab9 & 1.492647059 & 0.1253869302 \\
\hline ORF1 ab10 & 1.355932203 & 0.2621017856 \\
\hline ORF1 ab11 & 1.682341651 & -0.06430766167 \\
\hline ORF1 ab12 & 1.620639535 & -0.002605545884 \\
\hline ORF1 ab13 & 1.61322314 & 0.004810848504 \\
\hline ORF1 ab14 & 1.940509915 & -0.322475926 \\
\hline ORF1 ab15 & 1.820189274 & -0.2021552854 \\
\hline ORF1 ab16 & 1.650491277 & -0.03245728832 \\
\hline ORF1 ab17 § & 0.6470588235 & 0.9709751655 \\
\hline ORF1 ab18 & +1.750000000 & -0.131966011 \\
\hline SPIKE & 1.680224404 & -0.06219041493 \\
\hline ORF3a & 1.532110092 & 0.08592389726 \\
\hline Gene E (ref Yan Li Meng) & 1.620689655 & -0.002655666172 \\
\hline Gene M & 1.347368421 & 0.2706655679 \\
\hline ORF6 & 1.347368421 & 0.2706655679 \\
\hline ORF7a & 1.614285714 & 0.003748274714 \\
\hline ORF7b & 2.219512195 & -0.6014782061 \\
\hline ORF8 & 1.79389313 & -0.1758591408 \\
\hline Gene N & 1.117647059 & 0.5003869302 \\
\hline ORF10a & +1.925000000 & -0.306966011 \\
\hline ORF10b & 1.769230769 & -0.1511967802 \\
\hline ORF10c & 2.222222222 & -0.6041882332 \\
\hline 3UTR & 1.726190476 & -0.1081564872 \\
\hline Coordinates & 0.7826086957 & 0.8354252933 \\
\hline AVERAGE & 1.588022181 & $0.03001180791(1.85 \%)$ \\
\hline \multicolumn{3}{|l|}{ MRNA vaccines } \\
\hline Pfizer & 0.7593763169 & 0.8586576721 \\
\hline Moderna & 0.6132151491 & 1.00481884 \\
\hline
\end{tabular}

Table 10: Comparing UA ==> CG and CG ==> UA mutations in fifteen worldwide SARS-CoV2 variants (source https://covariants.org/).

\begin{tabular}{|l|l|l|}
\hline Variant reference & UA ==> CG & CG ==> UA \\
\hline $\begin{array}{l}\text { 20E(EU1) } \\
\text { https://covariants.org/variants/20A.EU1 }\end{array}$ & 1 & 1 \\
\hline 20A.EU2 & 1 & 3 \\
\hline
\end{tabular}




\begin{tabular}{|c|c|c|}
\hline $\begin{array}{l}\text { 20I/501Y.V1 } \\
\text { https://covariants.org/variants/S.501Y.V1 }\end{array}$ & 1 & 6 \\
\hline $\begin{array}{l}\text { 20H/501Y.V2 } \\
\text { https://covariants.org/variants/S.501Y.V2 }\end{array}$ & 0 & 4 \\
\hline $\begin{array}{l}\text { 20J/501Y.V3 } \\
\text { https://covariants.org/variants/S.501Y.V3 }\end{array}$ & 3 & 5 \\
\hline $\begin{array}{l}\text { 20C/S:452R } \\
\text { https://covariants.org/variants/S.L452R }\end{array}$ & 2 & 2 \\
\hline $\begin{array}{l}\text { 20C/S:484K } \\
\text { https://covariants.org/variants/20C.S.484K }\end{array}$ & 1 & 2 \\
\hline $\begin{array}{l}\text { 20A/S :484K } \\
\text { https://covariants.org/variants/20A.S.484K }\end{array}$ & 4 & 8 \\
\hline $\begin{array}{l}\text { 20A/S:439K } \\
\text { https://covariants.org/variants/20A.S.484K }\end{array}$ & 0 & 1 \\
\hline $\begin{array}{l}\text { S:677H.Robin1 } \\
\text { https://covariants.org/variants/S.Q677H.Robin1 }\end{array}$ & 1 & 4 \\
\hline $\begin{array}{l}\text { S:677P.Pelican } \\
\text { https://covariants.org/variants/S.Q677P.Pelican }\end{array}$ & 1 & 3 \\
\hline $\begin{array}{l}\text { 20A/S:98F } \\
\text { https://covariants.org/variants/S.S98F }\end{array}$ & 0 & 1 \\
\hline $\begin{array}{l}\text { 20C/S:80Y } \\
\text { https://covariants.org/variants/S.D80Y }\end{array}$ & 0 & 8 \\
\hline $\begin{array}{l}\text { 20B/S:626S } \\
\text { https://covariants.org/variants/S.A626S }\end{array}$ & 0 & 0 \\
\hline $\begin{array}{l}\text { 20B/S:1122L } \\
\text { https://covariants.org/variants/S.V1122L }\end{array}$ & 0 & 0 \\
\hline Total & 15 & 48 \\
\hline
\end{tabular}

Let out of the fifteen variants referenced $>$ three times more $C G==>$ UA than $U A==>C G$.

A very marginal residual number consists of U / A or C / G.

Morality: variants, by synonymous mutations most often seek to optimize (ie. "NATURALIZE")

the mRNA of the genome by privileging the UA, and probably the ratio UA / CG close to phi 1.618, this is what the Fibonacci analyzes shows on the variants by means of our curves.

As for the MODERNA and PFIZER mRNAs, they are MAJORITY in CG, therefore Fibonacci UA / CG NULS.

Now, what about the second question:

«For what technological reasons did the designers of the two mRNA vaccines decide to "dope" the sequences constituting their vaccines in CG bases? »

In (Jackson et al, 2020), we could read: «Last, codon optimization and modification of nucleotides have contributed to translation efficiency. For example, optimization of guanine and cytosine (GC) content can have a significant impact (Kudla et al, 2016) and has been well established with DNA vaccines ». 
(Kudla et al, 2016) detailed this « CG rich manufacturing technology »: « Mammalian genes are highly heterogeneous with respect to their nucleotide composition, but the functional consequences of this heterogeneity are not clear. In the previous studies, weak positive or negative correlations have been found between the silent-site guanine and cytosine (GC) content and expression of mammalian genes. However, previous studies disregarded differences in the genomic context of genes, which could potentially obscure any correlation between GC content and expression. In the present work, we directly ... »

This leads to a new question:

"Can we distinguish between natural variants and variants triggered by vaccines?"

This D80Y spike variant would be a good candidate for this variant for this vaccine question because it has a high number of syn $\mathrm{C}==>\mathrm{U}$ mutations.

We recall here this detailed variant:

Dedicated 20C/S:80Y Nextstrain build

Defining mutations

Nonsynonymous:

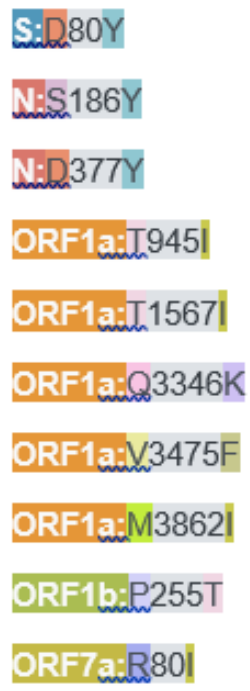

Synonymous :

G4960T

C6070T

C7303T

C7564T

C10279T

C10525T

C10582T

- C27804T

Of full list of eighteen nucleotide mutations, fifteen are mutations to T (possibly related to APOBEC-like editing within host, see (Simmonds, 2020).

This variant is found in at least 10 countries across Europe.

\section{S: D80Y}




\section{S:D80Y is the opposite end of the loop 'tucked in' by the 69/70 deletion (hypothetical

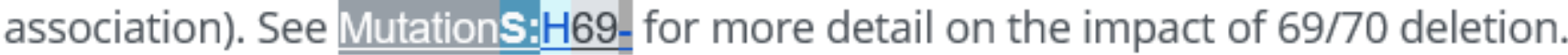

This strain is present everywhere in Europe.

Quite rightly, Professor Luc Montagnier asks me:

"I put my question again in another form: all the variants that you have studied have in the sequence of their Spike proteins a Fibonacci YES series? Why? Because it is a rule of harmonization of Nature that is followed by the variants during their passage through their successive hosts. The m-RNA sequences of vaccines were chosen by technologists ignoring these laws, which only had the aim of increasing the stability of their messages."

This is why I researched and found what technological reasons led them to make mRNA CG rich.

But another more speculative question then arises:

Between these two disjointed universes, mRNA and proteins, would having a HYPER STRUCTURED mRNA be able to transmit "a certain dynamic energy during the passage into amino acids" to the future protein, which would make it more stable? more functional?

If so, can our Fibonacci methods be used for that? One fact is certain, the two mRNAs of the Moderna and Pfizer vaccines will result in a low functionality of the spike vaccine because by doping these sequences in CG rich, their designers, in search of greater STABILITY of these RNAs will have built, sequences that, as soon as they are inserted into the human host, will seek to mutate, like SARS-CoV2 variants, towards CG ==> UA forms in order to improve, paradoxically, their STABILITY and their LIFETIME.

\subsection{DOES THE CG-RICH MODIFICATION OF THE SYNONYMOUS CODONS OF THE SPIKES OF THE 2 MRNA VACCINES AFFECT THE EXPRESSION AND QUANTITY OF SARS-COV2 ANTIBODIES?}

Analyzing Master Code fractal structure and stationary waveforms differences between Moderna and Pfizer Spikes mRNA.

In (Perez, 2015 and Perez, 2018), we present a unifying theoretical method, from the atomic masses of their bioatoms C O N H S P, the three biological universes of RNA, DNA and proteins. We published various articles involving applications based on this basic research (Perez, 2017b, Perez, 2017c).

The Master Code of the sequence can be applied indistinctly to all DNA or RNA sequences, irrespective of whether they are coding proteins or not, and to all protein sequences. To every nucleotide triplet (codon), or amino acid (AA), there can be associated a cypher comprising of between -3 and +7 . These cyphers are established in relation with the atomic masses of the chemical elements $\mathrm{C}, \mathrm{N}, \mathrm{O}, \mathrm{H}, \mathrm{S}, \mathrm{P}$ constituting the nitrogen bases (purines and pyrimidines) and the amino acids. They allow a simple numerical translation of the sixtyfour codons and twenty amino acids. Exposing here the concepts leading to this code goes beyond the scope of this article and we refer the budding mathematicians to the article (Perez, 2018) "Six Fractal Codes of Biological Life: perspectives in Exobiology and Artificial Intelligence Biomimetism Decisions Making, 2018". One could oppose the criticism that this representation reduces too drastically the physico-chemical reality of the translated sequences. However, it allows their underlying geometrical reality to be measured. This mathematical conversion has the advantage to reduce the complexity of the problem. We can cite here the great mathematician and physicist Von Neumann who used to say with humor "There's no sense in being precise when you don't even know what you're talking about".

Although the amino acid sequences of the spikes of the two mRNA vaccines are identical, it is interesting to analyze with these biomathematic methods their nucleotide sequences which are very different. Indeed ( $\& 3.8)$, we have seen that these two sequences were doped with CG rich nucleotides at the level of the synonymous codons coding for the same amino acid, therefore without affecting the sequence of the spike protein.

In Figure 23 below, we see that, while the two Moderna and Pfizer protein sequences (blue proteomics curves) are identical, their respective Genomics curves (red curves) are very different. We observe in particular a completely chaotic fractal roughness in the case of Pfizer spike. In fact, in the case of the two spikes of these vaccines, a large number of synonymous codons were modified in order to dope these sequences in CG bases without altering the amino acid sequence. We believe that this exceptional fractal roughness could affect the stability and the lifespan of 
the RNA, whereas the CG emphasis sought by the designers of Pfizer-BionTech was, precisely, to increase the stability of these RNAs. One advantage will be that these RNAs will be quickly destroyed (around ten days). On the other hand, the fragility of these RNAs could lead to "breaks" of the RNA strand, with the risk of erratic combinations (HERV retrovirus for example, naturally present in the cell).
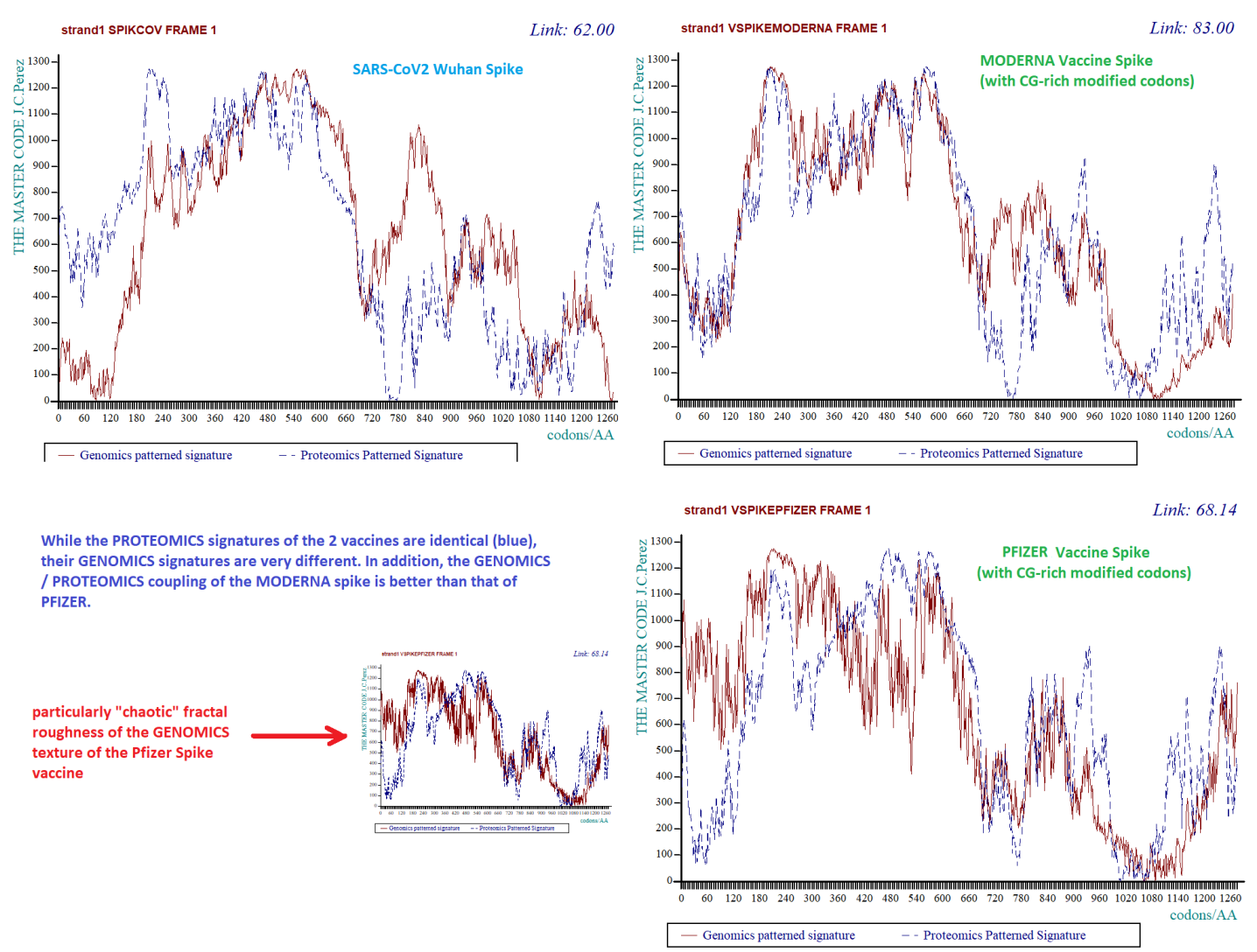

Figure 23: Comparing Master Code Genomics/Proteomics between SARS-CoV2 Wuhan, Moderna and Pfizer spikes.

Computing Standing waves:

In (Perez,2018), we describe this biomathematical method associating with any Genomics sequence periodic waves (numerical where period is a number of nucleotides).

The Genomics master code is generalized to meta-codons that no longer have three nucleotides as a codon, but four, five, ... one hundred nucleotides. Then we analyze the textures by the undulatory code. It then appears dissonances and resonances that will reveal periods of discrete waves, resonances, and standing waves.

This method provides a global analyzes of the roughness or fractal texture of the DNA sequences at the whole sequence scale. To do this, we generalize the method of numerical analyzes of the "Master Code". Thus, we restructure the sequence into different generic sequences based on "meta codons", no longer triplets of three nucleotides, but values ranging from one to a hundred nucleotides. This method of analyzes will then reveal, in most cases, discrete waves or interferences, most often dissonances resulting from Genomics Master code texture. However, sometimes there will emerge kinds of resonances where all scales of analyzes appear to be in symbiosis.

The following Figure 24 shows this kind of waveforms in the three cases of spike sequences provided by the SARS-CoV2 Wuhan reference, Moderna vaccine and Pfizer vaccine.

Figure 24 below illustrates and confirms, as before, standing waves of eight nucleotides quite similar for SARSCoV2 and Moderna spikes. On the contrary, the Spike Pfizer is characterized by a different frequency: period of seven nucleotides. 

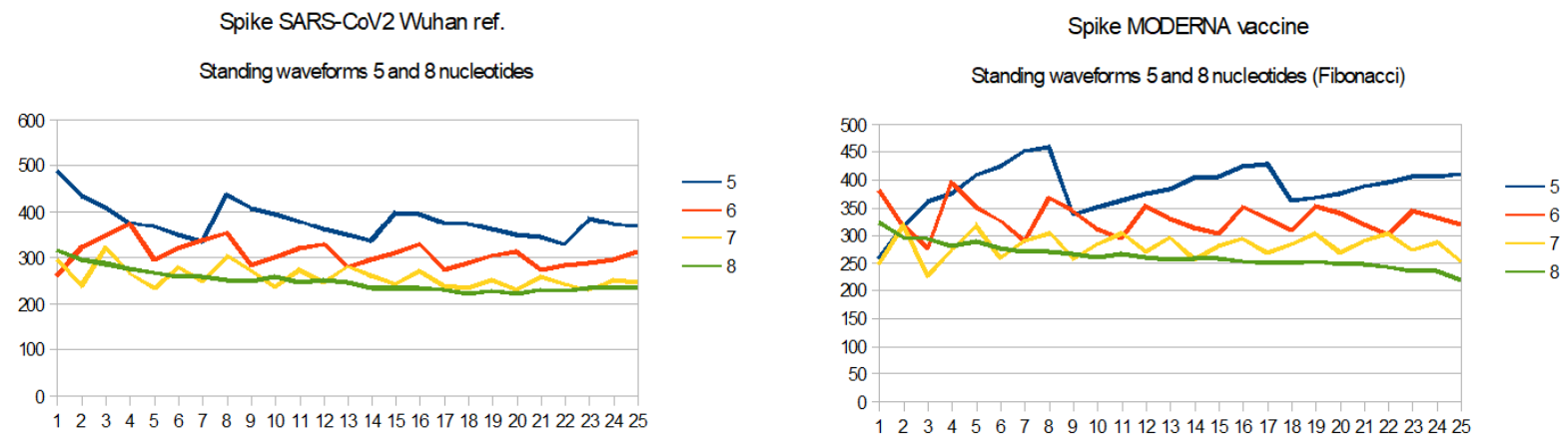

While the PROTEOMICS signatures of the 2 vaccines are identical, their GENOMICS signatures are very different. We find that the modifications of CG rich codons synonymous with MODERNA do not radically modify the standing waves of 8 nucleotides (Spikes SARS-CoV2 and MODERNA) whereas they are destroyed for the PFIZER vaccine (standing waves of 7 nucleotides).

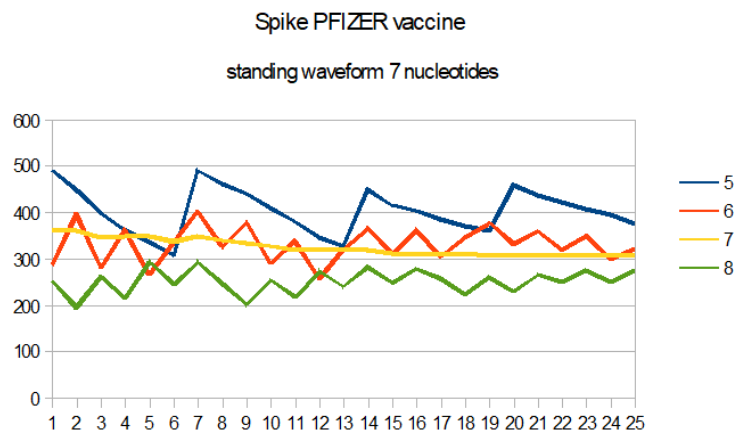

Figure 24: Comparing numerical « Standing waves » between SARS-CoV2 Wuhan, Moderna and Pfizer spikes.

From this comparison of the spikes of the two vaccines Moderna and Pfizer, we conclude a very probable difference in stability and shelf life of the two respective mRNAs of these two vaccines. However, conventional "State of the Art" analyzes will only rveal that their two protein sequences are strictly identical. By having modified their synonymous codons using different strategies, no-one can guarantee that the quantity of antibodies generated will be identical in the two cases.

No-one can affirm that this difference in the two mRNAs will not have contributed to the dynamic formation of the spike protein. This is all the more complex since these mRNAs contain certain modified U / T bases. Professor Roland Baker (Molecular Genetics, U.C. Berkeley) stated that: " T is for thymine used in DNA. U is for uracil used instead of T for mRNA. The mRNA vaccines made by Moderna and Pfizer use neither. Instead, they use 1-methyl-3'pseudouridylyl which either shows a $\mathrm{m} 1 \Psi$ or simply $\Psi$. 1-methyl-3'-pseudouridylyl is used to increase the half-life of the mRNA. Otherwise, it degrades too quickly. "

One might wonder why such a period of eight nucleotides is important? We observe that the spikes of SARSCoV2 (and all its variants), as well as the Moderna spike, retain this period 8, unlike the Pfizer spike.

8 is a Fibonacci number, and Figure 25 below illustrates how these Fibonacci periods (8 1321345589 ...) are conserved at the scale of whole genomes SARS-CoV2 Wuhan, but also in this variant CAL 21C collected from a Californian patient (Table3, CA51). It even appears that these Fibonacci standing wave periods at the scale of the entire genome would be "reinforced" in the case of the Californian variant (Figure 25) even though these two genomes are significantly different (29903nt for SARS-CoV2 and 29754nt for CA51).

CA51 contains one deletion encompassing S13I and another deletion encompassing W152C (see Table3), two of the three characteristic mutations of the California variant CAL.20C. However, despite this high level of deletions of the CAL.20C genome, the level of Fibonacci standing waves is preserved and even reinforced. At the same time, the number of Fibonacci UA / CG metastructures (Table3) is also reinforced with respect to the reference genome. 
SARS-COV2 Wuhan reference whole genome

Fibonacci standing wave 21 nucleotides period

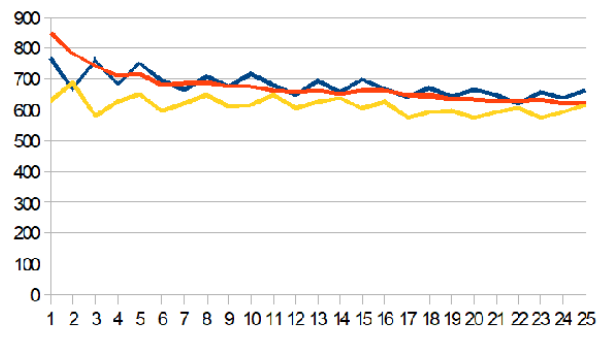

CAL.20C California variant patient CA51 whole genome

Fibonacci Standing Wave 21 nucleotides period

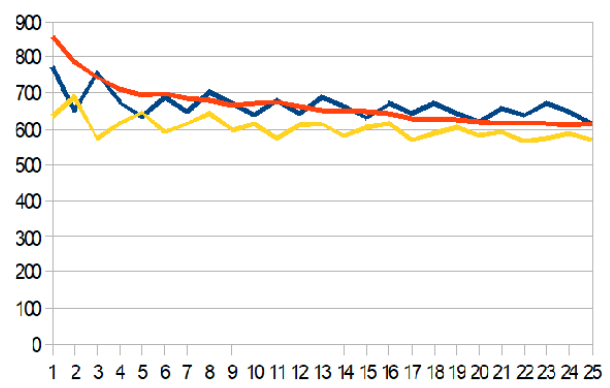

Comparing Fibonacci Standing Waves between SARS-CoV2 Wuhan and CAL.20C single patient whole genome: Evidence of conservation and improvement of Fibonacci standing waves despite large deletions in the genome of the california variant patient CA51
SARS-COV2 Wuhan reference whole genome

Fibonacci Standing Wave 34 nucleotides period

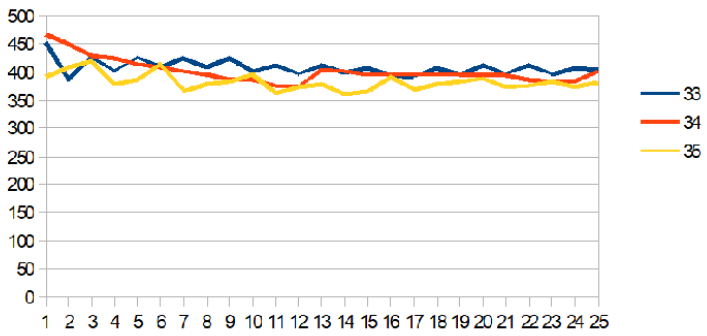

CAL20C California variant patient CA51 whole Genome

Fibonacci Stancing Wave 34 nucleotides period

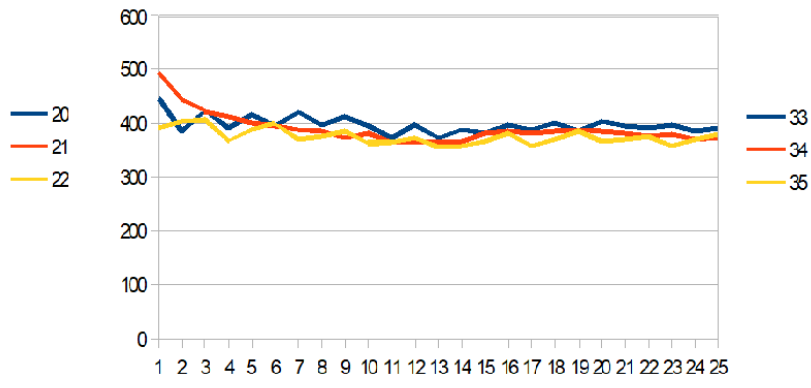

Figure 25: Comparing Fibonacci Standing Waves between SARS-CoV2 Wuhan and CAL.20C single patient whole genomes.

\section{The exceptional case of the Brazilian variant P.1.}

Although having appeared in Brazil (Manhaus) at the end of 2020, this P.1 variant has become almost uncontrollable in this country during April 2021. As shown by the mutations below, this P.1 variant accumulates the mutations of the majority of other variants. It seemed necessary to us to analyze its genome and its spike using the various biomathematic tools which were presented in this article.

Mutations on the SARS-CoV2 Wuhan reference genome recall. https://www.ncbi.nlm.nih.gov/nuccore/NC_045512

Recall locations of the 3 genes with mutations involved in in Brazil P.1:

$266 . .21555$

$$
\text { /gene="ORF1ab" }
$$

$28274 . .29533$

$$
\text { /gene="N" }
$$

21563..25384

$$
\text { /gene="S" }
$$

P.1 is the variant name associated with variant 20J/501Y.V3

Defining mutations 
Nonsynonymous :

SibibF

Sikst17

S: $5484 \mathrm{~K}$

Sins01Y

S:H655Y

ORF1a:S3675-

ORF1a:G3676-

ORF1a:F3677-

Nipion

NiR203K

- N:G204R

Synonymous :

- C241T

- $\mathrm{T} 733 \mathrm{C}$

- $\mathrm{C} 2749 \mathrm{~T}$

- C3037T

- A6319G

- A6613G

- C12778T

- C13860T

- A28877T

- G28878C

This variant is one of three 3 "Variants of Concern" reported at the end of 2020/beginning of 2021, in:

- The UK (201/501Y.V1 or B.1.1.7)

- South Africa (20H/501Y.V2 or B.1.351)

- Brazil ( 20J/501Y.V3 or P.1)

See a list of shared mutations for these variants. More information on each of these variants can be found by visiting the links above. 
View data generation scripts

\begin{tabular}{|c|c|c|c|c|c|c|}
\hline $\begin{array}{c}201 / 501 Y . V 1 \\
\text { (B.1.1.7) }\end{array}$ & $\begin{array}{c}20 \mathrm{H} / 501 \mathrm{Y} . \mathrm{V} 2 \\
\text { (B.1.351) }\end{array}$ & $\begin{array}{c}\text { 20J/501Y.V3 } \\
\text { (P.1) }\end{array}$ & $\begin{array}{c}\text { 20B/S.484K } \\
\text { (P.2) }\end{array}$ & $\begin{array}{l}\text { 20C/S.452R } \\
\text { (B.1.427/9) }\end{array}$ & $\begin{array}{c}20 \mathrm{C} / \mathrm{S} .484 \mathrm{~K} \\
\text { (B.1.526) }\end{array}$ & $\begin{array}{c}\text { 20A/S.484K } \\
\text { (B.1.525) }\end{array}$ \\
\hline \multicolumn{7}{|c|}{$\begin{array}{l}\text { Shared mutations } \\
\text { Sort bx:Commonness } \\
\text { Position }\end{array}$} \\
\hline $\begin{array}{l}\text { S.H69- } \\
\text { Sin70- } \\
\text { S.Y. 144- }\end{array}$ & Sibr18F & Sibl18F & & & & $\begin{array}{l}\text { S.H69- } \\
\text { S.X70- } \\
\text { S:Y144- }\end{array}$ \\
\hline S.N501Y & $\begin{array}{l}\text { S.K417N } \\
\text { S.E484K } \\
\text { S.N501Y }\end{array}$ & $\begin{array}{l}\text { S.K417T } \\
\text { S.E484K } \\
\text { S.N501Y }\end{array}$ & SiE $484 \mathrm{~K}$ & & SiE $484 K$ & S.E.484K \\
\hline S:D614G & $\begin{array}{l}\text { S:D614G } \\
\text { S.A701V }\end{array}$ & $\begin{array}{l}\text { S:D614G } \\
\text { SiV1176F }\end{array}$ & $\begin{array}{l}\text { S.D614G } \\
\text { S.V1176F }\end{array}$ & S:D614G & $\frac{\text { S:D614G }}{\text { S.A701V }}$ & S:D614G \\
\hline \multicolumn{7}{|c|}{ Other mutations } \\
\hline S:A570D & S:D80A & S:T2ON & & S:\$13| & SiLbF & S:Q52R \\
\hline S:P681H & S:D215G & S.P26S & & S.WW152C & S.T95I & S.A67V \\
\hline S:T716I & Silna 241- & S:D138Y & & Sib452R & S:D253G & S:Q677H \\
\hline S:S982A & Sibr242 & S:R190S & & & & S.E.688L \\
\hline S:D1118H & S:A243- & $\begin{array}{l}\text { S:H655Y } \\
\text { S:T1027I }\end{array}$ & & & & \\
\hline
\end{tabular}

BRAZL P1 Variant whole genome 20J/501Y.V3 (P.1)

Long range Fibonacci Metastructures

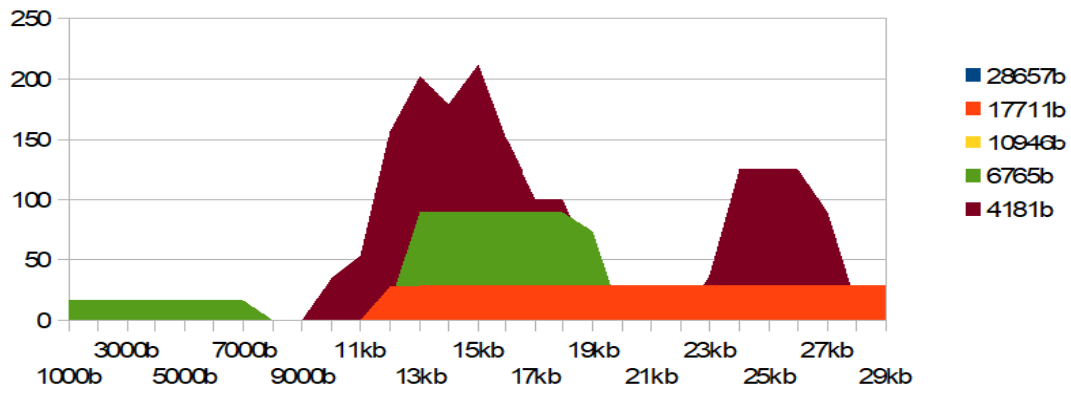

GENOME SARS-COV2 WUHAN

FIBONACCI UCAG Metastructures

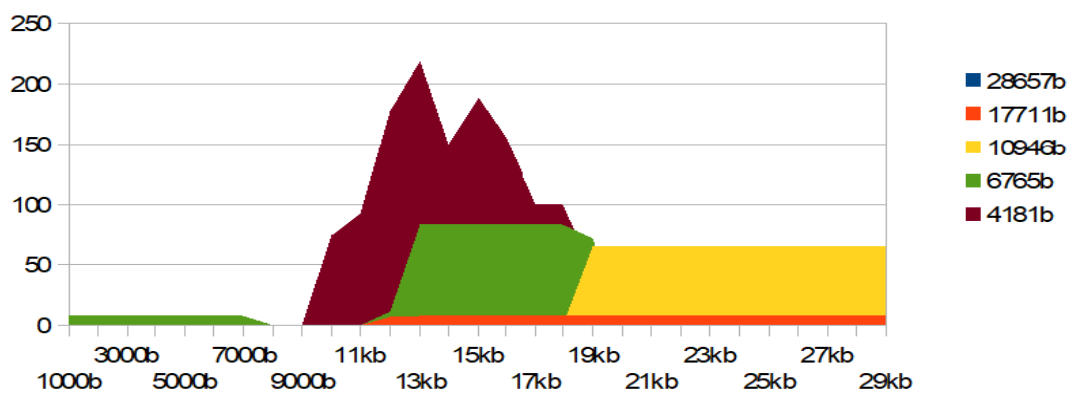

Comparing LONG RANGE 17711 bases Fibonacci metastructures:

SARS-CoV2 Wuhan genome: 8 Fibonacci 17711 metastructures.

SARS-CoV2 worldwide D614G genome: 8 Fibonacci 17711 metastructures

Brazil P.1 Variant Genome: 29 Fibonacci 17711 metastructures

BRAZIL P.1 17711 long range Fibonacci Metastructures are more than 3.6 more numerous than those of Wuhan reference and D614G GENOMES

Figure 26: Evidence of an increasing long range metastructure in the whole Brazil P.1 variant. 
Sars-Cov2 Variants and Vaccines mRNA Spikes Fibonacci Numerical UA/Cg Metastructures

SPIKE BRAZL VARANT 20J/501Y.V3 (P.1) Full Mutations

FBONACCI METASTRUCTURES

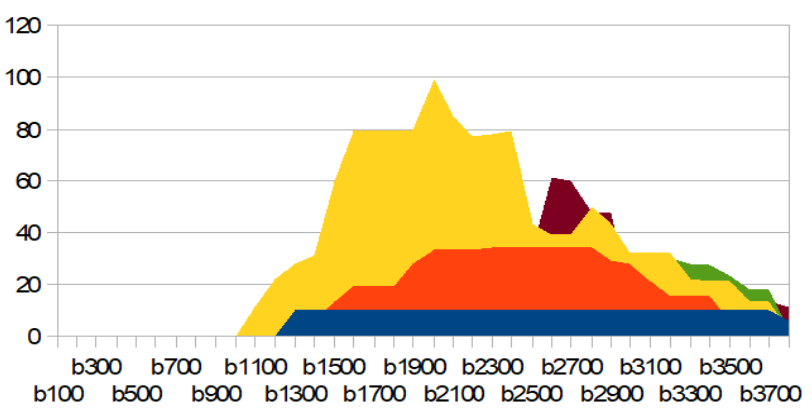

- 2584UACG

- 1597UACG

$987 \mathrm{UACG}$

-61OUACG

-3TINACG

SPIKE D614Greference

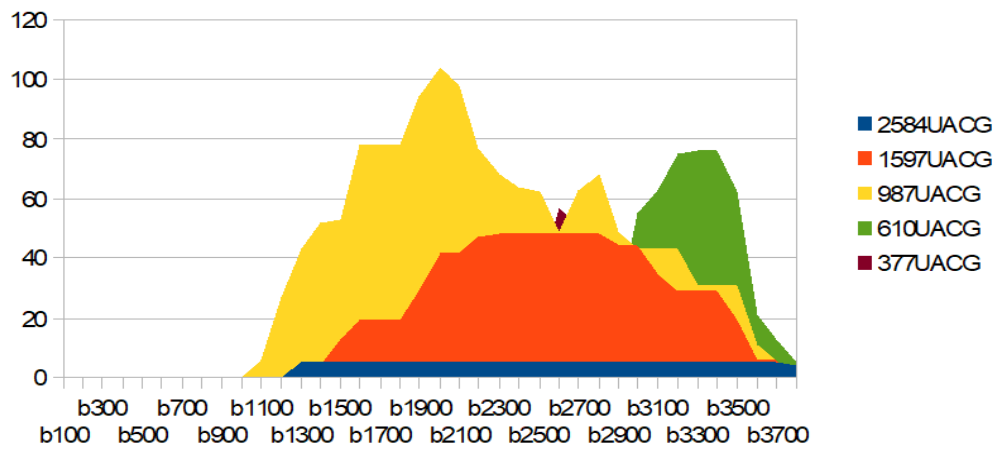

2584 UACG Long range FIBONACCI Metastructures are greather in BRAZIL P1 20J/501Y.V3 VARIANT than in D614G Worldwide SARS-CoV2 strain.

Figure 27: Evidence of an increasing long range metastructure in the Brazil P.1 variant spike.
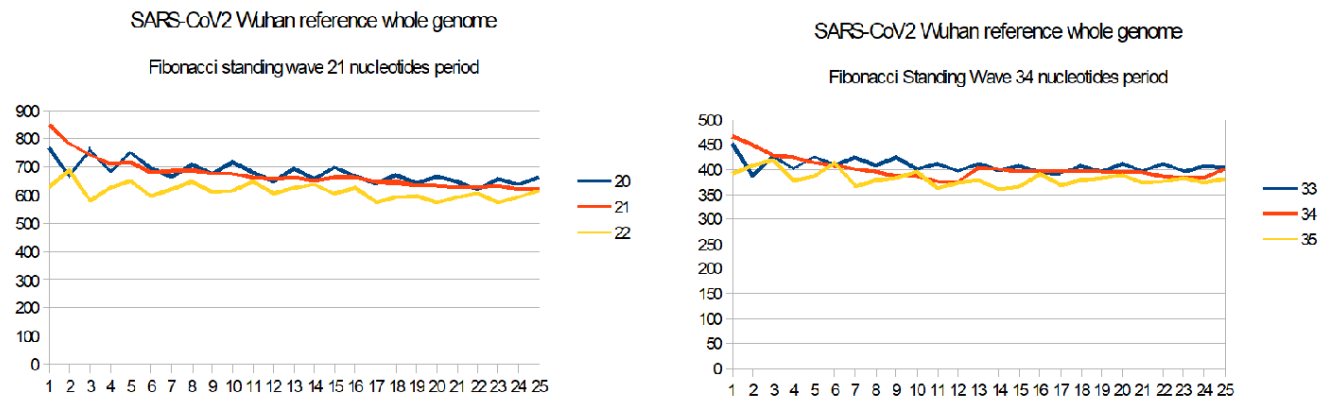

Brazil P.1 variant whole genome

Fibonacci standing wave 21 nucleotides period
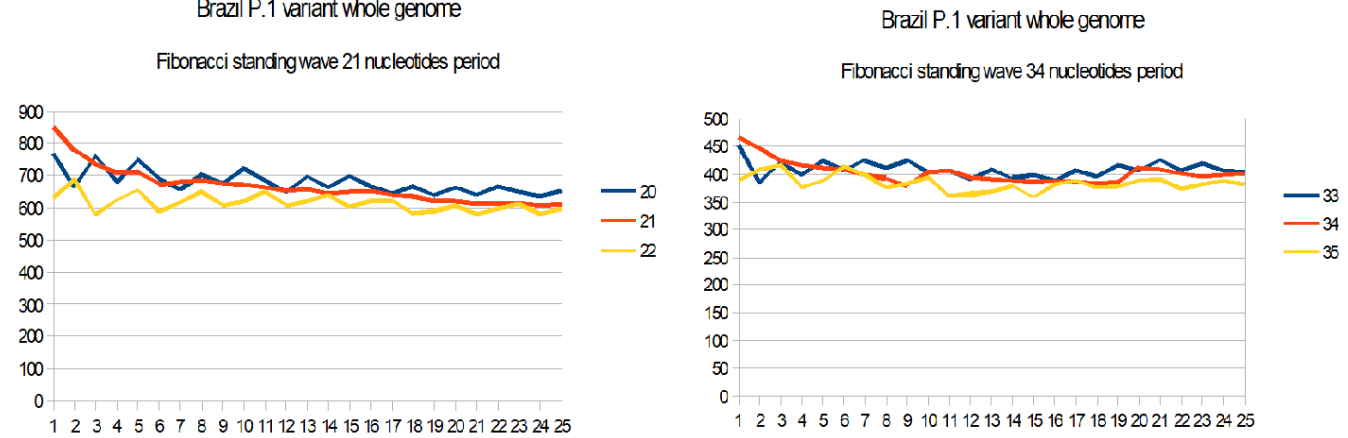

Figure 28: Evidence of long-range Fibonacci standing waves structuring the Brazil P.1 variant whole genome. 
We note that the analyzes of the number of Fibonacci metastructures of $\mathbf{1 7 7 1 1}$ base for the genome is considerable: 29 against 8 for the dominant strain D614G and for the original strain SARS-CoV2 Wuhan, that is to say nearly 3.62 times.

Secondly, the long-range Fibonacci standing waves 2358132134 (here 21 and 34 in Fugure 28) remain conserved despite the high level of mutations of this variant:

-12 mutations on Spike.

- 3 mutations on ORF1a.

- 3 mutations on gene $\mathrm{N}$.

- 10 synonymous mutations.

\section{CONCLUSIONS}

First, this study of spikes by Fibonacci metastructures highlights four primary conclusions:

- It presents a clarification by the image of links already suspected by multiple researchers between the spikes of bat RATG13, ZXC21, ZC45 and SARS-CoV2.

- As we had predicted and already verified (WA state USA) in (Perez \& Montagnier 2020), some variants deleted as a priority our predicted « EIE » HIV-like fragments from the dense HIV region at the start of the spike. This is the case with the English variant but also with several patients of the California variant CAL.20C.

- Overall, the reference spikes of all the variants studied here have a reinforcement of the most significant Fibonacci structures (2584 bases). But this phenomenon is amplified and confirmed when we analyze the spikes of patients (32 CAL.20C patients).

- We note the total absence of Fibonacci metastructures in the mRNAs of both mRNA vaccines PFIZER and MODERNA. This means that, although functional, these mRNAs will have a short lifespan and their overall physical structure will be very weak. These mRNAs will be able to split rather quickly into separate fragments which will risk combining with other mRNAs present in their environment.

- We demonstrate how the Brazilian variant P.1 which becomes uncontrollable in Brazil in April 2021 has a level of organization of long metastructures of 17,711 bases covering the genome which is 3.6 more important than that of the 2 reference genomes SARS-CoV2 Wuhan and worldwide D614G. We suggest that this high level of overall structure of this variant contributes to the stability of this genome and, possibly, to its greater contagiousness.

We will also conclude the tendency of the variant spikes to strengthen their overall structure, which may be correlated with their greater cohesion and lifespan of their mRNA spike, and probably the greater infectivity and pathogenicity of the variants.

Of the ten clusters of results presented here, three deserve to be revisited, reproduced and extended more deeply:

1) point -II-

Fibonacci metastructures "shed a radically new light on" the relationships already recognized or suspected "between the four Sars-CoV2 Wuhan (1/2020), SARS-covZC44 (2017), SARS-covPZXC2P1 (2015) and bat RATG13 genomes (2013). Added to this is evidence of manipulation of CODONS synonymous with spike of one or the other between SARS-CoV2 and beats RATG13, to the question "which of the 2 was manipulated?". We can assert that it is the SARS-CoV2 spike that has been manipulated to modify synonymous CODONS while retaining the functionality of the same amino acids. We believe that this manipulation will most certainly have attenuated the virulence and pathogenicity of SARS-CoV2 opposite bat RATG13 * (blue regions of the 2 images of their Spikes). 
Moreover, if at the level of the four respective genomes, the strong neighborhoods between SARS-CoV2 and bat RATG13 on one hand, and ZC45 and ZXC21 on the other are confirmed by these Fibonacci metastructures (vertical analogies in the image), a less expected bi-duality is highlighted at the level of their four respective spikes: on one hand, this obvious neighborhood between ZXC21 and bat RATG13, and, on the other , although less obvious, the neighborhood between ZC45 and SARS -CoV2 (horizontal analogies in the image).

2) the point $-\mathrm{V}-$

This point is at a level of fundamental research of mechanisms unknown to biology. Indeed, we demonstrate how, beyond and above the STOP codon which commands the protein manufacturing machinery to end the process, there would exist a sort of "end of gene message", which would be addressed, on the scale of messenger RNA, to this "code" and would be digital in nature, carried by the ultimate UA / CG metastructure of Fibonacci. We observe that this message would be the of Nature GIGOGNE, constituted like the Russian dolls of a nesting of proportions all ending on one of the three bases of the STOP codon. This discovery is validated in this article on fortythree spikes from UK, South Africa, BRAZIL and California variants. Of these spikes, thirtytwo were from real patients.

3) point -VII-

Here, we have gathered several pieces of evidence showing that, as they evolve, the variants would constitute and reinforce a kind of Palindrome-type symmetry based on "Russian doll" interlocking of their mRNA, which could lead to a double strand. of the "hairpin" type, thus reinforcing the stability and the lifespan of the spike mRNA, thus increasing the contagiousness of the variant virus.

In (Demongeot § Henrion-Caude, 2020), Alexandra Henrion-Caude and Jacques Demongeot proposed in 2020 a possible universel starting RNA 22 nucleotides sequence which could be a candidate bootstrap at origins of Life in a RNA primitive world.

Professor Luc Montagnier observes that these authors attribute an essential role in the origin of life to a circular RNA of 22 nucleotides. This is the length of our "EIE" (Exogenous Insertion Elements) in SARS-CoV2 genome published in https://zenodo.org/record/3975578

Particularly, this hyper constrainst circular 22nt sequence codes for the twenty amino acids + codon stop + only one redundant amino acid (MET). We found this archaic mRNA sequence using BLASTn long (14nt) contiguous sequences in HIV mRNA genomes... and also in SARS-CoV2 Wuhan reference mRNA genome!

But consider the circular character of this primitive RNA 22 nucleotides long UCAG. So, here is our original result on its multiple and SYSTEMATIC Fibonacci proportions as soon as it is a CIRCULAR RNA sequence ...

5' AUGGUACUGCCAUUCAAGAUGA 31
AUGGUACUGCCAUUCAAGAU G ==>A 13AU 8CG
AUGGUACUGCCAUUCAA G ==>AUGA 13AU 8CG
AUGGUACUGCCAUU C ==> AAGAUGA 13AU 8CG
AUGGUACUGC C ==> AUUCAAGAUGA 13AU 8CG
AUGGUACUG C ==> CAUUCAAGAUGA 13AU 8CG
AUGGUACU G ==> CCAUUCAAGAUGA 13AU 8CG
AUGGUA C ==> UGCCAUUCAAGAUGA 13AU 8CG
AUG G $==>$ UACUGCCAUUCAAGAUGA 13AU 8CG
AU G $==>$ GUACUGCCAUUCAAGAUGA 13AU 8CG

Seen from the point of view of the autopoiesis Francisco Varela theory (ref Varela), autonomy of Indoor vs. Outdoor systems, these results could be interpreted as the rest of the loop of 21 UACG (outdoor) "seen" from a base $\mathrm{C}$ or G (indoor). So, the perceived signal is a kind of Fibonacci resonance ... By virtue of Francisco Varela's theory of autopoiesis (Varela § Maturana, 1980) that we applied to Artificial Intelligence in the 1980s by creating the "fractal chaos" artificial neural network (Perez 1988). Thus, the Fibonacci numbers, therefore the optimal proportion of the Golden Tatio would perhaps have already been present from the first moments of life on earth, a life for which they would have served as a "matrix" ...

"If I followed correctly, the circular RNA sequence obeys the Fibonacci rule. If we extrapolate, we can think that Life was formed (or was created, according to our religion) from this RNA according to a mathematical principle? " (Luc Montagnier)? 
Actually, the RNA sequence proposed by the article by Alexandra Henrion-Caude, which seems to "spring" from nowhere can only intrigue the reader. Indeed, what is certain with this sequence is that God, or panspermia, or selforganization are indeed Mathematicians ...

Indeed: They already know how to count $4+5+6+7=22$.

I meant 4C, 5G, 6U, 7A

Let $\mathrm{C}+\mathrm{G}=9$

$\mathrm{U}+\mathrm{A}=13$

We are already very close to the $13 / 8=$ Phi ratio, the same one that we can verify in all SARS-CoV2 genomes. But also, pyrimidine purines:

$4 \mathrm{C}+6 \mathrm{U}=10 \mathrm{UC}$

$5 \mathrm{G}+7 \mathrm{~A}=12 \mathrm{AG}$

$10=2 \times 5$

$12=2 \times 6$

5 and 6 are the two key numbers associated with the harmonious but unstable shape of the Pentagon (5) and the harmonious but stable form of the Hexagon (6).

It is no coincidence that Nature (flowers) or religions - also - have invented stars with 5 or 6 branches ....

And the structure of RNA and DNA are built around Pentagons and Hexagons ...And "Pollack's Water Fourth state" structure of WATER (https://www.pollacklab.org/), also built around the hexagon ...

So, EVERYTHING seems to be potentially written in these 22 nucleotides ...

We also note $2 \times 6=12$ bases in primers of palindromes or mirror series:

AUGGUA mirror and UCAAGA quasi palindrome.

Finally, we will note cs 5 triplets of consecutive nucleotides:

GAA UGG GCC AUU CAA

Symetries purines pyrimidines on 4 of the 5 TRIPLETS

UGG CAA

GCC AUU

Finally, we must recall this open question:

\section{CONJECTURE of SARS-CoV2 VARIANTS:}

The growth of long Fibonacci structures in the shape of "podiums" for almost all of the variants studied (UK, California, South Africa, India, etc.) suggests the probable folding of the spike mRNA in the form of a "hairpin", can strengthen the cohesion and the lifespan of this mRNA.

\section{Three final conclusions:}

One fact is certain, the two mRNAs of the Moderna and Pfizer vaccines will result in a low functionality of the spike vaccine because by doping these sequences in CG rich, their designers, in search of greater STABILITY of these RNAs will have built sequences which, as soon as they are inserted into the human host, will seek to mutate, like SARS-CoV2 variants, towards CG ==> UA forms in order to improve their STABILITY and their LIFETIME...

Secondly, using new biomathematics theoretical methods (Master code and numerical standing waves), and comparing the spikes of the two vaccines of Moderna and Pfizer, we conclude a very probable difference in stability and shelf life of the two respective mRNAs of these two vaccines. However, current "State of the Art" analyzes will only reveal that their two protein sequences are strictly identical. By having modified their synonymous codons using different strategies, no-one can guarantee that the quantity of antibodies generated and sensitivity to variants will be identical in the two cases (Kustin et al, 2021).

Despite the immense progress of Biology, the RNA universe remains today full of unexplained mysteries. However, it is said, as we will see, that it could have constituted the first crucible of life. This is why we will have to exercise the greatest caution, on one hand in the face of an mRNA virus such as SARS-CoV2, but even more in the face of the unpredictable evolution of new vaccines, themselves based on RNA.

We must note the great ADAPTATION power - at the global scale of their genomes - of the most infectious VARIANTS such as the BRAZIL 20J / 501Y.V3 variant (P.1). This is very worrying for the VACCINES <==> VARIANTS run: We demonstrate how the Brazilian variant P.1 which becomes uncontrollable in Brazil in April 2021 has a level of organization of long metastructures of 17,711 bases covering the genome which is 3.6 more important than that 
of the 2 reference genomes SARS-CoV2 Wuhan and worldwide D614G. We suggest that this high level of overall structure of this variant contributes to the stability of this genome and, possibly, to its greater contagiousness.

Finally, we could propose a causal link between vaccines and variants as suggested in (Megawaty Tan et al, 2021).

\section{ADDENDUM BY PROFESSOR LUC MONTAGNIER}

For the first time the work of JC Perez allows the detection of numerical series in the natural sequence evolution of new variants of Covid-19 Corona virus.

Long Fibonacci séries are described by him in the variants which are the most spreading in the human population.

This would indicate a natural selection of more stable structures also possibly more transmissible.

This evolution is in contrast with the path followed by the vaccine makers:

to make the synonymous codons enriched in G-C in order to increase their m-RNA vaccine stability.

\section{SOURCES OF FUNDING}

This research received no specific grant from any funding agency in the public, commercial, or not-for-profit sectors.

\section{CONFLICT OF INTEREST}

The author have declared that no competing interests exist.

\section{ACKNOWLEDGMENT}

Thanks for fructuous discussions about this article to Megawaty Tan (A private researcher based in South Sumatera, Indonesia), Alexandra Henrion-Caude ( Future of Research Team, SimplissimA International Research Institute, 39 rue saint Louis, 11324 Port-Louis, Mauritius), Sami MacKenzie-Kerr private researcher in Indonesia ("The

Matrix", https://www.google.com/url?sa=t\&source=web\&rct=j\&url=https://matrix.fandom.com/wiki/The_Matrix/Crew\& ved=2ahUKEwjf6u7t0NXvAhUBCxoKHRQIA0IQFjAPegQIBxAC\&usg=AOvVaw10coHfMy2CVksJjUqkvBpU ), Robert Friedman M D. (author of "Nature's secret nutrient, golden ratio biomimicry, for PEAK health, performance and longevity), Philip Risby (initiator of "Learning to Survive") project in Portugal, Valère Lounnas, (Free-lance researcher at CMBI European Molecular Biology Laboratory (EMBL) Heidelberg ), Jacques Demongeot ( Laboratory AGEIS EA 7407, Faculty of Medicine, University of Grenoble Alpes, 38700 La Tronche, France ). Dr Daniel Favre, independant researcher, Brent, Switzerland, David Bensaid M.D Israel (www.emi-sion.com ), Christian Marc, ( retired, MSEE-Dipl-Eng Physics, MBA (Beta Gamma Sigma, USA), Harvard HBS Alumn, General Director https://www.caravanedelapaix.com/), Ethirajan Govindarajan (adjunct Professor, Department of Cybernetics, School of Computer Science, University of Petroleum and Energy Studies, Dehradun, Uttarakhand, India, Director, PRC Global Technologies Inc., Ontario, Canada, President, Pentagram Research Centre Pvt. Ltd., Hyderabad, India) and Xavier Azalbert, Director FRANCE-SOIR newspaper ( https://www.francesoir.fr/info-en-direct

We thank particularly dr Richard M Fleming PhD, MD, JD (https://www.flemingmethod.com/ and https://www.francesoir.fr/amp/article/videos-les-debriefings/dr-richard-fleming-son-debriefing) for discussions on SARS-CoV2 origins and prion like diseases risk (see https://biomedres.us/fulltexts/BJSTR.MS.ID.000369.php).

Finally, this work is the result of multiple exchanges and advice, since the very beginning of the COVID-19 pandemic, for which I must thank Professor Luc Montagnier (Nobel prizewinner for his discovery of HIV, Fondation Luc Montagnier Quai Gustave-Ador 621207 Geneva, Switzerland). 
Jean-Claude Perez

\section{REFERENCES}

[1] (Castro-Chavez, 2020), F. Castro-Chavez, (June 2020), Anticovidian v.2: COVID-19: Hypothesis of the Lab Origin versus a Zoonotic Event Which Can Also be of a Lab Origin, GJSFR, August 2020, https://zenodo.org/record/3988139\#.YGMMaq8zaM8

[2] (Dae Eun Jeong et al, 2021), Dae Eun Jeong et al, Assemblies-of-putative-SARS-CoV2-spike-encoding-mRNAsequences-for-vaccines-BNT-162b2-and-mRNA-1273, GitHub, March 2021, https://github.com/NAalytics/Assemblies-of-putative-SARS-CoV2-spike-encoding-mRNA-sequences-forvaccines-BNT-162b2-and-mRNA-1273

[3] (Da Silva Filipe, 2020), da Silva Filipe, A., Shepherd, J.G., Williams, T. et al. Genomic epidemiology reveals multiple introductions of SARS-CoV-2 from mainland Europe into Scotland. Nat Microbiol 6, 112-122 (2021). https://doi.org/10.1038/s41564-020-00838-z

[4] (Demongeot§Henrion-Caude, 2020), Demongeot J. § Henrion-Caude A., Footprints of a Singular 22-Nucleotide RNA Ring at the Origin of Life, Biology 2020, 9(5), 88; https://doi.org/10.3390/biology9050088

[5] (Govindarajan, 2020a) Ethirajan Govindarajan et al, "Pairwise Spatial Correlation of SARS-Corona Viruses", London Journal of Research in Computer Science and Technology, London Journals Press, Volume 20, Issue 1, Compilation 1.0, 2020, pp 11-78

[6] (Govindarajan, 2020b) Ethirajan Govindarajan et al, "Pairwise Spectral Correlation of SARS-Corona Viruses", London Journal of Research in Computer Science and Technology, London Journals Press, Volume 20, Issue 2, Compilation 1.0, 2020, pp 81-148

[7] (Gröhs Ferrareze P. A. , et al, 2021), Patrícia Aline Gröhs Ferrareze, et al, E484K as an innovative phylogenetic event for viral evolution: Genomic analysis of the E484K spike mutation in SARS-CoV-2 lineages from Brazil bioRxiv 2021.01.27.426895; doi: https://doi.org/10.1101/2021.01.27.426895

[8] (Jackson et al, 2020), Jackson, N.A.C., Kester, K.E., Casimiro, D. et al. The promise of mRNA vaccines: a biotech and industrial perspective. npj Vaccines 5, 11 (2020). https://doi.org/10.1038/s41541-020-0159-8

[9] (Kudla et al, 2016), Kudla, G., Lipinski, L., Caffin, F., Helwak, A. \& Zylicz, M. High guanine and cytosine content increases mRNA levels in mammalian cells. Plos Biol. 4, e180 (2016). High guanine and cytosine content increases mRNA levels in mammalian cells

[10] (Kustin T. et al, 2021), Evidence for increased breakthrough rates of SARS-CoV-2 variants of concern in BNT162b2 mRNA vaccinated individuals, Talia Kustin et al, medRxiv Preprints, Doi: https://doi.org/10.1101/2021.04.06.21254882

[11] (Megawaty Tan et al, 2021), Megawaty Tan et al. "May vaccines select SARS-CoV-2 variants more readily escaping immunity - an analysis of public data". Archives of Microbiology \& Immunology, in press.

[12] (Mengwen et al, 2006), Mengwen Jia, Liaofu Luo,

The relation between mRNA folding and protein structure, Biochemical and iophysical Research Communications, Volume 343, Issue 1,2006,Pages 177-182,ISSN 0006-291X, https://doi.org/10.1016/j.bbrc.2006.02.135.

(https://www.sciencedirect.com/science/article/pii/S0006291X06004451)

[13] (Montagnier L. § Kingsley Sanders F., 1963), Luc Montagnier and F. Kingsley Sanders « Replicative Form of Encephalomyocarditis virus RNA », Nature 199. 664-667. 1963

[14] (Naveca Felipe et al, 2021), Phylogenetic relationship of SARS-CoV-2 sequences from Amazonas with emerging Brazilian variants harboring mutations E484K and N501Y in the Spike protein, Virological.org, 2021, https://virological.org/t/phylogenetic-relationship-of-sars-cov-2-sequences-from-amazonas-withemerging-brazilian-variants-harboring-mutations-e484k-and-n501y-in-the-spike-protein/585

[15] (Perez, 1988), Perez J.C., De nouvelles voies vers l'Intelligence Artificielle, 1988, Ed. MASSON ELSEVIER, EAN 978-2225818158 ISBN 2225818150, https://livre.fnac.com/a223887/Jean-Claude-Perez-De-Nouvellesvoies-vers-l-intelligence-artificielle

[16] (Perez, 1991), J.C. Perez (1991), "Chaos DNA and Neuro-computers: A Golden Link", in Speculations in Science and Technology vol. 14 no. 4, ISSN 0155-7785, January 1991

Speculations in Science and Cell Motility 14(4):155-7785

https://www.researchgate.net/publication/258439719_JC_Perez_1991_Chaos_DNA_and_Neurocomputers_A_Golden_Link_in_Speculations_in_Science_and_Technologyvol_14_no_4_ISSN_0155-7785

[17] (Perez, 1997), Perez J.C, L'ADN décrypté, Ed. Marco Pietteur, ISBN: 2-87211-017-8

International Journal of Research -GRANTHAALAYAH 
EAN: $\quad 9782872110179, \quad$ https://www.editionsmarcopietteur.com/resurgence/91-adn-decrypte9782872110179.html

[18] (Perez, 2009), Perez J.C, Codex biogenesis - Les 13 codes de l'ADN (French Edition) [Jean -Claude ... 2009); Language: French; ISBN -10: 2874340448; ISBN -13: 978-2874340444 https://www.amazon.fr/CodexBiogenesis-13-codes-lADN/dp/2874340448

[19] (Perez, 2015), Deciphering Hidden DNA Meta-Codes -The Great Unification \& Master Code of Biology, journal of Glycémies abd Lipidomics, https://www.longdom.org/abstract/deciphering-hidden-dna-metacodes-the-great-unification-amp-mastercode-of-biology-11590.html, ISSN: 2153-0637, DOI: 10.4172/2153-0637.1000131

[20] (Perez, 2017), J.C Perez, 2017, Sapiens Mitochondrial DNA Genome Circular Long Range Numerical Meta Structures are Highly Correlated with Cancers and Genetic Diseases mtDNA Mutations January 2017 Journal of Cancer Science and Therapy 09(06) DOI: 10.4172/1948-5956.1000469

[21] (Perez, 2017b), Jean Claude Perez, "The Master Code of Biology: Self-assembly of two identical Peptide's beta A4 1-43 Amyloid in Alzheimerâ€ ${ }^{\mathrm{TM}} \mathrm{s}$ Diseases," Biomedical Journal of Scientific \& Technical Research, Biomedical Research Network+, LLC, vol. 1(4), pages 1191-1195, September. Handle: RePEc:abf: journl: v:1: y:2017: i:4: p:1191-1195 DOI: 10.26717/BJSTR.2017.01.000394

[22] (Perez, 2017c), Perez JC (2017) The "Master Code of DNA": Towards the Discovery of the SNPs Function (Single-Nucleotide Polymorphism). J Clin Epigenet. 3:26. doi: 10.21767/2472-1158.100060, https://clinical-epigenetics.imedpub.com/the-master-code-of-dna-towards-the-discovery-of-the-snpsfunction-singlenucleotide-polymorphism.pdf

[23] (Perez, 2018), Perez, J.C. Six Fractal Codes of Biological Life: perspectives in Exobiology, Cancers Basic Research and Artificial Intelligence Biomimetism Decisions Making. Preprints 2018, 2018090139 (doi: 10.20944/preprints201809. 0139.v1). Perez, J.C. Six Fractal Codes of Biological Life:perspectives in Exobiology, Cancers Basic Research and Artificial Intelligence Biomimetism Decisions Making. Preprints 2018, $2018090139 \quad$ (doi: $10.20944 /$ preprints201809. https://www.preprints.org/manuscript/201809.0139/v1

[24] (Perez, 2019), Perez, J. Epigenetics Theoretical Limits of Synthetic Genomes: The Cases of Artificials Caulobacter (C. eth-2.0), Mycoplasma Mycoides (JCVI-Syn 1.0, JCVI-Syn 3.0 and JCVI_3A), E-coli and YEAST chr XII. Preprints 2019, 2019070120 (doi: 10.20944/preprints201907. 0120.v1). https://www.preprints.org/manuscript/201907.0120/v1

[25] Perez J.C, (2020). “WUHAN COVID-19 SYNTHETIC ORIGINS AND EVOLUTION.” International Journal of Research - Granthaalayah, 8(2), 285-324.

https://doi.org/10.5281/zenodo.3724003

[26] (Perez§Montagnier, 2020a), Perez, j.c, \& Montagnier, L. (2020, April 25). COVID-19, SARS and Bats Coronaviruses Genomes unexpected Exogeneous RNA Sequences. https://doi.org/10.31219/osf.io/d9e5g

[27] (Perez\%Montagnier, 2020b), Jean claude Perez, \& Luc Montagnier. (2020). COVID-19, SARS AND BATS CORONAVIRUSES GENOMES PECULIAR HOMOLOGOUS RNA SEQUENCES. International Journal of Research GRANTHAALAYAH ISSN (print): 2394-3629 July 2020, Vol 8(07), 217 - 263 DOI: Https://doi.org/10.29121/granthaalayah.v8.i7.2020.678, Vol 8(07), 217 - 263(Vol 8(07), 217 - 263), Vol 8(07), 217-Vol 8(07), 263. http://doi.org/10.5281/zenodo.3975578

[28] (Rapoport § Perez, 2018), Rapoport D. § Perez J.C, Golden ratio and Klein bottle Logophysics: The Keys of the Codes of Life and Cognition. Quantum Biosystems. 9(2) 8-76.; Vol. 9 - n.2 - 2018

[29] (Simmonds P, 2020), P. Simmonds, Rampant C->U hypermutation in the genomes of SARS-CoV-2 and other coronaviruses - causes and consequences for their short and long evolutionary trajectories. bioRxiv 2020.05.01.072330; doi: https://doi.org/10.1101/2020.05.01.072330

[30] (Varela § Maturana, 1980), Maturana H. \& Varela F.J. (1980). Autopoiesis and cognition: the realization of the living. Reidel, Boston.

[31] (Wenjuan Zhang et al, 2021), Emergence of a novel SARS-CoV-2 strain in Southern California, USA, medRxiv 2021.01.18.21249786; doi: https://doi.org/10.1101/2021.01.18.21249786. 